\title{
Caenagnathids of the Dinosaur Park Formation (Campanian) of Alberta, Canada: anatomy, osteo- histology, taxonomy, and evolution
}

\section{Gregory F. Funston}

School of GeoSciences, University of Edinburgh, Edinburgh, Scotland, UK and Department of Biological Sciences, University of Alberta, Edmonton, Alberta, Canada; Gregory.Funston@ed.ac.uk

Abstract: Our understanding of caenagnathid anatomy, diversity, and ecology has improved considerably in the past twenty years, but numerous issues still remain. Among these, the diversity and taxonomy of caenagnathids from the Dinosaur Park Formation of Alberta, Canada, have remained problematic. Whereas some authors recognize three genera, others suggest only two are present, and there is considerable disagreement about which specimens are referable to which genus. This study aims to resolve this issue by reviewing the known specimens and using osteohistology to establish a testable taxonomic framework of Dinosaur Park Formation caenagnathids. Numerous new specimens from all regions of the skeleton provide insight into morphological variation in caenagnathids, and three morphotypes are recognized based on a combination of morphological features and body size. Osteohistology shows that representatives in each body size class are at skeletal maturity, and therefore supports the delineation of three taxa: the smaller Citipes elegans gen. nov., the intermediate Chirostenotes pergracilis, and the larger Caenagnathus collinsi, new material of which shows it rivalled Anzu wyliei in size. However, these analyses also raise concerns about the referral of isolated material to each taxon in the absence of skeletal overlap between specimens or osteohistological analysis. Caenagnathids are consistently recovered throughout the Dinosaur Park Formation interval, and two geographic clusters of increased abundance probably reflect collection and taphonomic biases. The coexistence of three taxa was apparently facilitated by differences in both adult body size and functional morphology of the dentary and pes, which suggests that caenagnathids minimized niche overlap rather than subdividing niche space. Regardless, little is known of the exact roles caenagnathids played in Late Cretaceous ecosystems. Incorporation of the new material and taxonomic framework into a phylogenetic analysis drastically improves our understanding of the relationships between caenagnathines, and sheds light on the evolution of body size in caenagnathids and its role in their diversification.

http://zoobank.org/urn:Isid:zoobank.org:pub:89F4545C-03E7-44B8-9CFE-28DE4AD6CFB9

\section{INTRODUCTION}

Caenagnathidae was a group of oviraptorosaurian theropods from the Late Cretaceous of Asia and North America (Fig. 1). The first caenagnathids (Gilmore 1924a; Sternberg 1932, 1940; Parks 1933) were recovered from the Dinosaur Park Formation (DPF) of Alberta, which continues to produce the most abundant caenagnathid material worldwide. However, caenagnathids are now also known from China (Yao et al. 2015; Yu et al. 2018), Mongolia (Osmólska 1981; Currie et al. 2016a), throughout the United States
(Zanno and Sampson 2005; Lamanna et al. 2014) and from Uzbekistan (Currie et al. 1993; Sues and Averianov 2015). These new discoveries show that caenagnathids include the enigmatic 'elmisaurs' (Currie 1989), and that they encompassed a wide range of body sizes, morphologies, and presumably niches (Ma et al. 2017, 2020; Funston et al. 2018; Yu et al. 2018).

The abundance of caenagnathid material from the DPF has led to several advances in our understanding of caenagnathid anatomy and ecology (Currie and Russell 1988; Currie et al. 1993; Funston and Currie 2014; Funston 

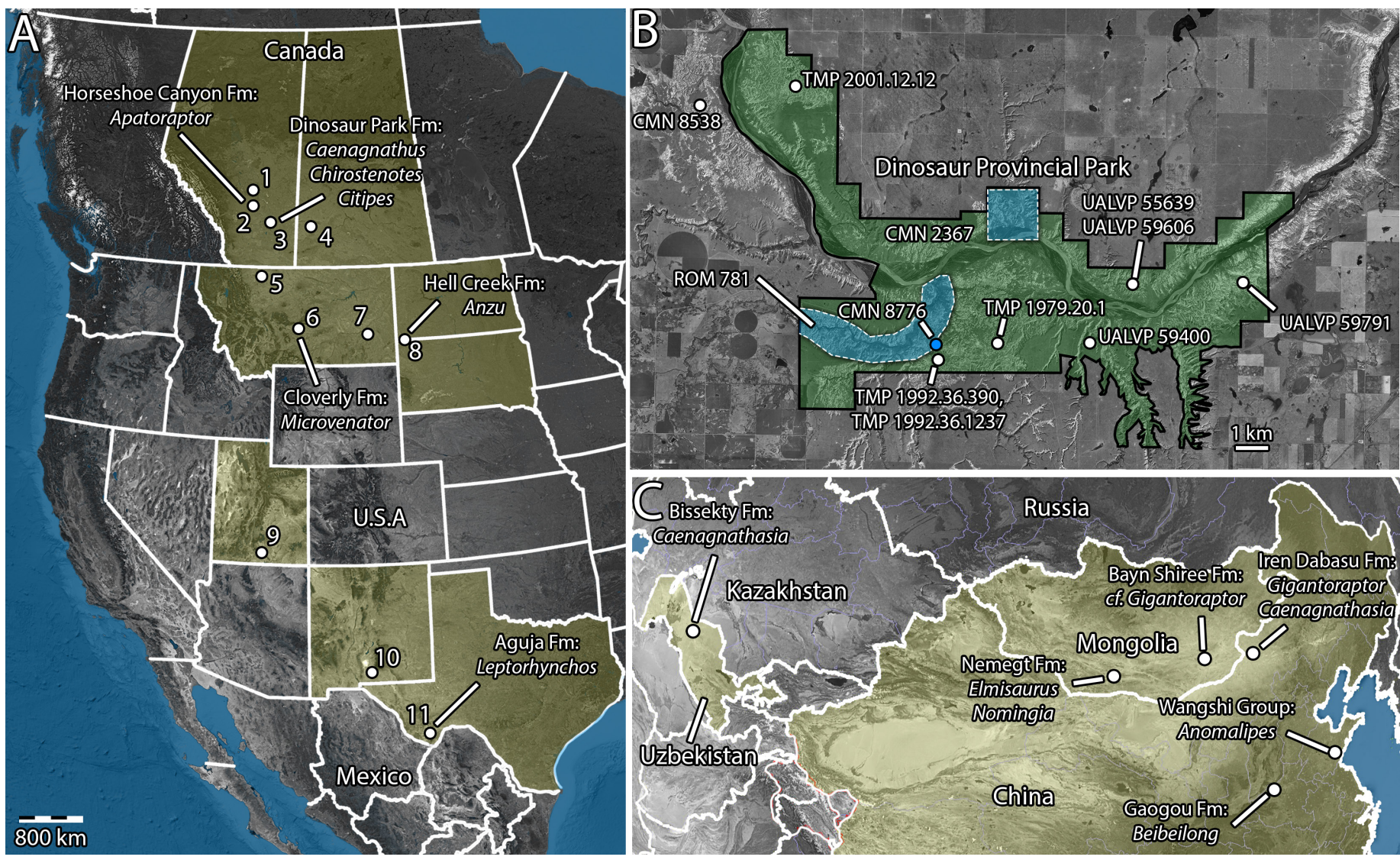

Figure 1. Maps of caenagnathid occurrences. Map (A) of North America, showing provinces and states from which caenagnathids have been collected (highlighted in yellow), and formations where caenagnathids are known to occur. Names and horizons are provided for caenagnathids for which mandibular material has been found. Map (B) of Dinosaur Provincial Park in Alberta, Canada (highlighted in green), showing locations of notable caenagnathid specimens. The regions that produced the holotypes of each species are highlighted in blue; the exact quarry of only one of these (Caenagnathus collinsi) is known with certainty (blue dot). Map (C) of western Asia, showing countries where caenagnathids have been found (highlighted), with names and horizons of named taxa. Abbreviations: 1, Scollard Formation (Maastrichtian); 2, Horseshoe Canyon Formation (Campanian-Maastrichtian), 3, Dinosaur Park Formation (Campanian); 4, Frenchman Formation (Maastrichtian), 5, Hell Creek Formation, Northern Montana (Maastrichtian); 6, Cloverly Formation (Aptian-Albian); 7, Hell Creek Formation, Eastern Montana (Maastrichtian); 8, Hell Creek Formation, North and South Dakota (Maastrichtian); 9, Kaiparowitz Formation (Campanian); 10, Ojo Alamo Formation (Maastrichtian); 11, Aguja Formation (Campanian). Modified from Funston et al. (2019a, b).

et al. 2015, 2016a), but numerous issues remain unresolved. Of chief importance is the taxonomy of DPF caenagnathids, which remains problematic because of fragmentary, isolated specimens, and little overlap between referable material of each taxon. Three taxa are now generally recognized. Chirostenotes pergracilis was described first by Gilmore (1924a) and is represented by the most complete skeletal material (Currie and Russell 1988). Caenagnathus collinsi (Sternberg 1940) is known solely from the holotype mandible and some provisionally referred material (Funston et al. 2015). Finally, Citipes elegans gen. nov., formerly 'Ornithomimus', 'Elmisaurus' or 'Leptorhynchos' elegans (Parks 1933; Currie 1989; Longrich et al. 2013) is known from several tarsometatarsi (Funston et al. 2016a) and possibly mandibular material (Longrich et al. 2013; Funston et al. 2020). These three taxa appear to represent each of the three general morphotypes that can be delineated within caenagnathines (caenagnathids more derived than Gigantoraptor erlianensis). Caenagnathus collinsi has an elongate, flattened mandible, which is also the case in Anzu wyliei, whereas Citipes elegans gen. nov. has a fused tarsometatarsus, like in Elmisaurus rarus. In contrast, Chirostenotes pergracilis apparently lacked both of these features (Funston and Currie 2020).

Regardless, the poor skeletal representation of these key taxa means that the evolution of these features is ambiguous, and it remains unclear whether known material even supports the distinction of three taxa. Historically, the diversity of DPF caenagnathids has been widely debated. Currie (1989) distinguished material with fused tarsometatarsi from Chirostenotes, but within Elmisaurus, and suggested that Caenagnathus should also be retained separately. Sues 
(1997), however, suggested that Caenagnathus collinsi was the junior synonym of Chirostenotes pergracilis, although 'Caenagnathus sternbergi' might still be distinct. Sullivan et al. (2011) suggested that the material from the Horseshoe Canyon Formation described by Sues (1997) was not, in fact, Chirostenotes pergracilis, and they erected Epichirostenotes curriei for this specimen. Longrich et al. (2013) suggested that the fused tarsometatarsi described by Currie (1989) and material of 'Caenagnathus sternbergi' were from the same taxon, which they named 'Leptorhynchos' elegans. However, Lamanna et al. (2014) argued that without overlapping material, it was inappropriate to unite these separate elements into a single taxon, and their analysis retained them as separate operational taxonomic units.

In recent years, numerous additional caenagnathid specimens have been recovered throughout North America and Asia (Fig. 1), but particularly the DPF. Some of these have already been described and tentatively referred to previously established taxa, but the entire breadth of known material has not been considered. Furthermore, many of these referrals rely on adult body size as a distinguishing character between these taxa, but this has not been conclusively demonstrated with osteohistological analyses.

Here I conduct a comprehensive review of the caenagnathids from the DPF and use new and recently described material to assess their morphology, diversity and growth. In light of improved understanding of the anatomy and variation in oviraptorosaurs, I redescribe and figure the holotypes and important specimens of Caenagnathus collinsi and Chirostenotes pergracilis, which provides more data for future studies. I present osteohistological analyses of some new and previously described material, and synthesize previous analyses to understand body size variation in DPF caenagnathids. I test whether the new specimens from the DPF support the delineation of the three proposed genera (Caenagnathus collinsi, Chirostenotes pergracilis, and Citipes elegans gen. nov.), and, if so, which specimens are referable to which taxon. I also describe some significant specimens that are nonetheless taxonomically indeterminate, in the hopes that future discoveries will establish overlap between these specimens and material of known affinities. Finally, I incorporate these data into an updated phylogeny, which sheds light on the relationships and evolution of caenagnathids.

\section{INSTITUTIONAL ABBREVIATIONS}

CM, Carnegie Museum of Natural History, Pittsburgh, Pennsylvania, USA; CMN, Canadian Museum of Nature, Ottawa, Ontario, Canada; MPC, Institute of Palaeontology and Geology, Mongolian Academy of Sciences, Ulaanbaatar, Mongolia; ROM, Royal Ontario Museum, Toronto, Ontario, Canada; RSM, Royal Saskatchewan
Museum, Regina, Saskatchewan, Canada; TMP, Royal Tyrrell Museum of Palaeontology, Drumheller, Alberta, Canada; UALVP, University of Alberta Laboratory for Vertebrate Palaeontology, Edmonton, Alberta, Canada.

\section{MATERIALS AND METHODS}

The results in the systematic palaeontology section are presented in light of the taxonomic conclusions reached in the discussion section, summarized in Table 1. In short, support is found for three taxa: Caenagnathus collinsi, Chirostenotes pergracilis, and Citipes elegans gen. nov., alongside a host of indeterminate material. Therefore, specimens are described within the taxon to which they are referred, but the rationale for these referrals is presented later in the discussion section.

The taxonomic referrals follow a modified apomorphybased approach, based on that suggested by Nesbitt and Stocker (2008). This approach differs in several aspects from that proposed by Nesbitt and Stocker (2008), which is appropriate because of the limited taxonomic and stratigraphic scope of the study and the paucity of anatomically overlapping specimens. In particular, the approach relies on several testable assumptions that allow a greater weight to be placed on body size evidence and the absence of apomorphies. The first assumption is that only three caenagnathid taxa are present in the DPF, an assumption that is supported by the consistent recovery of three morphotypes in elements where multiple specimens are known (dentaries, ilia, metatarsals), and the absence of positive evidence for a fourth taxon after nearly a century of collecting and a sample of hundreds of elements. It is also supported by the osteohistological results presented here, which indicate that three adults of significantly different body size are present in the known material. This assumption is testable by morphological or histological evidence for a fourth taxon or synonymy of any of the three delineated taxa. The second assumption, which is tested and supported here, is that the adult body sizes of these three taxa were significantly different and that body size at maturity can be treated as an apomorphy. This assumption is supported here by the osteohistological analyses showing that specimens of significantly different size are each histologically mature. Two of these specimens overlap anatomically with the holotype specimens of their respective taxa, constraining the adult body sizes of Chirostenotes pergracilis and Citipes elegans gen. nov. The third specimen is significantly larger than either of these taxa, and is comparable in terms of histological maturity, which supports the presence of a larger-bodied taxon. Considering the first assumption of only three taxa and the larger size of the holotype mandible of Caenagnathus collinsi, these elements are referred to this taxon. This second assumption is further testable by continued osteohistological 
Table 1. Taxonomic referrals of caenagnathid specimens from the Dinosaur Park Formation.

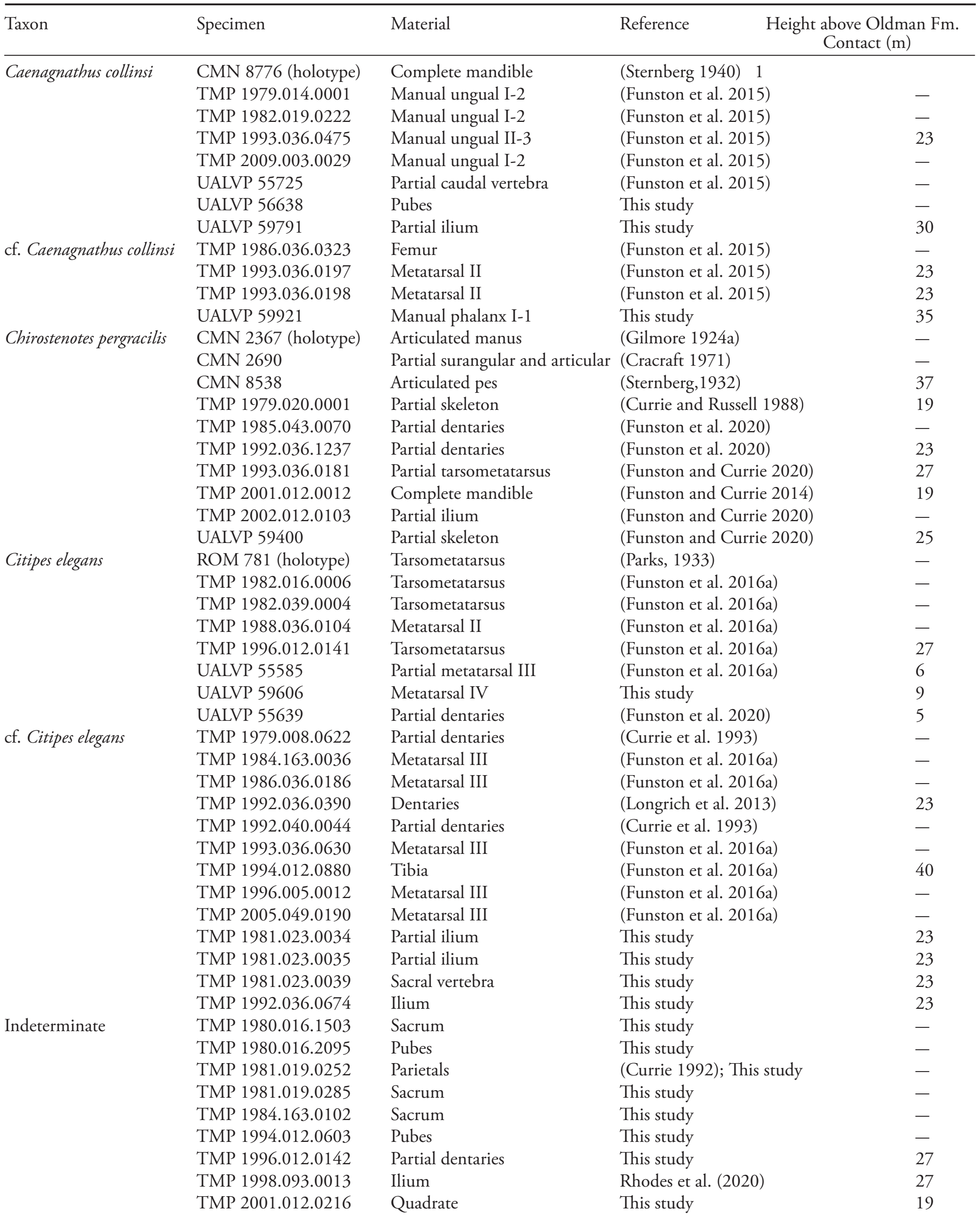

Note: height above Oldman Fm. contact is estimated in metres based on elevation (masl) of the collection site and the closest contact of the Oldman-Dinosaur Park Formation as recorded in Currie and Koppelhus (2005). 
sampling, and would be overturned if histological evidence showed that these taxa overlapped broadly in adult body size. Finally, the relatively complete material of Chirostenotes pergracilis means that its apomorphies (including body size at maturity) are well known. Thus, it is assumed that the absence of these apomorphies in an element eliminates Chirostenotes pergracilis as a possible identification for that element, and, following the first assumption, this means that it must pertain to either Caenagnathus collinsi or Citipes elegans gen. nov.. Importantly, body size is only used as an apomorphy when relative maturity can be assessed, either histologically or qualitatively based on external features (e.g., fusion of the tarsometatarsus), and body size is never used as the sole character for a referral.

Late Cretaceous caenagnathid material in the collections of the CGMP, CMN, MPC, ROM, TMP, and UALVP was examined firsthand. Casts of the type (CM 78000) and paratype (CM 78001) of Anzu wyliei were examined for comparison. The material was measured using digital calipers to an accuracy of $0.5 \mathrm{~mm}$ or a fabric measuring tape to an accuracy of $1 \mathrm{~mm}$ (Tab. 2). Photographs were taken using a Nikon D5000, a Nikon D7200, or a Nikon Coolpix AW120 using conventional photographic techniques. For conservation prior to histological sampling, three-dimensional models of some specimens were generated using photogrammetric reconstruction in Agisoft Photoscan Standard v. 1.4.3. Some material was scanned using computed tomography using either a Skyscan 1174 or a Siemens Sensation 64 Medical CT scanner. Reconstructed slices were segmented using Mimics 14.0, Dragonfly 3.1, or 3DSlicer 4.8.

Specimens for histological analysis were chosen based on availability and the ability to be linked to one of the three DPF caenagnathid taxa. New specimens included a large pubis (UALVP 56638), and a metatarsal IV with a fused distal tarsal IV (UALVP 59606). A metatarsal III previously sampled by Funston et al. (2016a) was redescribed in more detail. Thin sections were made as close to the midshaft or neutral growth zone as possible, while avoiding areas of muscle attachment or other features that would obscure a skeletochronological signal (e.g., the pubic apron). Although comparing disparate bones to assess maturity is not ideal, several factors suggest that this is unlikely to introduce significant error into the current study. Intraskeletal histovariability in theropods (Lee and O'Connor 2013), including caenagnathids (Cullen et al. 2020), can lead to significant differences in quantitative variables like osteocyte lacunar density, line of arrested growth (LAG) spacing, and LAG counts. However, assessments of relative maturity remain consistent between these bones, especially where an external fundamental system (EFS; Padian and Lamm 2013) is present (Lee and O'Connor 2013). Importantly, oviraptorosaur hindlimbs scale isometrically (Lü et al. 2013), so it is unlikely that growth in hindlimb elements would cease asynchronously. Although girdle bones are infrequently chosen for histological analysis, evidence from theropods (Porfiri et al. 2014) and other dinosaurs (Klein and Sander 2008; Redelstorff and Sander 2009) suggests they are suitable for skeletochronology and correspond to growth as recorded in the limb bones.

Histological thin-sections were made by vacuum-embedding the specimens in Buehler Epothin Resin (UALVP 55585) or Castolite AC polyester resin (UALVP 56638, UALVP 59606), and cutting the billet using a Hillquist Thin Section Machine (UALVP 55585) or an Isomet 1000 Precision Sectioning Saw (UALVP 56638, UALVP 59606). Billets were adhered to plexiglass slides using Buehler Epothin Resin (UALVP 55585) or 3M Cyanoacrylate glue (UALVP 56638, UALVP 59606). Thin sections were ground and polished from the mounted slides using a variety of grits on a lapidary wheel or by hand on a glass plate. Slides were imaged under plane polarized and cross-polarized light using NIS Elements on a Nikon Eclipse E600POL trinocular polarizing microscope with an attached Nikon DXM 1200F digital camera. Panoramic images of the entire slide were generated by stitching smaller images together with NIS Elements, or by photographing them with transmitted light using a Nikon D7200 (UALVP 56638). For enhanced clarity and depth of field, some pictures were generated using $\mathrm{Z}$-stacked images. Histologically sampled material was conserved either by casting the complete element, or by $3 \mathrm{D}$-printing the removed portions of the specimen using a Machina MK2 3D Printer using photogrammetrically-derived meshes. 3D-printed models were affixed to the original material, replacing the sampled regions. Histological terminology follows Padian and Lamm (2013). Cyclical growth marks (CGMs) are identified as recurring, punctuated intervals of slow growth that are continuous around the cortex. In the specimens described here, all of these manifest as distinct LAGs (and sometimes doublet and triplet LAGs), which are dark lines at low magnification, but CGMs can also be represented by broader annuli of parallel-fibered bone (Erickson 2000; Funston and Currie 2018). Following our current understanding, CGMs are interpreted as recording annual intervals of growth (Köhler et al. 2012; Padian and Lamm 2013). Phylogenetic analysis was carried out using the matrix, methods, and trees of Funston et al. (in review), which include the updated skeletal representation of caenagnathids described here. Character scores also include specimens which are tentatively referred to cf. Caenagnathus collinsi and cf. Citipes elegans gen. nov. Anomalipes zhaoi was added to the matrix, but the characters added by Yu et al. (2019) were not included in the character set. Beibeilong sinensis 
Table 2. Selected measurements of caenagnathid specimens from the Dinosaur Park Formation.

\begin{tabular}{|c|c|c|c|c|}
\hline Taxon & Specimen & Material & Measurement & Value $(\mathrm{mm})$ \\
\hline \multirow[t]{12}{*}{ Caenagnathus collinsi } & \multirow{4}{*}{ CMN 8776 (holotype) } & \multirow{4}{*}{ Complete mandible } & Mandible length & 230 \\
\hline & & & Shortest symphyseal length & 1.9 \\
\hline & & & Width behind symphysis & 48.3 \\
\hline & & & Minimum height of dentary & 14.9 \\
\hline & TMP 1979.014.0001 & Manual ungual I-2 & Length around curve & $90 \mathrm{e}$ \\
\hline & TMP 1982.019.0222 & Manual ungual I-2 & Length around curve & 91 \\
\hline & TMP 1993.036.0475 & Manual ungual II-3 & Length around curve & 108 \\
\hline & TMP 2009.003.0029 & Manual ungual I-2 & Length around curve & 85 \\
\hline & UALVP 55725 & Partial caudal vertebra & Centrum length & 39.8 \\
\hline & UALVP 56638 & Pubes & Total length & 416 \\
\hline & \multirow[t]{2}{*}{ UALVP 59791} & \multirow[t]{2}{*}{ Partial ilium } & Length of acetabulum & 66 \\
\hline & & & Height above acetabulum & 81 \\
\hline \multirow[t]{5}{*}{ cf. Caenagnathus collinsi } & \multirow[t]{2}{*}{ TMP 1986.036.0323 } & \multirow[t]{2}{*}{ Femur } & Length & 370 \\
\hline & & & Circumference & 114 \\
\hline & TMP 1993.036.0197 & Metatarsal II & Length & 261 \\
\hline & TMP 1993.036.0198 & Metatarsal II & Length & 245 \\
\hline & UALVP 59921 & Manual phalanx I-1 & Length & 102 \\
\hline \multirow[t]{36}{*}{ Chirostenotes pergracilis } & \multirow[t]{7}{*}{ CMN 2367 (holotype) } & \multirow[t]{7}{*}{ Articulated manus } & I-1 Length & 63 \\
\hline & & & I-2 Length & 44 \\
\hline & & & II-1 Length & 65 \\
\hline & & & II-2 Length & 72 \\
\hline & & & II-3 Length & 62 \\
\hline & & & III-3 Length & 44 \\
\hline & & & III-4 Length & 36 \\
\hline & \multirow[t]{19}{*}{ CMN 8538} & \multirow[t]{19}{*}{ Articulated pes } & Proximal width & 56 \\
\hline & & & MT II Length & 205 \\
\hline & & & MT III Length & 230 \\
\hline & & & MT IV Length & 212 \\
\hline & & & MT V Length & 60 \\
\hline & & & I-1 Length & 58 \\
\hline & & & I-2 Length & 42 \\
\hline & & & II-1 Length & 78 \\
\hline & & & II-2 Length & 63 \\
\hline & & & II-3 Length & 60 \\
\hline & & & III-1 Length & 75 \\
\hline & & & III-2 Length & 52 \\
\hline & & & III-3 Length & 58 \\
\hline & & & III-4 Length & 60 \\
\hline & & & IV-1 Length & 59 \\
\hline & & & IV-2 Length & 35 \\
\hline & & & IV-3 Length & 31 \\
\hline & & & IV-4 Length & 34 \\
\hline & & & IV-5 Length & 39 \\
\hline & \multirow{10}{*}{ TMP 1979.020.0001 } & \multirow{10}{*}{ Partial skeleton } & Sacrum Length & 200 \\
\hline & & & Coracoid Height & 58.1 \\
\hline & & & Coracoid Length & 52.1 \\
\hline & & & Manual I-1 Length & 65.4 \\
\hline & & & Manual II-1 Length & 71.9 \\
\hline & & & Manual II-2 Length & 75.8 \\
\hline & & & Manual II-3 Length around curve & 83 \\
\hline & & & Manual III-1 Length & 30.3 \\
\hline & & & Manual III-3 Length & 39.3 \\
\hline & & & Manual III-4 Length around curve & ve 48 \\
\hline
\end{tabular}


Table 2 continued.

\begin{tabular}{|c|c|c|c|c|}
\hline Taxon & Specimen & Material & Measurement & Value (mm) \\
\hline & & & Ilium Length & 255 \\
\hline & & & Height above acetabulum & 91 \\
\hline & & & Acetabulum Length & 55 \\
\hline & & & Ischium Length & 138 \\
\hline & & & Femur Length & 304 \\
\hline & & & Femur circumference & 100 \\
\hline & & & Tibia Length & 367 \\
\hline & & & MT I Length & 42.4 \\
\hline & & & MT II Length & 181 \\
\hline & & & MT III Length & 207 \\
\hline & & & MT IV Length & 186 \\
\hline & & & Pedal I-1 Length & 39.8 \\
\hline & & & Pedal III-1 Length & 54.1 \\
\hline & TMP 1985.043.0070 & Partial dentaries & Shortest symphyseal length & $19 \mathrm{e}$ \\
\hline & TMP 1992.036.1237 & Partial dentaries & Shortest symphyseal length & 38.5 \\
\hline & TMP 1993.036.0181 & Partial tarsometatarsus & MT II Length & 221 \\
\hline & & & MT IV Length & 220 \\
\hline & TMP 2001.012.0012 & Complete mandible & Mandible Length & 188 \\
\hline & & & Shortest symphyseal length & 32.8 \\
\hline & & & Width behind symphysis & 51.2 \\
\hline & & & Minimum height of dentary & 20.9 \\
\hline & TMP 2002.012.0103 & Partial ilium & Acetabulum Length & 70 \\
\hline & UALVP 59400 & Partial skeleton & Minimum height of dentary & 20.7 \\
\hline & & & Cervical vertebra 7 centrum length & $49 \mathrm{e}$ \\
\hline & & & Cervical vertebra 8 centrum length & $57 e$ \\
\hline & & & Caudal vertebra 8 centrum length & 27.1 \\
\hline & & & Caudal vertebra 9 centrum length & 25.2 \\
\hline & & & Caudal vertebra 10 centrum length & 22.3 \\
\hline & & & Caudal vertebra 11 centrum length & 21.4 \\
\hline & & & Caudal vertebra 12 centrum length & 19.5 \\
\hline & & & Caudal vertebra 13 centrum length & 19.4 \\
\hline & & & Caudal vertebra 14 centrum length & 16.1 \\
\hline & & & Caudal vertebra 15 centrum length & 20.4 \\
\hline & & & Caudal vertebra 16 centrum length & 20.9 \\
\hline & & & Caudal vertebra 17 centrum length & 16.9 \\
\hline & & & Chevron 8 Length & 58.7 \\
\hline \multirow[t]{14}{*}{ Citipes elegans } & ROM 781 (holotype) & Tarsometatarsus & MT II Length & 155 \\
\hline & & & MT III Length & 161 \\
\hline & & & MT IV Length & 157 \\
\hline & & & Proximal width of metatarsus & 39 \\
\hline & TMP 1982.016.0006 & Tarsometatarsus & MT II Length & 152.4 \\
\hline & & & MT III Length & 172.2 \\
\hline & & & MT IV Length & 160.5 \\
\hline & & & MT V Length & 44.3 \\
\hline & & & Proximal width of metatarsus & 48.5 \\
\hline & TMP 1982.039.0004 & Tarsometatarsus & Proximal width of metatarsus & 37 \\
\hline & TMP 1996.012.0141 & Tarsometatarsus & MT II Length & $130 \mathrm{e}$ \\
\hline & & & MT IV Length & $135 \mathrm{e}$ \\
\hline & & & Proximal width of metatarsus & 35.7 \\
\hline & UALVP 59606 & Metatarsal IV & MT IV Length & 146 \\
\hline \multirow[t]{3}{*}{ cf. Citipes elegans } & TMP 1979.008.0622 & Partial dentaries & Shortest symphyseal Length & 21 \\
\hline & & & Width behind symphysis & 32 \\
\hline & TMP 1992.036.0390 & Dentaries & Shortest symphyseal Length & 29.6 \\
\hline
\end{tabular}


Table 2 continued.

\begin{tabular}{|c|c|c|c|c|}
\hline Taxon & Specimen & Material & Measurement & Value $(\mathrm{mm})$ \\
\hline & \multirow{4}{*}{ TMP 1992.040.0044 } & \multirow{4}{*}{ Partial dentaries } & Width behind symphysis & 34 \\
\hline & & & Minimum height of dentary & 17.6 \\
\hline & & & Shortest symphyseal Length & 32 \\
\hline & & & Minimum height of dentary & 18 \\
\hline & TMP 1994.012.0880 & Tibia & Length & 280 \\
\hline & TMP 1981.023.0034 & Partial ilium & Acetabulum Length & 45 \\
\hline & \multirow[t]{2}{*}{ TMP 1981.023.0035 } & \multirow[t]{2}{*}{ Partial ilium } & Acetabulum Length & 46 \\
\hline & & & Height over acetabulum & 62 \\
\hline & \multirow[t]{2}{*}{ TMP 1992.036.0674 } & \multirow[t]{2}{*}{ Ilium } & Acetabulum Length & 60 \\
\hline & & & Height over acetabulum & 70 \\
\hline
\end{tabular}

Note: 'e' designates a value that is estimated

(Pu et al. 2017) was not added to the analysis because of its perinatal age, which would skew its placement and introduce noise into the results. Gobiraptor minutus was also not added to the analysis because it likely represents a juvenile Conchoraptor gracilis rather than a distinct taxon (Funston 2019). Similicaudipteryx yixianensis was merged with Incisivosaurus gauthieri based on reassignment of two specimens to the latter taxon (Xu 2020). These specimens were used, in part, by Lamanna et al. (2014) to score Similicaudipteryx when it was added to their matrix. Xingtianosaurus ganqi (Qiu et al. 2019) was not added to the matrix because its phylogenetic position is outside the scope of the study. No characters were added or removed from the matrix of Funston et al. (in review). All characters were treated as unordered. The dataset was analysed in TNT v.1.5. A preliminary tree search was run with 10000 replications of Wagner trees, followed by tree-bisection reconnection (TBR) branch swapping, holding up to 10 trees each round. A subsequent round of TBR branch swapping ensured that all most parsimonious trees were recovered. Ganzhousaurus nankangensis was recovered as a wildcard taxon and was therefore pruned from the final analysis, which was conducted using the same parameters as the preliminary analysis. Bremer support values (decay indices) were calculated using the 'Bremer.run' script included in TNT v.1.5. As in Funston et al. (in review), the tree was time-calibrated using the 'strap' package in R 3.6.1 and the 'equal' method of Brusatte et al. (2008). Root length was arbitrarily set at $10 \mathrm{Ma}$. Ages and references used for time calibration are provided in the supplement of Funston et al. (in review) and were updated using the age of the Upper Wangshi Group established by An et al. (2016).

Biogeographic range estimates were produced by stochastic simulation of tip data for 1000 replicates with the make.simmap function of 'phytools' v0.6-44, using a continuous-time reversible Markov model with equal rates of transformation. Ancestral biogeographic ranges are represented by the posterior probability at each node. Body mass estimates for oviraptorosaurs were calculated where femoral circumference measurements were available using the formula of Campione et al. (2014). Where body mass could not be estimated for a taxon, it was calculated by scaling the body mass estimate of a closely related taxon based on linear measurements of overlapping material. For example, the femur of Citipes elegans gen.nov. is unknown, so its body mass was estimated by scaling the body mass of Elmisaurus rarus (based on femoral circumference) relative to the length of the tibiae, which are known for both taxa. This approach introduces error because of variation in anatomical proportions, and although none of the estimates produced were outlandish, future discoveries may refine or change the body mass evolution patterns described here. Nevertheless, the available data are sufficient to resolve coarse trends throughout oviraptorosaur evolution. Banji long, Microvenator celer, and Yulong mini, each known only from juvenile specimens, were dropped from the body mass analysis to avoid skewing ancestral states estimations with ontogenetic variation. Indeed, the basal positions of Microvenator celer and Yulong mini-likely caused in part by their young ontogenetic stages (Currie et al. 2016b) pulled the ancestral body mass estimates of Caenagnathidae and Oviraptoridae down considerably in preliminary analyses. Body masses were plotted as a phenogram with 95\% confidence intervals of $\log 10$ Body Mass $(\mathrm{kg})$ versus time from the root of Oviraptorosauria using phytools v0.6-44 in R (Revell 2012).

The distribution of caenagnathids within Dinosaur Provincial Park was assessed using the accessioned collections of the RTMP, available online through the Government of Alberta Heritage Resources Management Information System (HeRMIS). The province of Alberta is legally subdivided into a numbered grid of Townships (counted from north-south) and Ranges (counted from east-west), each of which is further subdivided into 36 legal sections 1 sq. mile 
$\left(-2.6 \mathrm{~km}^{2}\right)$ in dimension. Early collections of caenagnathids predated the advent of GPS mapping, but specimens were nonetheless labelled and mapped with Township-RangeSection data. Some of these quarries or localities have been relocated and mapped using GPS coordinates, but these form the minority of known material. To provide a more complete sample of distribution, custom searches were conducted using HeRMIS for each legal subdivision in the environs of Dinosaur Provincial Park, and the number of specimens identified as caenagnathid was tallied. Not all of the identities of the specimens could be verified firsthand, but some specimens, such as teeth, casts, or moulds were excluded from the counts. Specimens for which GPS coordinates are known were added to this dataset - these were not returned as results during the HeRMIS searches. Stratigraphic positions of specimens with elevation data were estimated as the difference between the measured elevation of the specimen and the elevation of the closest measured contact between the Oldman and DPF based on the data of Currie and Koppelhus (2005).

\section{SYSTEMATIC PALAEONTOLOGY}

\author{
DINOSAURIA Owen, 1842 \\ SAURISCHIA Seeley, 1888 \\ THEROPODA Marsh, 1881 \\ COELUROSAURIA Huene, 1914 \\ MANIRAPTORA Gauthier, 1986 \\ OVIRAPTOROSAURIA Barsbold, 1976 \\ CAENAGNATHIDAE R.M. Sternberg, 1940 \\ Caenagnathus collinsi R.M. Sternberg, 1940
}

\section{Holotype: CMN 8776, mandible \\ Previously referred material: TMP 1979.014.0001,} manual ungual I-2; TMP 1982.019.0222, manual ungual I-2; TMP 1986.036.0323, right femur (cf. Caenagnathus collinsi); TMP 1993.036.0197, right metatarsal II (cf. Caenagnathus collinsi); TMP 1993.036.0198, right metatarsal II (cf. Caenagnathus collinsi); TMP 1993.036.0475, manual ungual II-3; TMP 2009.003.0029, manual ungual I-2; UALVP 55725, partial caudal vertebra.

Newly referred material: UALVP 56638, nearly complete pubes; UALVP 59791, partial ilium; UALVP 59921 (cf. Caenagnathus collinsi), manual phalanx I-1.

Horizon and locality: Upper Cretaceous (Campanian) Dinosaur Park Formation. All specimens recovered from Dinosaur Provincial Park, Alberta, Canada.

Revised diagnosis: Large caenagnathid oviraptorosaur diagnosed by the following combination of features and autapomorphies (indicated by asterisks): elongate dentary symphysis* (shared with Anzu wyliei); low quadrate articular ridge of mandible; large posterior protuberance on proximal end of metatarsal II*; groove between proximal articular surface and flexor tubercle present in manual ungual II-3 but not I-2*; rounded ventral edge of preacetabular blade; low ilium above the acetabulum; inclined ventral edge of pubic peduncle of ilium; pubic peduncle of ilium with anteroposterior ridge on ventral surface for contact with pubis, forming concavo-convex contact*; pubes relatively straight in anterior view, producing transversely narrow proximal end; iliac contact of pubis with anteroposterior concavity for ridge on the pubic peduncle of the ilium, forming concavo-convex contact*.

\section{Osteological Description}

CMN 8776: The holotype mandible of Caenagnathus collinsi was described by Sternberg (1940) and Currie, Godfrey, and Nessov (1993). However, since those descriptions, new information has become available regarding the variation and morphology of caenagnathid mandibles. In this light, the specimen is worthy of redescription, especially considering that no detailed photographs of the specimen are available in the literature. CMN 8776 (Fig. 2) is a nearly complete mandible and is the largest caenagnathid mandible recovered from the DPF (Tab. 2). The right angular was reconstructed below the external mandibular fenestra during final preparation, which has distorted the right ramus of the mandible (Fig. 2A).

The dentary can be distinguished from those of other caenagnathids, besides Anzu wyliei, by its low occlusal margin and anterior elongation (Fig. 2B, D). Like other caenagnathids, the symphysis is fused without a suture. However, the symphysis is much longer anteroposteriorly than most caenagnathids and is not upturned anteriorly into a sharp occlusal margin (Fig. 2B). The features of the occlusal surface of the dentary (Fig. 2E) are less pronounced than those of TMP 2001.012.0012 (Chirostenotes pergracilis) and TMP 1992.036.0390. For example, the lingual groove and ridge are shallower and the tubercle of the lingual ridge is level with the low occlusal margin of the dentary. The symphyseal sulcus is shallow and tapers anteriorly instead of posteriorly (Fig. 2E), unlike the condition in TMP 2001.012.0012 and TMP 1992.036.0390. At its anterior end, there is a prominent midline tubercle (Fig. 2E), which is absent in other caenagnathids, including Anzu wyliei. Anterolateral to this tubercle, there is a circular fossa that corresponds to the anterior occlusal groove of other caenagnathids. However, there is no midline anterior occlusal groove, which is usually present. The symphyseal sulcus is bordered laterally by a shallow lingual ridge with a poorly developed tubercle. Lateral to this ridge, the occlusal surface is slightly depressed into a lingual groove, bordered laterally by six lateral occlusal grooves separated by five lateral occlusal ridges (Fig. 2E). The anterior lateral occlusal ridges and grooves are pronounced, 


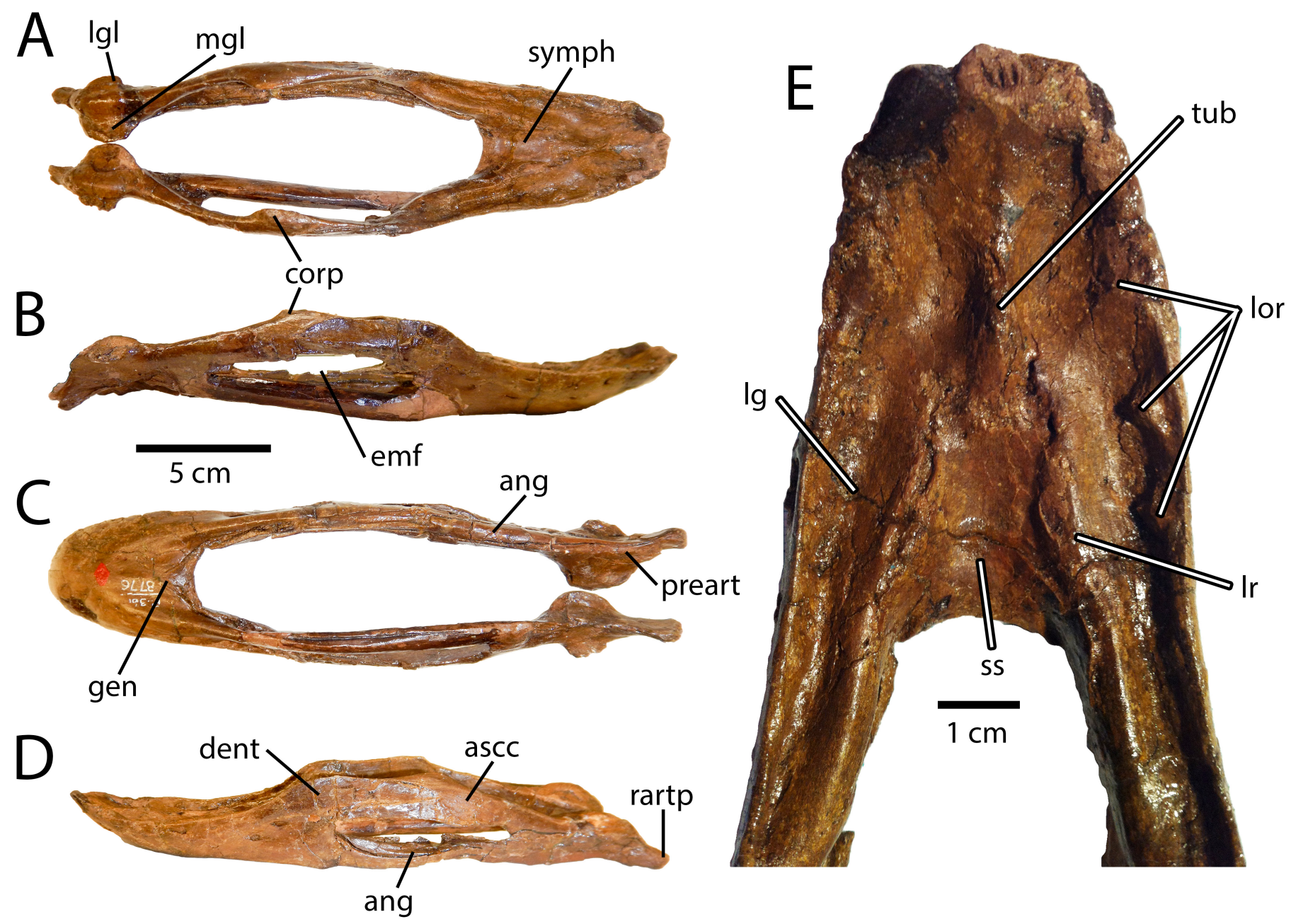

Figure 2. CMN 8776, holotype mandible of Caenagnathus collinsi. Photographs of CMN 8776 in dorsal (A), right lateral (B), ventral (C), and left lateral (D) views. Detail (E) of occlusal surface of dentaries in dorsal view. Abbreviations: ang, angular; ascc, articular-surangular-coronoid complex; corp, coronoid process; dent, dentary; emf, external mandibular fenestra; gen, attachment of m. genioglossus; lg, lingual groove; Igl, lateral glenoid; lor, lateral occlusal ridges; Ir, lingual ridge; mgl, medial glenoid; preart, prearticular; rartp, retroarticular process; ss, symphyseal sulcus; symph, symphysis; tub, tubercle.

but each successive ridge is less pronounced than those anterior to it, forming a gradual decrease in the ridges from anterior to posterior. The lateral surface of the dentary is marked by several distinct foramina, but lacks a deep mandibular fossa, which is present in TMP 2001.012.0012 and TMP 1992.036.0390. Instead, there is a shallow depression underneath a poorly-developed lateral shelf (Fig. 2B, D). This shelf is similar in position to the lateral flange of Anzu wyliei, but is less well developed. Two large foramina, probably pneumatopores, pierce this depression, similar to the pneumatopores in the mandibular fossae of other caenagnathid dentaries. The ventral surface of the dentary is much flatter than those of 'deep-beaked' caenagnathids, but is similarly pierced by numerous foramina. The Meckelian grooves extend along the ventromedial surfaces of the dentaries and converge anteriorly at the posterior end of the symphysis. A vascular canal extends anteromedially from each Meckelian groove, and these canals converge just anterior to the poorly-defined attachment for $m$. genioglossus. The posterodorsal ramus of the dentary is dorsoventrally broad and tapers to a pointed posterior end. The posteroventral ramus is anteroposteriorly longer and dorsoventrally narrower than the posterodorsal ramus. It inserts onto the lateral surface of the angular and is slight bowed both laterally and ventrally.

Caenagnathid mandibles are characterized by a fusion of the articular, surangular, and coronoid, termed the articular-surangular-coronoid (ASC) complex (Currie et al. 1993). Both of the ASC complexes are preserved in CMN 8776 , but the left side is slightly better preserved. The anterior part of the surangular has an interdigitating contact with the dentary (Fig. 2D). The anteroposterior length of this contact is greater than in Chirostenotes pergracilis (TMP 2001.012.0012) or TMP 1992.036.0390, extending posteriorly to the level of the coronoid process. Ventral to 
this contact, the surangular flares laterally as it forms the dorsal edge of the external mandibular fenestra, but not to the same degree as in Chirostenotes pergracilis (TMP 2001.012.0012). The coronoid process is rugose and medially inturned, but does not project far above the highest point of the dentary (Fig. 2D), contrasting with the condition in Chirostenotes pergracilis (TMP 2001.012.0012). The dorsoventrally broad ramus of the surangular descends towards the articular, which is in the form of a low ridge. There is no surangular foramen, but there is a shallow fossa on the medial surface of the surangular posterior to the external mandibular fenestra. The medial glenoid of the articular is larger transversely and anteroposteriorly than the lateral one. The retroarticular process is hatchet-shaped and directed posteroventrally and slightly laterally. The angular is mostly missing on the right side, and its reconstruction has distorted the right ramus of the mandible, pulling it medially. On the left side, it is completely preserved and well articulated with the dentary (Fig. 2D). Anteriorly, it is sheet-like and inserts on the medial surface of the dentary. It tapers dorsoventrally towards its midshaft, becoming more rod-like where it underlies the external mandibular fenestra. Here, it has a prominent lateral ridge underlain by a groove, which accommodate the posteroventral ramus of the dentary. Posterior to the external mandibular fenestra, the angular becomes plate-like and lies against the lateral surface of the surangular. It extends to the posterior end of the mandible and forms the lateral portion of the retroarticular process. The splenial is a thin splint of bone that extends along the medial surface of the angular. Posteriorly, it underlies the prearticular, which is also rod-like in this region. The prearticular expands dorsoventrally towards its posterior end, where it is plate-like as it underlies the medial glenoid of the articular region. It contributes to the medial and ventral parts of the retroarticular process.

UALVP 59921: UALVP 59921 (Fig. 3) is a large manual phalanx I-1 (102 $\mathrm{mm}$ in length), intermediate in size between those of Hagryphus giganteus $(87 \mathrm{~mm}$, Zanno and Sampson 2005) and Anzu wyliei (123 mm, Lamanna et al. 2014). Like all caenagnathids for which this element is known, it is transversely narrow (Fig. 3B, C), and this distinguishes it from similarly-sized theropods like ornithomimids. Even among caenagnathids, this specimen is particularly gracile, especially compared to similarly-sized phalanges (Anzu wyliei and Hagryphus giganteus). The proximal articulation is bisected by a well developed ridge, which separates the equal-sized lateral and medial articular facets (Fig. 3F). The ventral margin of the proximal end is in line with the
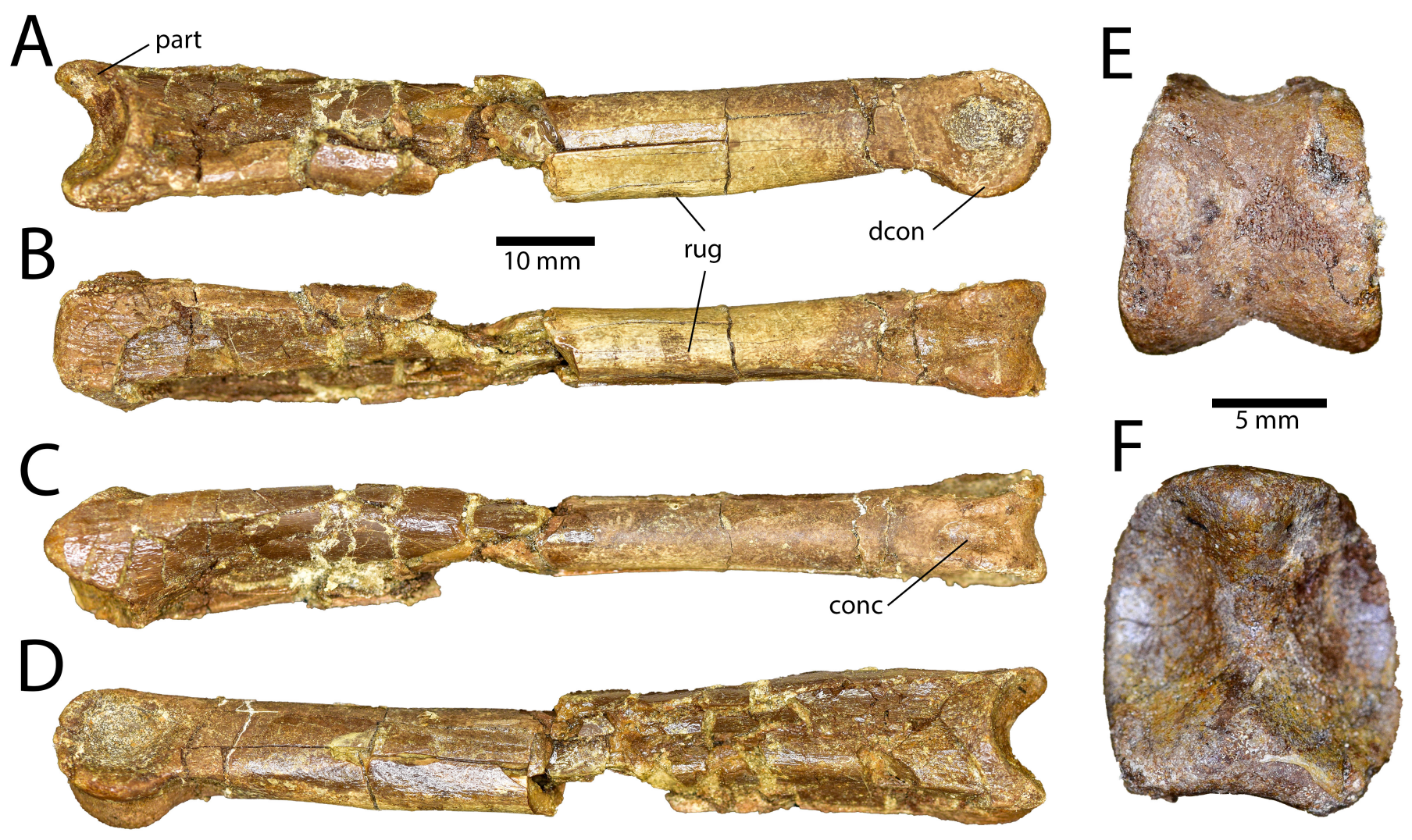

Figure 3. UALVP 59921, manual phalanx I-1 of cf. Caenagnathus collinsi. Photographs in lateral (A), ventral (B), dorsal (C), medial (D), distal (E), and proximal (F) views. Abbreviations: conc, concavity; dcon, distal condyle; part, proximal articular surface; rug, rugosity. 
ventral margins of the shaft, rather than flaring ventrally as is the case in Anzu wyliei (CM 78000), Chirostenotes pergracilis (CMN 2367 and TMP 1979.020.0001), and Elmisaurus rarus (Osmólska 1981). The shaft of the phalanx appears slightly ventrally bowed, which has been emphasized by breakage to the middle of the shaft. Most of this ventral bow is the result of a curved ventral edge as in Hagryphus giganteus (Zanno and Sampson 2005), and the phalanx becomes dorsoventrally deepest about two-thirds of the length from the proximal end. In this area, several foramina and longitudinal ridges are present on the ventral edge of the phalanx, producing a rugose surface texture (Fig. 3A, B). The dorsal edge is straight for most of its length, except for a slight depression just proximal to the distal condyles. The shaft of the phalanx is transversely straight in dorsal view, rather than bowing laterally as in Elmisaurus rarus (Osmólska 1981) and Hagryphus giganteus (Zanno and Sampson 2005). The distal condyles are equal in size and are not inclined relative to the long axis of the phalanx, unlike in Chirostenotes pergracilis (CMN 2367 and TMP 1979.020.0001). The collateral ligament pits are deep but grade into the surfaces of the condyle, producing basins rather than sharp-edged pits.

\section{Osteohistology}

UALVP 56638: A fragment of the proximal shaft of the pubis UALVP 56638 was thin sectioned in the transverse plane (Fig. 4B). Unlike the limb bones of caenagnathids, the pubes lack a hollow medullary cavity, so there is minimal endosteal resorption of the cortex. The histological texture of the cortex of UALVP 56638 differs greatly between the anterior and posterior halves of the bone (Fig. 4B). Whereas anteriorly the cortex is composed of primary bone, posterior to its midpoint, the cortex is densely remodeled by numerous generations of secondary osteons (Fig. 5D). In between these regions, in the inner cortex, are numerous erosive cavities forming the spongy medullary region. Trabeculae between these cavities are composed of low vascularity parallel-fibered bone, and some, but not all, of the cavities are lined with endosteally-derived lamellae (Fig. 5A).

The primary bone in the anterior cortex is predominantly fibrolamellar with dense osteocyte lacunae, high vascular density, and well-developed lines of arrested growth (LAGs; Fig. 4C, D). One patch of large secondary osteons is present near the mid-cortex (Fig. 5B), but secondary remodeling is otherwise absent. In the inner cortex, vascularity is predominantly longitudinal in orientation, but in some areas it is better described as reticular, and intermittent radial canals are present throughout. Osteocyte lacunae in this region are typically globose and randomly distributed. Towards the outer cortex, there is a stark shift in the bone matrix and vascular orientations, which coincides with a decrease in LAG spacing. Bone in the anterior part of the outer cortex has much denser osteocyte lacunae, which are larger, more globose, and sometimes arranged into linear rows parallel to the periosteal surface (Fig. 5E, F). Vasculature in this area is more zonal, with rows of radial vascular canals, both simple and within primary osteons, grading through reticular to longitudinal osteons and decreasing in density in each growth interval. Each vascular zone is succeeded by a zone of low-vascularity bone with a high proportion of parallel-fibered matrix, and finally a distinct cyclical growth mark (CGM). Some of these CGMs comprise multiple LAGs, which converge laterally. Whereas all CGMs are preceded by an annulus of parallel-fibered bone of varying thickness (Fig. 5C), some LAGs in the outer anterior cortex are also succeeded by an annulus. Where this occurs, dense osteocyte lacunae are aligned on the periosteal margin of the annulus, producing a 'pseudo-LAG' under low magnification (Fig. 5E, F). Similar 'pseudo-LAGs' also occur within the growth intervals, and these sometimes, but not always, coincide with changes in vascular arrangement or density.

Each of the zones in the outer anterior cortex tapers in thickness towards the lateral and medial sides of the pubis, eventually grading into an annulus of avascular parallel-fibered bone. Thus, the cortex of the medial and lateral sides of the pubis contrasts strongly with the bone in the anterior part. In these areas, the inner cortex is primary fibrolamellar bone with longitudinal-reticular vascular orientation, divided into zones by single LAGs of regularly decreasing spacing, each of which is preceded by an annulus of low-vascularity parallel-fibered bone (Fig. 4A). After the fifth LAG, there is a stark transition to nearly-avascular parallel-fibered bone with seven much more closely packed LAGs. Where vascularity is present, it is in the form of simple vascular canals, rather than well-developed osteons. LAGs decrease regularly in spacing throughout this region. This band of parallel-fibered bone occupies only the periosteal $10 \%$ of the cortex on the lateral side of the pubis, whereas the equivalent anterior zones occupy more than $30 \%$ of the cortex (Fig. 4C, D).

\section{Chirostenotes Gilmore, 1924}

Chirostenotes pergracilis Gilmore, 1924 sensu Longrich et al., 2013

= Caenagnathus sternbergi Cracraft, 1971

= Macrophalangia canadensis Sternberg, 1932

Holotype: CMN 2367, left and right hands.

Referred material: CMN 2690, partial articular and surangular (Caenagnathus sternbergi Cracraft, 1971); CMN 8538 (Macrophalangia canadensis Sternberg, 1932), right partial tibia, astragalus, and foot; TMP 1979.20.1, partial 

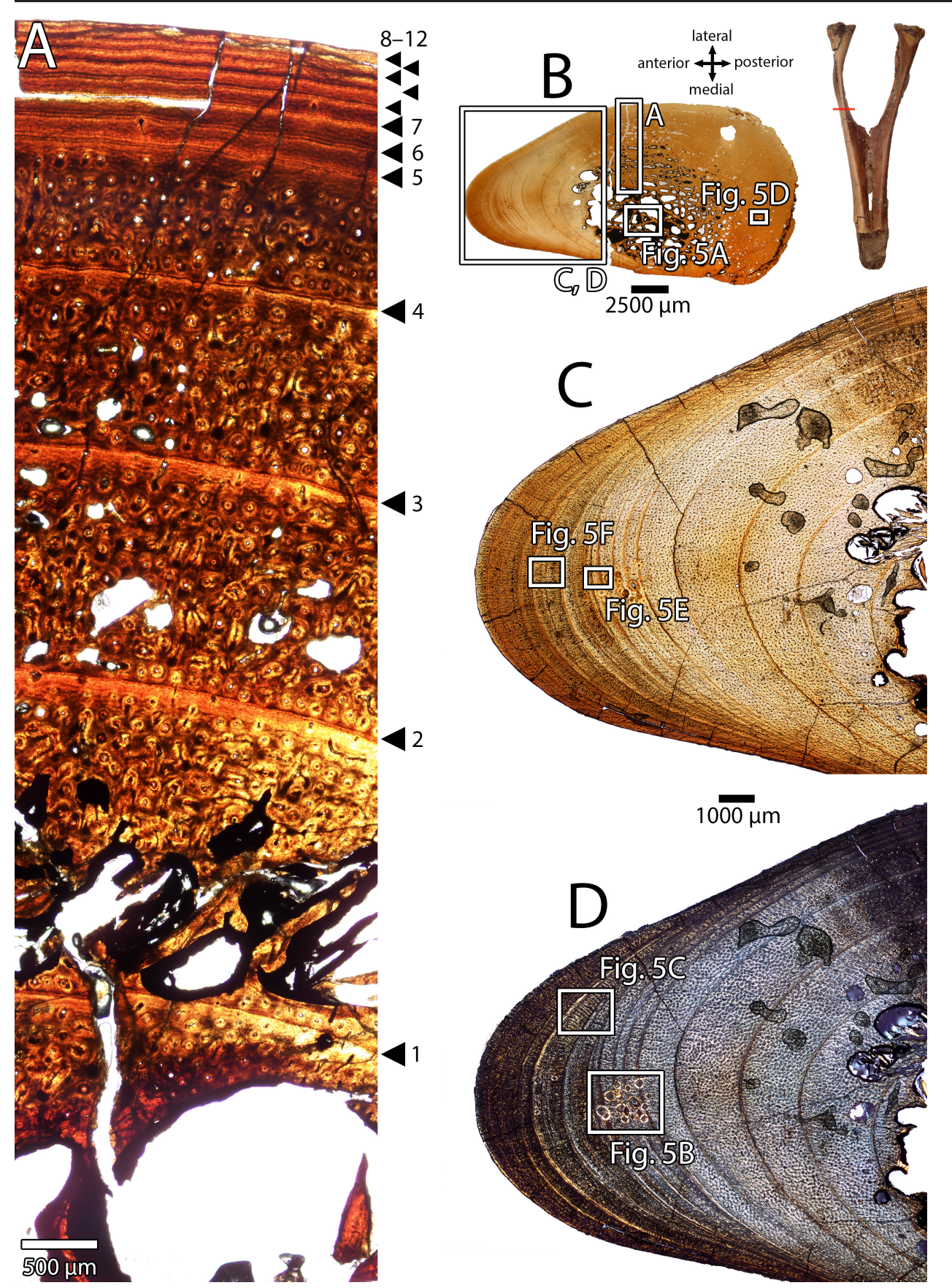

Figure 4. Osteohistology of UALVP 56638, pubes of Caenagnathus collinsi. Detail (A) of cortex of UALVP 56638 in plane-polarized light, showing twelve cyclical growth marks (numbered arrows). Overview (B) of the location of the section (red line on pubes in anterior view) and the entire thin section of UALVP 56638 in plane-polarized light, showing primary bone on the anterior side and densely remodeled Haversian bone on the posterior side, as well as the locations of close-ups in Fig. 5. Details (C, D) of anterior portion of UALVP 56638 in plane-polarized (C) and cross-polarized (D) light, showing cyclical growth marks, predominantly primary bone tissue, and locations of close-ups in Fig. 5. skeleton; TMP 1984.043.0070, partial dentaries; TMP 1990.56.6, dentary; TMP 1992.036.1237, partial dentaries; TMP 2001.12.12, nearly complete mandible; UALVP 59400, partial skeleton including mandible, cervical vertebrae, caudal vertebrae, distal end of tibia, astragalus, and distal tarsal III.

Horizon and locality: Upper Campanian of the Dinosaur Park Formation. All specimens found within Dinosaur Provincial Park, Alberta, Canada.

\section{Diagnosis (from Funston and Currie 2020):}

Medium-sized $(-65 \mathrm{~kg})$ caenagnathid oviraptorosaur diagnosed by the following autapomorphies $\left(^{*}\right)$ and combination of characters: occlusal tip of dentary upturned at approximately $45^{\circ}$; dentaries fused with well-developed symphyseal shelf; deep mandibular fossa; dentary excluded from dorsal margin of external mandibular fenestra by surangular; articular ridge of mandible distinctly offset from dorsal margin of surangular; cervical vertebrae with low neural spines and small epipophyses; six sacral vertebrae with pleurocoels; distal caudal vertebrae with anteriorly directed transverse processes; posterior chevrons anteroposteriorly elongate at proximal end, as long or longer anteroposteriorly than corresponding caudal vertebrae*; digit III of manus longer than digit I, but with slender phalanges; tall, dolichoiliac ilium with reduced postacetabular blade*; distal tarsals and proximal metatarsals not coossified at 


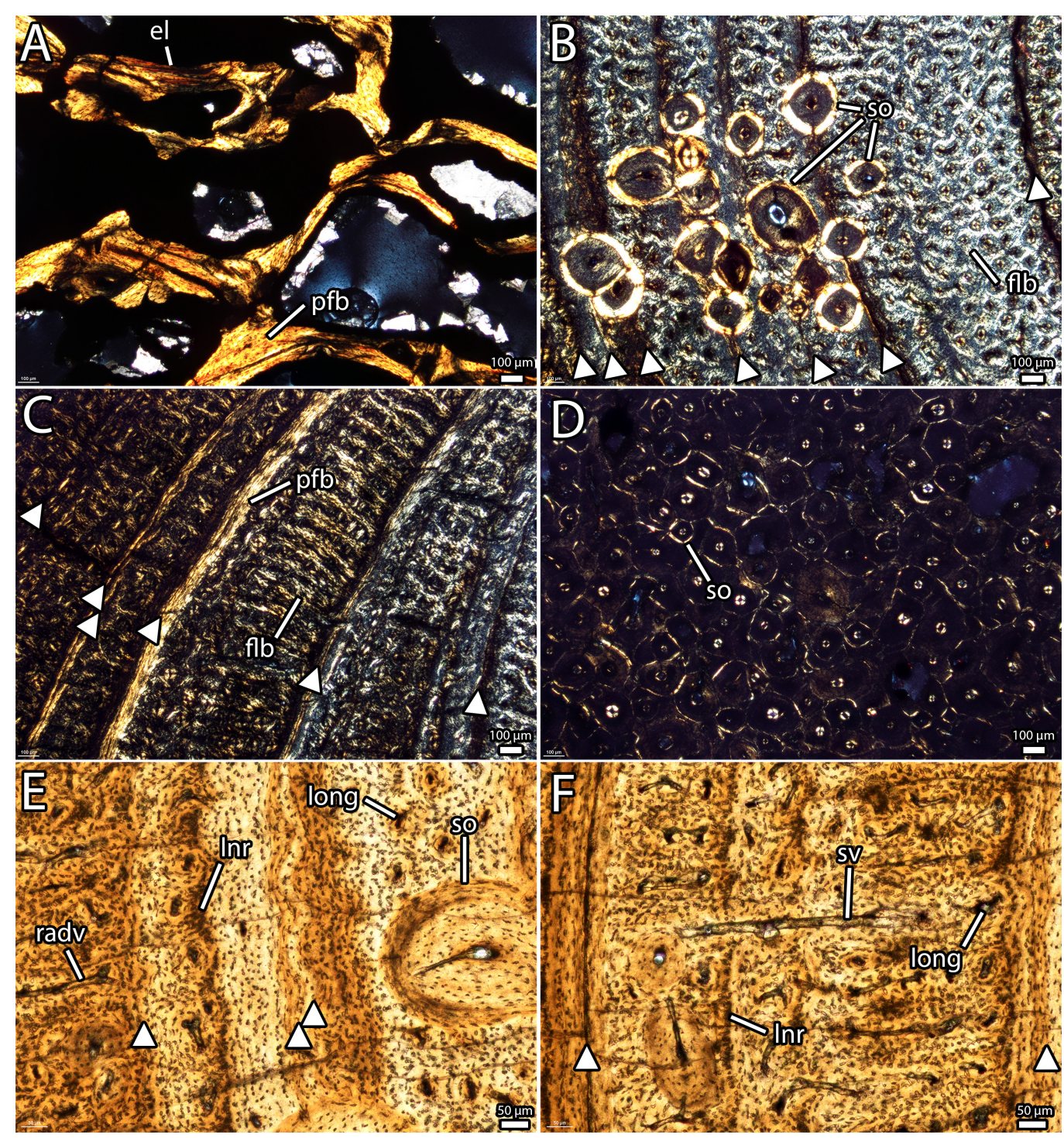

Figure 5. Osteohistological aspects of UALVP 56638, pubes of Caenagnathus collinsi. Close-up (A) of endosteal lamellae and large erosive cavities in the medullary region of the pubis in cross-polarized light. Detail (B) of localized secondary remodeling with well-developed secondary osteons, cyclical growth marks (arrows), and longitudinally oriented vasculature in the primary bone of the anterior portion of the pubis in cross-polarized light. Detail (C) of parallel-fibered bone and primary fibrolamellar bone in association with cyclical growth marks (arrows) in the exterior cortex of the pubis under cross-polarized light. Detail (D) of dense Haversian bone in the posterior cortex of the pubis under cross-polarized light. Close-up (E) of variation in primary bone texture, alignment of osteocyte lacunae, and cyclical growth marks (arrows) in the anterior portion of the cortex under plane-polarized light. Close-up (F) of variation in vascular orientation and alignment of osteocyte lacunae between cyclical growth marks (arrows) in the cortex of the pubis under plane-polarized light. Abbreviations: flb, fibrolamellar bone; Inr, linear features created by alignment and density changes of osteocyte lacunae; long, longitudinal vasculature; $\mathrm{pfb}$, parallel-fibered bone; radv, radial vasculature; so, secondary osteon; sv, simple vascular canal.

maturity; metatarsal III proximally pinched between metatarsals II and IV, but only the proximal tip is excluded from the anterior surface of the metatarsus; metatarsal V strongly procurving and not fused to distal tarsal IV*.

\section{Osteological Description}

CMN 2367: The type of Chirostenotes pergracilis was described by Gilmore (1924), but has received little attention since, except for comparison with TMP 1979.020.0001 (Currie and Russell 1988). The specimen (Fig. 6) comprises two partial articulated hands, the right slightly more complete than the left. Phalanges I-1, II-1, II-2 and III-1 from the left hand are preserved, alongside the unguals I-2 and II-3 (Fig. 6A, B). Phalanx I-1 is mostly complete, although it is missing its proximal end. The shaft is straight and cylindrical, although its ventral surface is flattened distally. The condyle is nearly symmetrical, and the lateral and medial portions 
are equal in size. However, the medial ligament fossa is deeper and more circular than the lateral one. Ungual I-2 is complete except for a small part of the distal tip. It is strongly recurved and has a large flexor tubercle (Fig. 6A). The proximodorsal lip is well-developed. The flexor tubercle has a flat ventral surface and is separated from the proximal articular surface by a pronounced sulcus, which differentiates it from Caenagnathus collinsi. The medial and lateral vascular grooves are well developed but neither bifurcates proximally. Phalanx II-1 is crushed and only the distal half is preserved. The shape of the shaft is deformed by crushing, but it is generally cylindrical with slight elongation along its dorsoventral axis. The distal condyle is asymmetrical, with a ventrally directed medial portion and a dorsally deflected lateral portion. Accordingly, the sulcus between the two condyles is inclined ventromedial to dorsolateral. Phalanx II-2 is complete and, despite some crushing and fragmentation, is relatively undeformed. The proximal end is saddle-shaped, and the median ridge and saddles correspond in inclination to the offset distal condyles of phalanx II-1. The shaft of phalanx II-2 is slightly twisted, which results in the lateral surface of the distal condyle being more exposed in dorsal view. The distal condyles are relatively equal in size, but the lateral condyle is further dorsal and slightly inclined, as previously described. Ungual II-3 is relatively straight (Fig. 6A), like that of Apatoraptor pennatus Funston and Currie, 2016 (Funston and Currie 2016) and other caenagnathids in general. The flexor tubercle is distally positioned and is greatly reduced compared to ungual I-2 and even other unguals II- 3 of other caenagnathids, like Anzu wyliei, Apatoraptor pennatus, and those described by Bell et al., (2015). In contrast, the proximodorsal lip is pronounced and extends further dorsally than the flexor tubercle extends ventrally. Separating the crescentic proximal articulation from the flexor tubercle is a wide but shallow sulcus, contrasting with the deeper grooves of Anzu wyliei, Apatoraptor pennatus, and those described by Bell et al. (2015). Each side has a vascular canal extending from the blunt distal tip of the ungual. Neither bifurcates proximally, and the lateral groove is both deeper and positioned further dorsally than the medial one. Phalanx III-3 is the only phalanx from the third digit
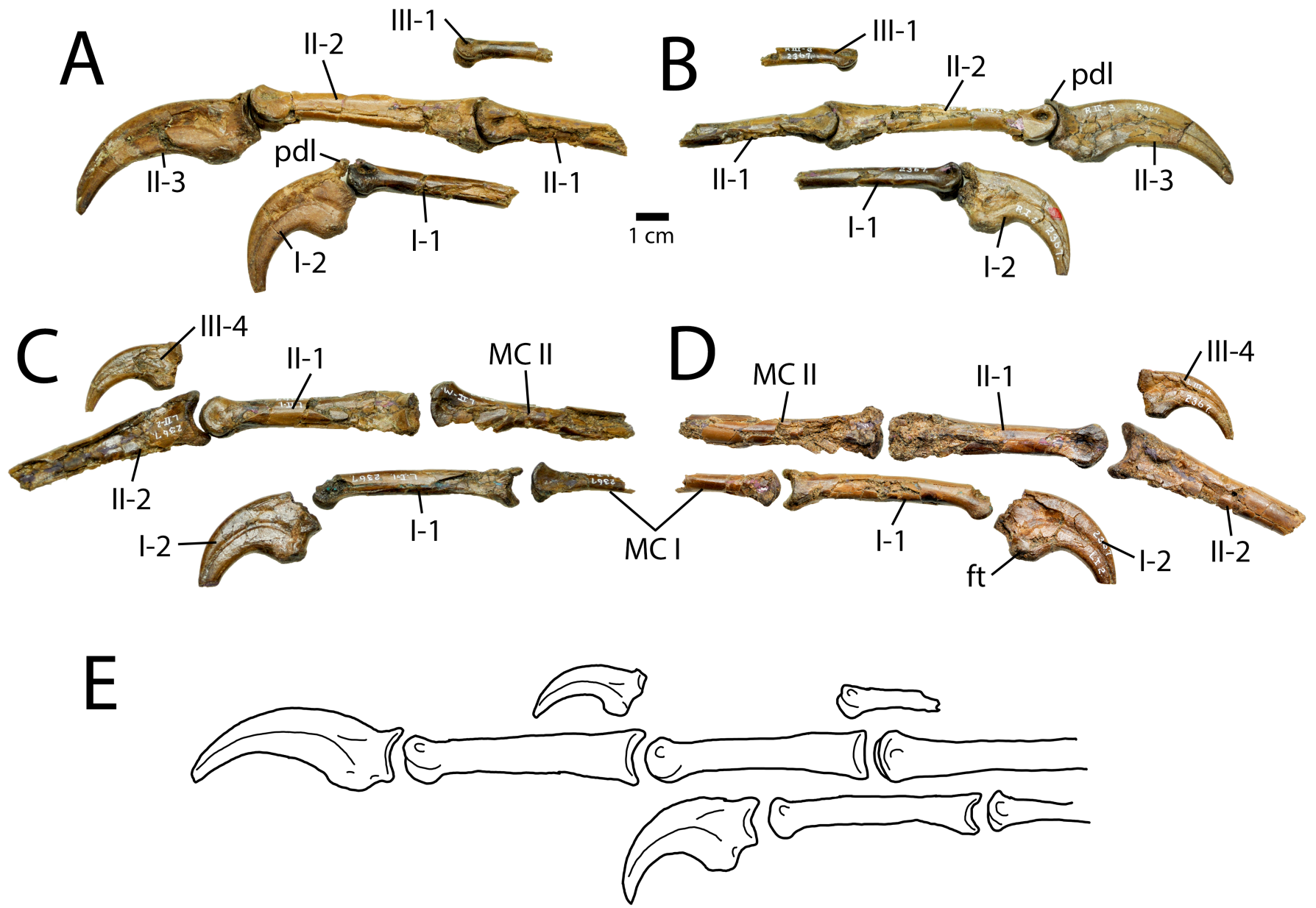

Figure 6. CMN 2367, holotype manus of Chirostenotes pergracilis. Right manus in medial (A) and lateral (B) views. Left manus in lateral (C) and medial (D) views. Reconstruction (E) of right manus in medial view based on composite of both mani. Abbreviations: ft, flexor tubercle; MC I, metacarpal I; MC II, metacarpal II; pdl, proximodorsal lip. 
preserved on the left side. It is small and the proximal end is missing. The shaft is roughly cylindrical, although it is slightly compressed mediolaterally, and it is flattened dorsally just proximal to the condyles. The distal condyles do not protrude dorsally beyond the shaft, which contrasts with the other phalanges preserved from the left hand. Like phalanx II-1, the distal condyles are inclined dorsolaterally to ventromedially. Although ungual III- 4 is shown in Gilmore's (1924) original plates, it is not currently present in the CMN collection. It is possible that it was damaged during collection, or that it has been lost since.

The right hand (Fig. 6C, D) includes parts of metacarpals I and II, phalanges I-1, II-1, II-2, III-3 and unguals I-2 and III-4. Metacarpal I is represented by the distal third of the bone. The shaft is ovate in cross-section, with the long axis inclined dorsolateral to ventromedial relative to the condyles. The condyles are unequal, and the medial is larger and protrudes further distally. Phalanx I-1 is nearly complete, missing only the dorsal part of the distal condyles. The proximal articulation is asymmetrical and the lateral facet is larger than the medial one. Similarly, the medial facet is excavated more deeply than the lateral facet, which complements the more distally projecting medial condyle of metacarpal I. The shaft of phalanx I-1 is gently arched dorsally (Fig. 6C), but not to the same degree as Apatoraptor pennatus (Funston and Currie 2016). The distal condyles are damaged, but there is no reason to suspect that they differ from those of the left phalanx I-1. The right ungual I-2 is slightly larger than the left, but is consistent in morphology. The flexor tubercle is well developed and there is a groove separating it from the proximal articular surface. The proximodorsal lip has been removed by erosion. Metacarpal II is represented by a portion of the shaft and the distal condyles. The shaft is slightly elliptical in cross-section, and there is a facet on its dorsolateral surface that probably accommodated metacarpal III. The lateral distal condyle is mostly missing, but together the condyles appear to have formed a saddle-shaped articulation. The distal outline of the medial condyle is crescentic, and both condyles appear to have protruded dorsally and ventrally past the margins of the shaft. The medial ligament fossa is shallow and roughly oval in shape. Phalanx II- 1 is complete except for the lateral side of the proximal end. The medial facet of the proximal end faces posteromedially, rather than directly posteriorly, which accommodates the large crescentic medial condyle of metacarpal II. The shaft is mediolaterally compressed and has a small groove on its ventrolateral surface similar to that on phalanx II- 2 of $A n z u$ wyliei (Lamanna et al. 2014), but it is not as well developed. Like in the left hand, the distal end of phalanx II-1 is asymmetrical, with a larger, more dorsally-directed lateral condyle. Only the proximal part of phalanx II-2 is preserved, and it is badly crushed. The proximal articular surface is identical to that on the left hand, and is roughly symmetrical with a median ridge. The shaft is mediolaterally compressed and lacks the groove on the ventrolateral surface that is present in Anzu wyliei (Lamanna et al. 2014). Gilmore's (1924) original plates show at least one phalanx from the third digit articulating with the ungual, and based on their position below the second digit, it is possible that the entire third digit was preserved. Regardless, only the ungual remains in the CMN collection. Ungual III-4 is small and intermediate in curvature between I-2 and II-3, but more gracile than either (Fig. $6 \mathrm{C}, \mathrm{D})$. The flexor tubercle is large, square, and positioned far from the proximal articular surface, which is broken. A moderately deep groove would have separated these features. The proximodorsal lip is broken, but Gilmore's (1924) plates show it was small regardless.

TMP 1979.020.0001: This partial skeleton was described by Currie and Russell (1988), but new insights into caenagnathid anatomy mean a redescription is warranted. The specimen consists of a sacrum, right coracoid, partial hand, partial pelvis, and a relatively complete but crushed right hindlimb.

Like those of other caenagnathids, the sacrum of TMP 1979.020.0001 (Fig. 7) incorporates six vertebrae. The neural arches are indistinguishably fused, but sutures can still be discerned between the centra of the first five vertebrae. The centrum of the sixth vertebra does not appear to be fused to the fifth sacral (Fig. 7D). With the exception of the first centrum, which is barrel-shaped, the centra become progressively more flattened dorsoventrally. The first five centra have deep lateral pleurocoels, but these decrease in size successively. The ventral surfaces of sacral vertebrae $2-5$ each have a midline sulcus, which is best developed on sacral 3. Fusion of the neural spines forms a tall fan that decreases in height posteriorly (Fig. $7 \mathrm{~A})$. There is a gap between the neural spines of sacral vertebrae 3 and 4; this same condition is present in another sacrum, TMP 1984.163.102 (discussed subsequently), which suggests it is not the result of breakage. Each neural arch is invaded by a series of pneumatic fossae, and these depressions are separated by tall ridges on the lateral sides of the neural spines. The sacral ribs are positioned lower on the neural arches successively, with the exception of sacral rib 4, which is directed more dorsally. Most of the sacral ribs are represented only by their bases, which are fused to the sacrum, but the left sacral rib 5 is fully preserved. It is hatchet shaped in ventral view and expands posteriorly into a pointed process (Fig. 7C, D).

The coracoid (Fig. 8A, B) is relatively complete, missing only its dorsal edge. It was not fused to the scapula, based on clean bone surface on the posterior edge. The glenoid is transversely thickened compared to the rest of the bone, and it forms the posterior part of a raised platform that connects with the biceps tubercle. Dorsal to this, a small 


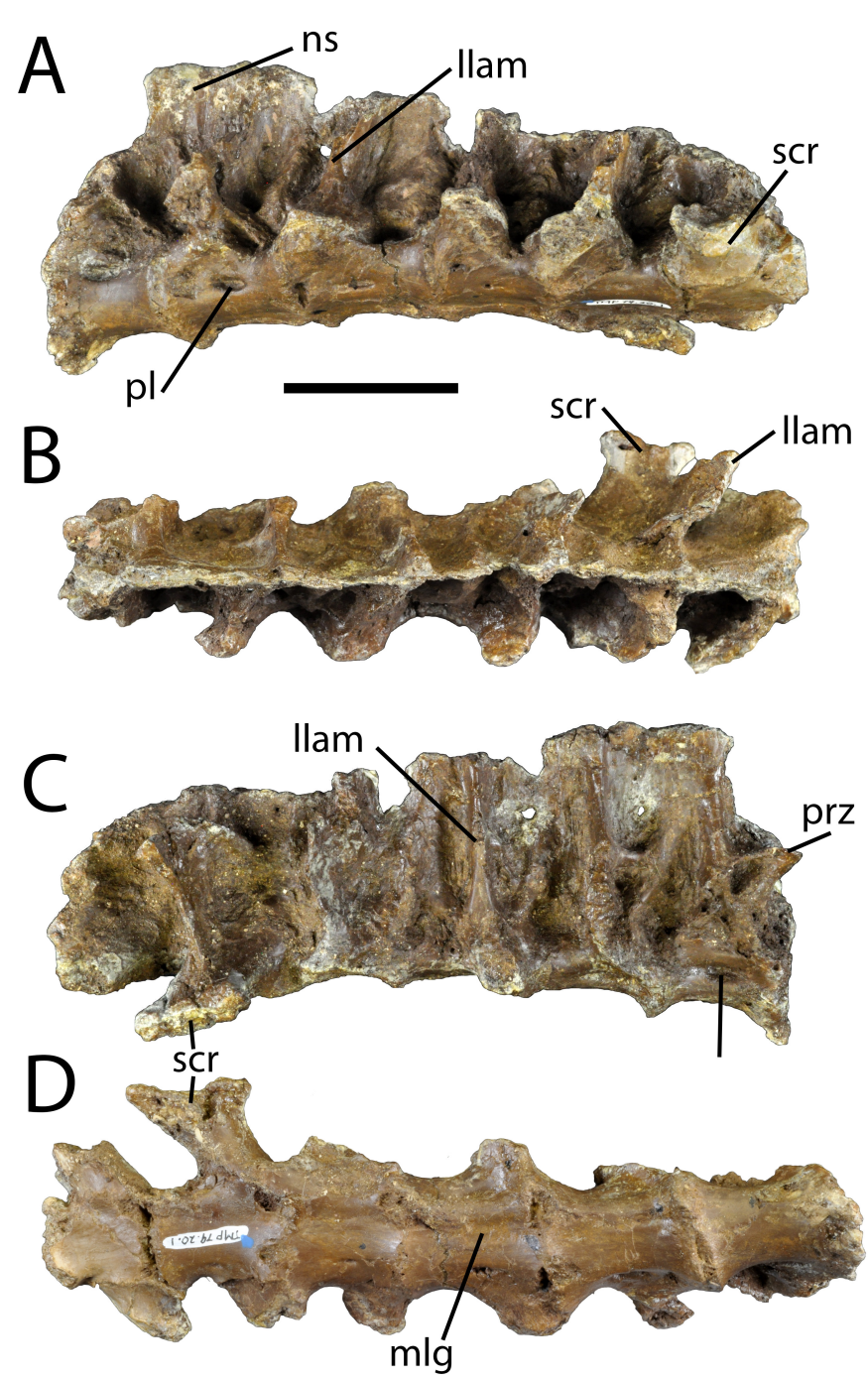

Figure 7. TMP 1979.020.0001, sacrum of Chirostenotes pergracilis. Sacrum in left lateral (A), dorsal (B), right lateral (C) and ventral (D) views. Abbreviations: Ilam, lateral lamina; mlg, midline groove; ns, neural spine; pl, pleurocoel; prz, prezygapophysis; scr, sacral rib.

coracoid foramen pierces the bone, which opens dorsally because of the raised platform. The dorsal portion of the coracoid is plate-like but it thickens transversely towards the caudoventral process. This process (Fig. 8A) is relatively short for an oviraptorosaur, but strongly curved posteriorly into a hook-like process. The medial surface of the coracoid is concave, following the convex profile of the lateral surface. There is a small fossa medial to the biceps tubercle, as is the case in MPC-D 100/33, an oviraptorid from the Nemegt Formation of Mongolia.

The left manus of TMP 1979.020.0001 (Fig. 8C) consists of the distal end of metacarpal I, phalanges I-1, II-1, II-2, III-3, and unguals I-2 and II-3. Currie and Russel (1988) figured phalanx III-1 of the specimen, but that element is no longer accessioned with the rest of the material. It has perhaps been lost or damaged in the intervening period.
Metacarpal I has a crescentic distal end, virtually identical to that of CMN 2367. Like in that specimen, the lateral part of the condyle is slightly larger than the medial part. As is typical of caenagnathids, phalanx I-1 is comparable in length and width to II-1 (Fig. 8C), rather than being much longer and more robust, as is the case in heyuannine oviraptorids (Funston et al. in review). The shaft is relatively straight, rather than being curved dorsally as in Apatoraptor pennatus. Ungual I-1 is smaller than II-3. It has a prominent proximodorsal lip, but the flexor tubercle is missing. Phalanx II-1 is about equal in length to II-2, but has larger, more gingylmoid distal condyles. Phalanx II-2 is the longest of the hand. Unlike $A n z u$, it lacks a ventral groove for flexor tendons (Fig. 8C). Ungual II-3 is elongate and straighter than typical in oviraptorosaurs, but not as straight as in Apatoraptor pennatus. It has a large proximodorsal lip and a modest flexor tubercle separated from the proximal articulation by a shallow transverse groove. Phalanx III-3 is gracile and would have had a relatively ginglymoid distal condyle. Its length relative to other phalanges of the third digit cannot be determined, although Currie and Russell (1988) figured it longer than phalanx III-1, which is typical of oviraptorosaurs.

The left ilium (Fig. 9A-C) is nearly complete, but is missing a small portion of the preacetabular process. The ilium is tall and strongly dolichoiliac, with a small, pointed postacetabular blade and a large, anteriorly downturning preacetabular blade. In these features it differs from Nomingia gobiensis, where the postacetabular blade is broad and rounded, and the preacetabular blade is not as downturned. The cuppedicus fossa is relatively well developed (Fig. 9B), but is only minimally exposed laterally. The pubic peduncle is larger than the ischiatic peduncle and its straight ventral edge is inclined anterodorsal-posteroventral relative to the long axis of the ilium. It extends further ventrally than the ischiatic peduncle. The acetabulum is circular and the dorsal articular surface is transversely constricted towards its midpoint. The ischiatic peduncle is triangular and flares slightly laterally, although there is not a well-developed antitrochanter. The postacetabular blade has a straight ventral edge and a curved dorsal edge that converge into a pointed posterior process (Fig. 9A). The medial surface of the iliac blade has three concavities separated by ridges (Fig. 9C). The anteriormost concavity is small and shallow, occupying the area just dorsal to the pubic peduncle. The middle concavity is the smallest but deepest and has a parabolic outline, opening dorsally. The posterior concavity is large and occupies the entire area dorsal to the brevis shelf on the postacetabular blade. Whereas posteriorly its ventral border is confluent with the brevis shelf, there is a flat platform separating these features anteriorly. The brevis fossa is small compared to that of 


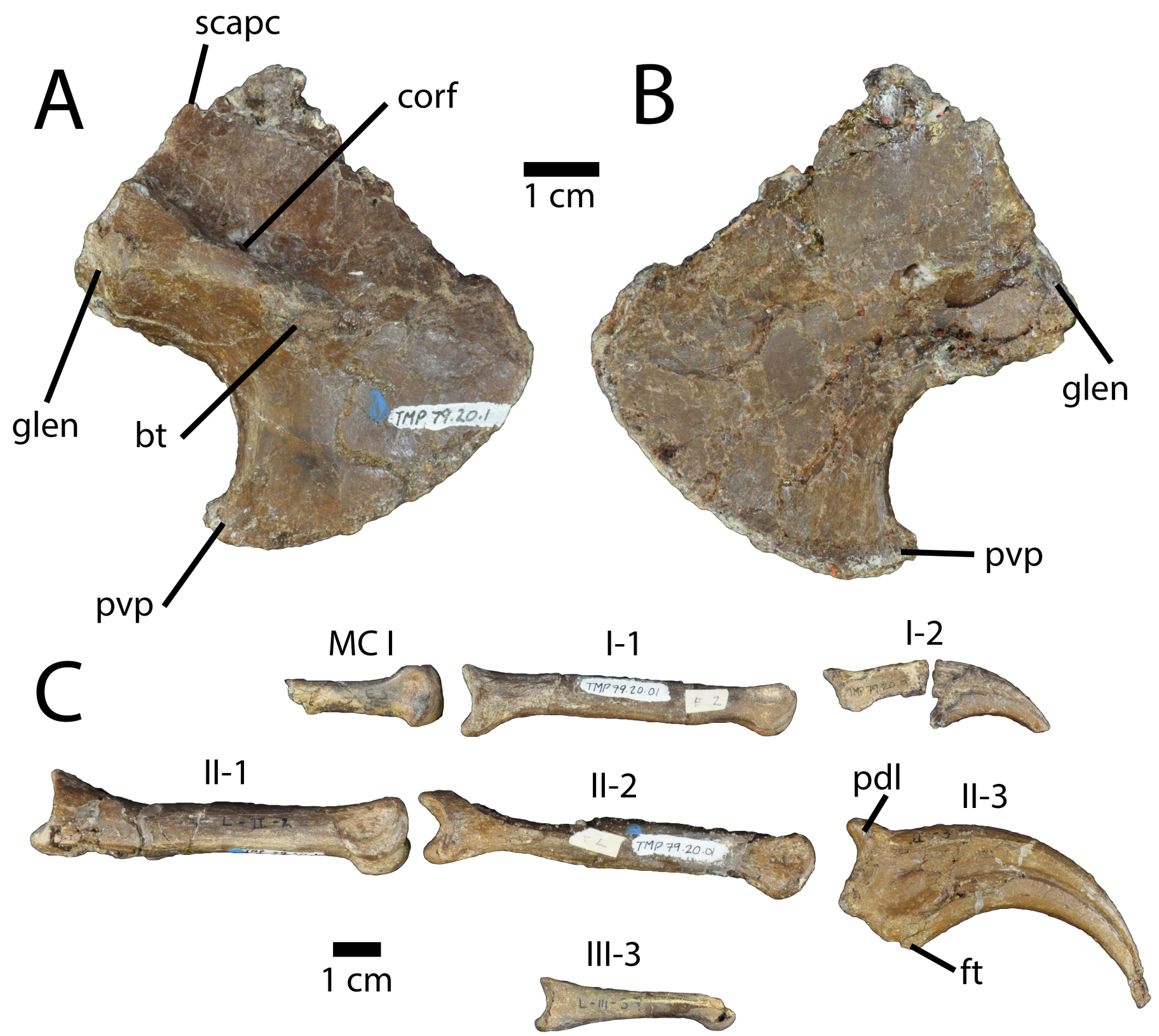

Figure 8. TMP 1979.020.0001, forelimb elements of Chirostenotes pergracilis. Coracoid in lateral (A) and medial (B) views. Partial left manus in medial (C) view. Abbreviations: bt, biceps tubercle; corf, coracoid foramen; $\mathrm{ft}$, flexor tubercle; glen, glenoid; pdl, proximodorsal lip; pvp, posteroventral process; scapc, scapular contact.

most oviraptorosaurs and occupies only the posterior half of the postacetabular blade.

The right ischium (Fig. 9D, E) is relatively well preserved. The proximal head has widely separated contacts for the ilium and pubis, suggesting that it contributed significantly to the acetabulum, unlike in oviraptorids. The pubic contact is badly crushed, so the exact angle at which it contact the pubis cannot be determined, but it extends ventrally to a lesser degree than in Anzu wyliei (Lamanna et al. 2014), Epichirostenotes curriei (Sues 1997; Sullivan et al. 2011), and Nomingia gobiensis (Barsbold et al. 2000), and is not distinctively hooked like it is in those taxa. The acetabular portion is relatively straight, rather than rounded as in most oviraptorosaurs. The shaft of the ischium is narrow in dorsoventral breadth, and curves strongly posterodorsally. A constricted neck separates the head from a large, tab-like obturator process (Fig. 9D). Unlike in oviraptorids, this process is less than half the length of the ischium from the head, and is not accompanied by a wide sheet of bone. The obturator process protrudes more from the rest of the ischium than in Anzu wyliei or Epichirostenotes curriei, partly because the distal end of the ischium is narrower dorsoventrally. The ventral edge of the ischium distal to the obturator process is relatively straight, and the bone 


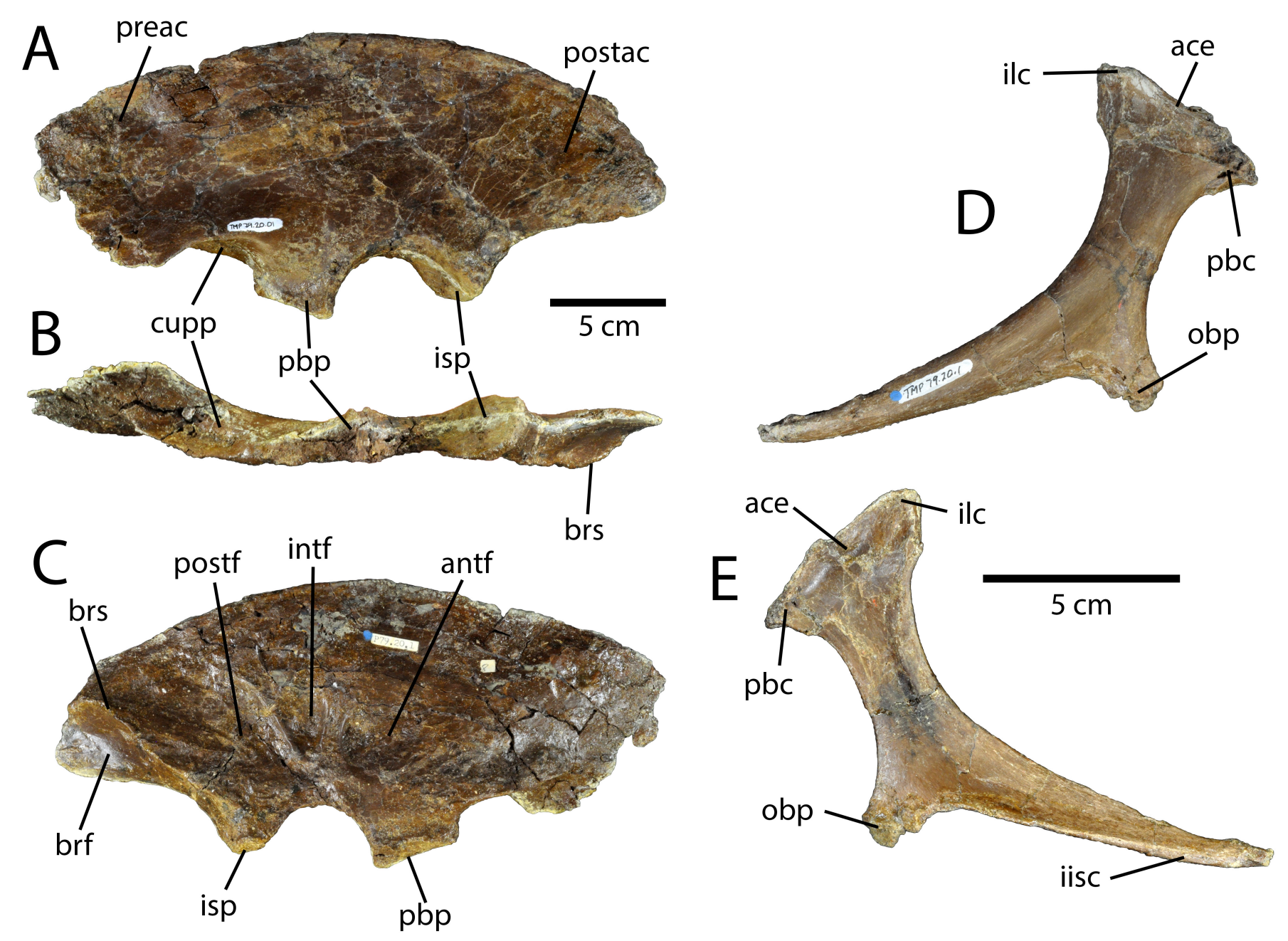

Figure 9. TMP 1979.020.0001, pelvic elements of Chirostenotes pergracilis. Left ilium in lateral (A), ventral (B), and medial (C) views. Right ischium in lateral (D) and medial (E) views. Abbreviations: ace, acetabulum; antf, anterior fossa; brf, brevis fossa; brs, brevis shelf; cupp, cuppedicus fossa; iisc, interischiadic contact; ilc, iliac contact; intf, intermediate fossa; isp, ischiadic peduncle; obp, obturator process; pbc, pubic contact; pbp, pubic peduncle; postf, posterior fossa; postac, postacetabular process; preac, preacetabular process.

thickens transversely at its distal end, rather than forming a wing-like sheet of bone as in oviraptorids.

The right femur (Fig. 10) is badly crushed, but some features can still be discerned. The proximal head is rounded and would have been separated from the greater and anterior trochanters by a shallow groove, if any (Fig. 10A). The anterior trochanter is tightly appressed to the anterior edge of the greater trochanter, and a small cleft can be observed between them (Fig. 10F). This contrasts with the femora of Caenagnathasia martinsoni and Avimimus spp., which have an anteriorly projecting, fingerlike anterior trochanter that is separated from the greater trochanter by a wide space (Funston et al. 2018; Sues and Averianov 2015). Distal to the anterior trochanter of TMP 1979.020.0001, there is an accessory trochanteric ridge similar to that of Anzu wyliei, although this feature may be exaggerated by anteroposterior crushing of the femur. The shaft of the femur is badly crushed, but appears to have bowed anteroposteriorly in life. There is no trace of a fourth trochanter on the posterior surface of the shaft. Instead, a slight ridge occupies the posterolateral surface of the middle third of the shaft. Distally, the distal condyles are well developed and are separated posteriorly by a deep, proximally-tapering popliteal fossa (Fig. 10E). A small ectocondylar tuber occupies the lateral surface of the lateral condyle, it is separated from the crista tibiofibularis by a groove paralleling the popliteal fossa. The medial condyle is well developed and rounded in distal view. The lateral condyle extends further ventrally and is separated from the crista tibiofibularis by a wide but shallow gap.

The right tibia (Fig. 11) is complete, but like the femur, is crushed anteroposteriorly. Neither the astragalus nor fibula were recovered, which indicates that these bones had not yet fused to the tibia, unlike the tibiotarsus of Avimimus spp. (Funston et al. 2016b, 2018). The cnemial crest is restricted to the distal end of the tibia (Fig. 11A, C), but the extent of its anterior projection has been obscured by crushing. 

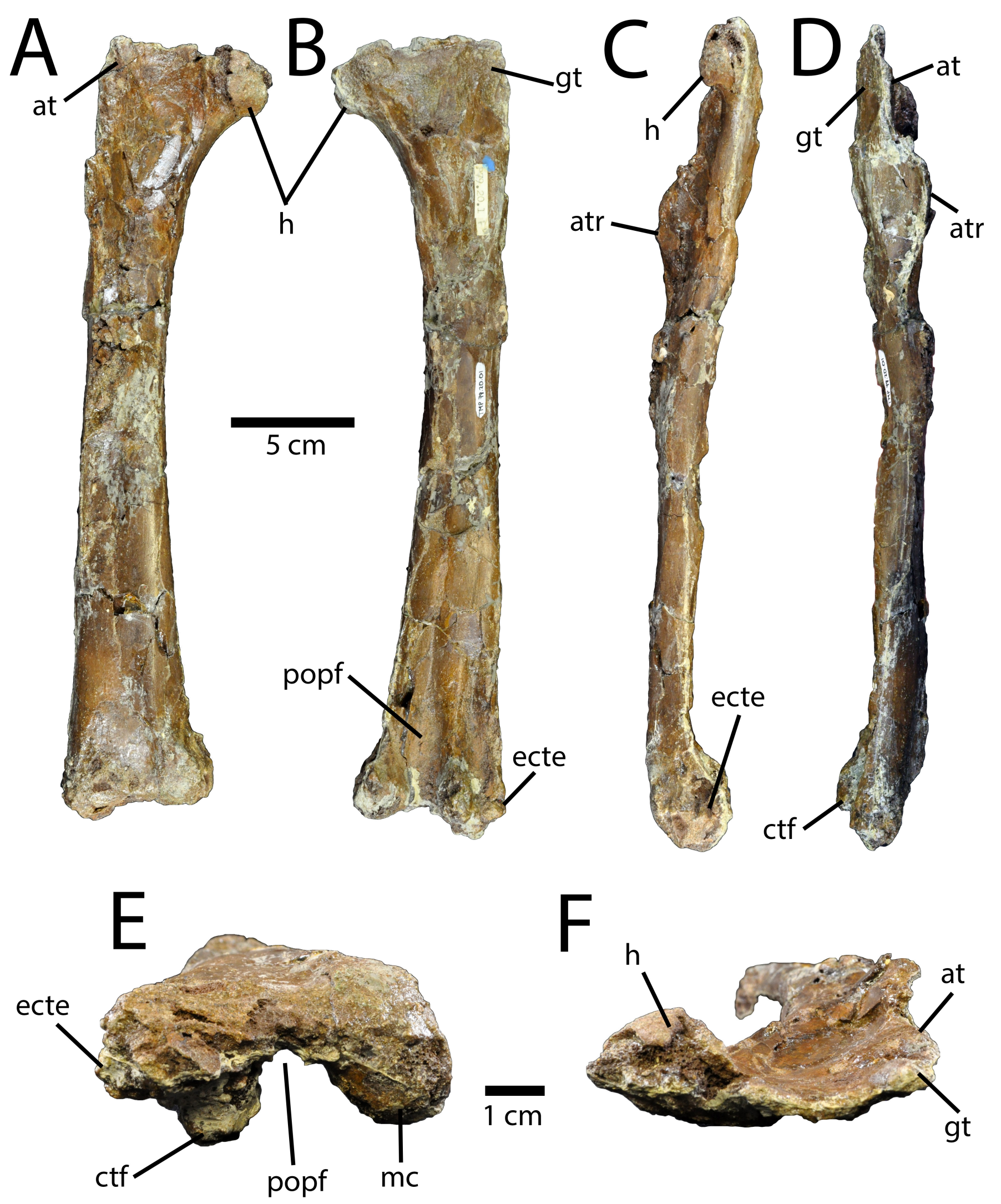

Figure 10. TMP 1979.020.0001, femur of Chirostenotes pergracilis. Right femur in anterior (A), posterior (B), medial (C), lateral (D), distal (E), and proximal (F) views. Abbreviations: at, anterior trochanter; atr, accessory trochanteric ridge; ctf, crista tibiofibularis; ecte, ectepicondylar tuber; gt, greater trochanter; h, head; mc, medial condyle; popf, popliteal fossa. 
Its apex is at its ventral end, in contrast to the dorsal apices of ornithomimid cnemial crests, and it is thickened. The fibular condyle projects laterally (Fig. 11A, B), but it has been badly crushed and the shape of the incisura tibialis cannot be determined. It appears that a small groove may have separated it from a posterior condyle, but, again, this is mostly obscured by crushing. The fibular crest has been shifted medially by crushing, and faces anteriorly instead of laterally (Fig. 11A). It begins just distal to the cnemial crest, and extends about $7 \mathrm{~cm}$ distally, where it grades into the shaft of the tibia. Although it may be deformed by crushing, it appears more robust than that of Elmisaurus rarus, which projects laterally as a thin sheet of bone. Near the distal end of the fibular crest of TMP 1979.020.0001, on its
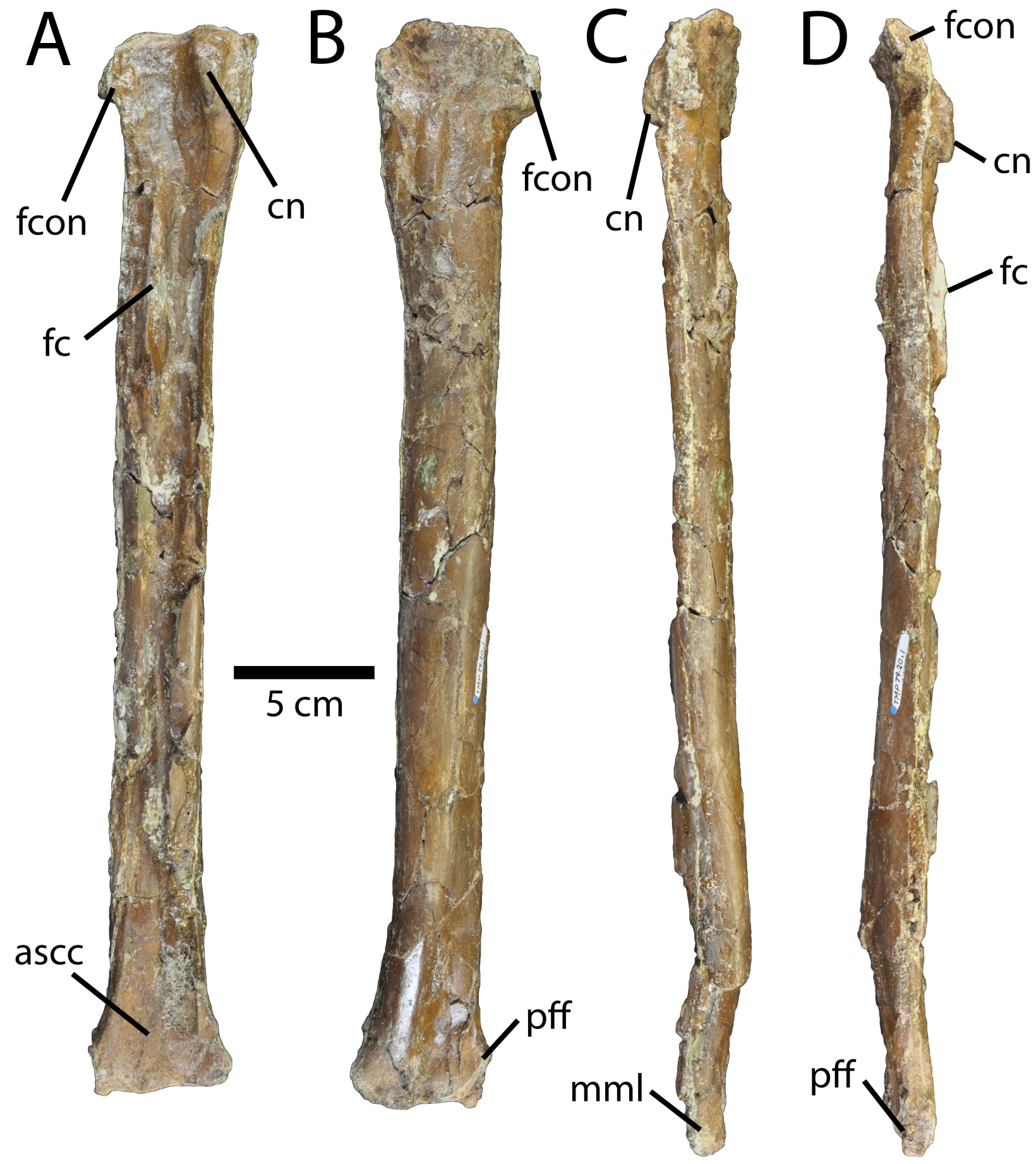

Figure 11. TMP 1979.020.0001, tibia of Chirostenotes pergracilis. Right tibia in anterior (A), posterior (B), medial (C) and lateral (D) views. Abbreviations: ascc, contact for the ascending process of the astragalus; $\mathrm{cn}$, cnemial crest; fc, fibular crest; fcon, fibular condyle; mml, medial malleolus; pff, postfibular flange. 
posterior side, there is a nutrient foramen associated with a dorsal groove, as is characteristic for many oviraptorosaurs. The shaft of the tibia is badly crushed, but rounded medial and lateral shoulders indicate that it would have shared the semicircular cross-section of all caenagnathids (Funston and Currie 2018). The distal end of the tibia flares only slightly mediolaterally, and is anteriorly flattened for the astragalus. Like in Anzu wyliei, this facet is bisected into medial and lateral parts by a shallow longitudinal ridge (Fig. 11A). On the posterior part of the lateral malleolus, there is a distinctly ridged postfibular flange, however, it is less pronounced than those of Elmisaurus rarus and cf. Citipes elegans gen. nov..

The right metatarsus (Fig. 12) is represented by all of the metatarsals. Although Currie and Russell (1988) did not comment on the distal tarsals, they are present on the proximal ends of the metatarsals. Distal tarsal III is represented by badly crushed fragments adhered to the proximal ends of metatarsals II and III (Fig. 12C, D). It tapers in thickness anteriorly, which is best observed on the fragment attached to metatarsal II. Distal tarsal IV covers the proximal end of metatarsal IV (Fig. 12H, I) and a suture can be discerned between these bones. It is thinner than distal tarsal III, but also tapers anteriorly. On its anterolateral edge, there is a tall proximodorsal process, as described in Elmisaurus rarus and Citipes elegans gen. nov. The full length of this process cannot be determined because its proximal end is broken. The position of the proximodorsal process is unusual, but it is possible that this can be accounted for by the direction in which the metatarsal was crushed. Mediolateral crushing has flattened the metatarsal so that the anterior and lateral surfaces are on the same side, opposite the medial and posterior sides.

Metatarsal I (Fig. 12A, B) is small, composed of a tapering shaft and a bulbous condyle. These two features are separated by a slightly constricted neck. The shaft tapers proximally and, in combination with the constricted neck, gives the proximal part of the metatarsal a spearhead shape. The distal condyle is larger medially and strongly ginglymoid. There is a small triangular process extending laterally from its lateral surface, just posterior to the shallow lateral ligament pit.

Metatarsal II (Fig. 12C, D) is badly crushed transversely, which has deformed its shape and proportions. Regardless, it would have been the shortest of the three weight-bearing metatarsals. The proximal end has a large, distally tapering posterior facet for metatarsal III and a smaller anterior facet for metatarsal IV; these have been crushed to lie in the same plane. The lateral surface of the shaft is marked by a proximally-tapering facet for metatarsal III. The posteromedial ridge is modestly developed, its protrusion from the metatarsal may be enhanced by crushing. The distal condyle would have been bulbous, although it has been compressed into a single plane. The medial ligament pit is shallow, whereas the lateral one is deeper.

Metatarsal III (Fig. 12E-G) is complete and has suffered less crushing than the other metatarsals. It is the longest of
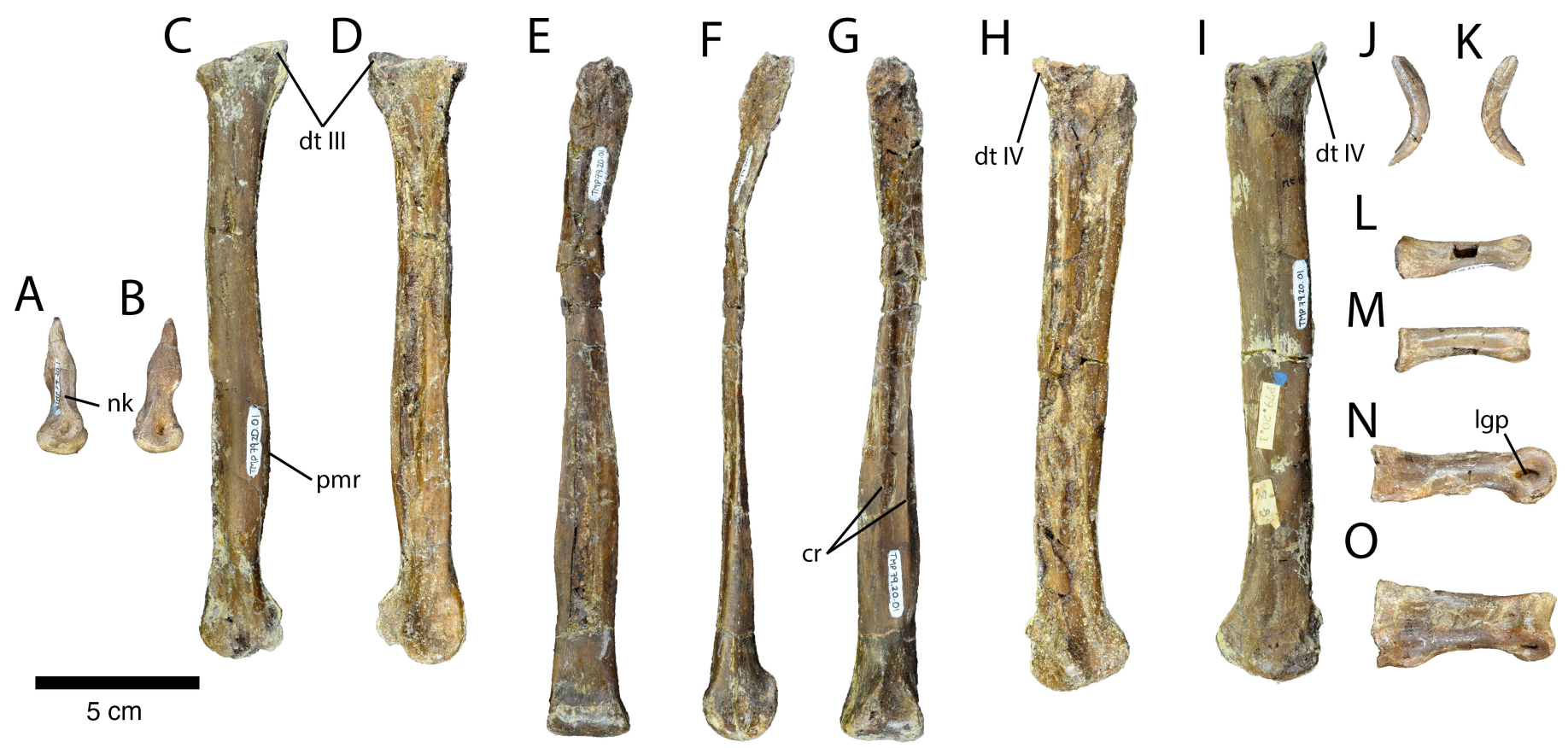

Figure 12. TMP 1979.020.0001, pedal elements of Chirostenotes pergracilis. Right metatarsal I in medial (A) and lateral (B) views. Right metatarsal II in medial (C) and lateral (D) views. Right metatarsal III in anterior (E), medial (F), and posterior $(G)$ views. Right metatarsal IV in medial $(\mathrm{H})$ and lateral $(\mathrm{I})$ views. ?Left metatarsal V in lateral $(\mathrm{J})$ and medial $(\mathrm{K})$ views. Right phalanx I-1 in lateral $(\mathrm{L})$ and dorsal $(\mathrm{M})$ views. Right phalanx III-1 in lateral $(\mathrm{N})$ and dorsal $(\mathrm{O})$ views. Abbreviations: $\mathrm{cr}$, cruciate ridges; dt III, distal tarsal III; dt IV, distal tarsal IV; Igp, ligament pit; nk, neck; pmr, posteromedial ridge. 
the metatarsals, but is also the most gracile. However, its proximal end is crushed anteroposteriorly, which artificially increases its transverse width. The proximal head of the metatarsal is poorly preserved, but clearly expanded from the proximal end of the shaft. It is not clear whether a posterior protuberance was present on the posterior surface of the proximal head of metatarsal III, as is the case in Elmisaurus rarus. The shaft of metatarsal III is strongly compressed anteroposteriorly, and it is overall much wider transversely than it is deep anteroposteriorly. On the posterior surface of the shaft there are two longitudinal ridges (Fig. 12G) that correspond to the cruciate ridges described for Elmisaurus elegans and Citipes elegans gen. nov. (Currie et al. 2016a; Funston et al. 2016a), however, these ridges are not continuous with the condylar ridges as they are in those two taxa. Instead, these ridges end about one fifth of the way from the distal end. In addition to the discontinuous cruciate ridges, the posterior surface of the distal end of metatarsal III has an accessory ridge that is continuous with the medial edge of the metatarsal. The distal condyle is ginglymoid and its articular surface extends more than $180^{\circ}$. Both collateral ligament pits are shallow.

Metatarsal IV (Fig. 12H, I) appears more robust than the other metatarsals, and is slightly longer than metatarsal II. It has been crushed mediolaterally, which artificially increases its anteroposterior breadth and has deformed it. For example, the proximodistal process of the distal tarsal appears to be on the medial side of the metatarsal, rather than the lateral side, although this is probably because it has been flattened. Like in other caenagnathids, the proximal end of metatarsal IV has a notch just posterior to the proximodorsal process of distal tarsal IV, which accommodated metatarsal V. The shaft of metatarsal IV is badly crushed, but does not appear to have a pronounced posterolateral ridge, unlike the condition in Elmisaurus rarus and Citipes elegans gen. nov. The distal condyle has a shallow lateral ligament pit, and the articular surface is slightly bulbous but not nearly as ginglymoid as metatarsal III.

Metatarsal V (Fig. 12J, K) is a small, crescentic splint of bone. What is presumably the distal end is tapered, and oriented nearly perpendicular to the proximal end, although its orientation relative to the rest of the metatarsus cannot be determined. In other caenagnathids (Elmisaurus rarus, Citipes elegans gen. nov.), metatarsal V is relatively straighter, rather than tracing a semicircular outline (Currie et al. 2016a; Funston et al. 2016a).

Two pedal phalanges (Fig. 12L-O) are preserved. One is likely phalanx I-1 (Fig. 12L, M), based on its small size and flattened medial surface. It is virtually identical to phalanx I-1 of CMN 8538 ('Macrophalangia'). The other can be identified as phalanx III-1 (Fig. 12N, O) on the basis of its cup-shaped proximal articulation and general symmetry. It is relatively elongate and its distal condyle is strongly ginglymoid compared to other theropods.

\section{Citipes gen. nov.}

Etymology: From the Latin 'citipes', meaning 'fleet-footed'. Type species: Citipes elegans (Parks, 1933)

Referred species: None.

Diagnosis: As for the type species

Citipes elegans (Parks, 1933), nov. comb.

= Ornithomimus elegans Parks, 1933

= Elmisaurus elegans Currie, 1989

= Leptorhynchos elegans Longrich et al., 2013 (in part)

Holotype: ROM 781, partial tarsometatarsus, Dinosaur Park Formation, Dinosaur Provincial Park.

Referred specimens: ROM 37163, distal metatarsal II; TMP 1982.016.0006, complete right tarsometatarsus; TMP 1982.039.0004, proximal tarsometatarsus; TMP 1988.036.0104, distal half of metatarsal II; TMP 1994.012.0880, left tibia (cf. Citipes elegans); TMP 1996.012.0141, left tarsometatarsus; UALVP 55585, distal shaft of metatarsal III; UALVP 55639, partial fused dentaries. Newly referred specimens: TMP 1981.023.0034-35 + TMP 1981.023.0039, partial left and right ilium and associated last sacral vertebra (cf. Citipes elegans); TMP 1992.036.0674, pathological ilium (cf. Citipes elegans); UALVP 59606, complete metatarsal IV and distal tarsal IV.

Horizon and locality: All specimens are from the Dinosaur Park Formation of Dinosaur Provincial Park, Alberta, Canada.

Revised diagnosis: Small caenagnathid oviraptorosaur diagnosed by the following combination of features: distal tarsals III and IV coossified with each other and proximal metatarsus at maturity; metatarsals II and IV lacking posteriorly protruding proximal ends (in contrast to Elmisaurus rarus); metatarsal III with prominent cruciate ridges on posterior surface.

\section{Osteological Description TMP 1981.023.0039: TMP 1981.023.0039 is an} isolated last sacral vertebra associated with two ilia, which was figured, but not described by Rhodes et al. (2020). The centrum is relatively low and wide, resulting in a barrel shape similar to the proximal caudal vertebrae of most oviraptorosaurs. The anterior articular surface is unbroken, indicating that it had not fused to the preceding sacral vertebra, as in TMP 1979.020.0001. The anterior articular face is convoluted, with a median ridge and adjacent lateral depressions towards the dorsal side. The posterior articular surface is 
deeply concave and is inclined to face posterodorsally. It is roughly trapezoidal in posterior view, with a transversely wider ventral edge than dorsal edge. On the lateral surface of the centrum there is a small, posteroventrally opening foramen just ventral to the sacral rib. This likely corresponds to the lateral pleurocoels of more anterior sacral vertebrae, but it is much smaller. Dorsal to this foramen, there is a second, larger opening that pierces the posterior side of the sacral rib. The ventral surface of the centrum has a wide, shallow midline sulcus. The neural canal is consistent in transverse width for its length, and is roughly elliptical in anteroposterior view. The sacral ribs are indistinguishably fused to the centrum, but the area where they lap onto the dorsal part of the centrum can be distinguished. Little can be discerned about the morphology of the sacral ribs because they are broken just lateral to their contact with the centrum.

UALVP 59606: UALVP 59606 (Fig. 13) is a complete left metatarsal IV and associated distal tarsal IV. The distal tarsal is wedge-shaped, tapering in dorsoventral thickness anteriorly (Fig. 13D). The distal tarsal is incompletely fused to the metatarsal and a gap can be seen around the entirety of the distal tarsal. The proximodorsal process is broken, so its size cannot be determined. Posterior to this process, there is a fossa in the distal tarsal that is continuous with a groove on the posterolateral surface of the proximal end of metatarsal IV (Fig. 13E). These features would have accommodated metatarsal $\mathrm{V}$, which is fused in some other specimens of Citipes elegans. The medial edge of the distal tarsal is broken where it would have fused to distal tarsal III. This reveals that the internal trabeculae of the metatarsal and distal tarsal are continuous and fusion had begun internally.

Metatarsal IV is elongate and elliptical in cross-section. The proximal end is roughly semicircular in proximal view (Fig. 13E). Posteriorly, the proximal head has a mound that overhangs the shaft (Fig. 13B, C), similar to the posterior protuberance in Elmisaurus rarus, but much smaller. Proximally, the posterolateral edge of the metatarsal is attenuated into a ridge anterior to where metatarsal $\mathrm{V}$ would have attached. This ridge is continuous with the more distal posterolateral ridge that contributes to the posterior concavity of the tarsometatarsus. Medially, the proximal head has two facets for articulation: the larger, more posterior one is for metatarsal III, whereas the other projects medially to contact metatarsal II anterior to metatarsal III. A small gap separates the triangular proximal facet for metatarsal III from the distally expanding contact for metatarsal III on the rest of the shaft. Presumably, this gap accommodated the $a$. tarsalis plantaris, as in Elmisaurus rarus (Currie et al. 2016). Distally, the facet for metatarsal III invades the anterior surface of the shaft. Lateral to this, the anterior surface of the shaft has a ridge oriented proximomedial-distolateral. There is also a small ridge, oriented the same way, on the posterior sur- face of the shaft just proximal to the lateral condylar ridge. The distal condyle is bulbous and its main articular part is nearly spherical (Fig. 13F). On its lateral side, it flares into a triangular process behind the shallow lateral ligament pit. The medial ligament pit is deeper and teardrop-shaped, with its apex pointing dorsally. Just anterior to this pit, there is a small, rugose tubercle for $m$. tibialis cranialis. Posteriorly, the condylar ridges are separated by a shallow concavity.

\section{Osteohistology}

UALVP 55585: The osteohistology of the metatarsal III UALVP 55585 was briefly described by Funston et al. (2016), and additional details are provided here. The cortex of UALVP 55585 (Fig. 14) is extensively remodeled, and secondary osteons and endosteal resorption have obliterated most of the primary bone near the endosteal surface of the bone. The density of secondary osteons decreases periosteally, so that more primary bone is visible between secondary osteons in the mid-cortex. However, these regions are too small to assess the organization of the interstitial primary bone. The outer cortex is composed of primary parallel-fibered bone, which is present around the entire periosteal surface. The thickest region of primary bone is on the anterolateral side of the cortex. In this region, the vasculature consists of relatively sparse primary osteons, oriented predominantly longitudinally, accompanied by some simple vascular canals. However, some circumferentially-oriented primary osteons are present towards the anterior part of the metatarsal. Primary bone throughout the entire cortex shows abundant Sharpey's fibers, oriented radially, and on the medial and posterior surfaces of the metatarsal, these are accompanied by large collagen bundles (Fig. 14E). On the lateral side of the metatarsal, there is a thin layer of primary woven-fibered bone on the periosteal surface with simple longitudinal vascular canals (Fig. 14C). A small region in the inner posterior cortex is composed of compact coarse cancellous bone, identified by the presence of remodeled trabeculae of parallel-fibered bone (Fig. 14B). Most of the inner cortex of UALVP 55585 is Haversian bone with well developed secondary osteons (Fig. 14F). No cross-cutting can be detected between these secondary osteons. The secondary osteons are cross-cut, however, by the endosteal layer (Fig. 14D). The endosteal layer is composed of multiple layers of avascular parallel-fibered bone, and it lines the entirety of the medullary cavity. The only exception is a trabecula that extends into the lateral side of the medullary cavity, where the endosteal surface exhibits Howship's lacunae, evidence of active resorption. The endosteal layer is thickest medially and thinnest anterolaterally, where Howship's lacunae indicate it is being actively resorbed. No LAGs or other CGMs can be detected in the primary bone. 


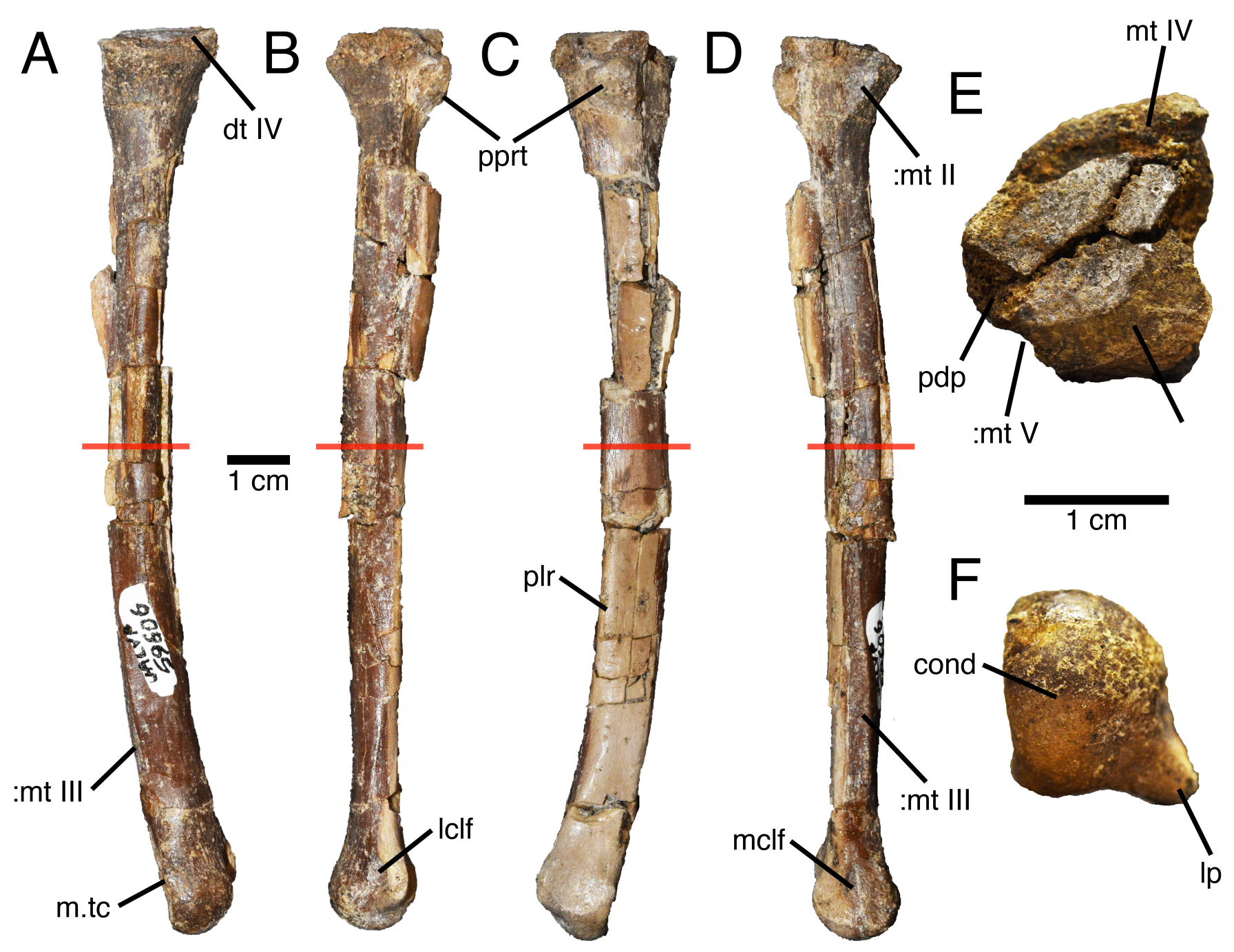

Figure 13. UALVP 59606, metatarsal IV of Citipes elegans. Left metatarsal IV and fused distal tarsal IV of UALVP 59606 in anterior (A), lateral (B), posterior (C), medial (D), proximal (E) and distal (F) views. Red line indicates plane of section in Figure 15. Abbreviations: cond, condyle; dt IV, distal tarsal IV; Iclf, lateral collateral ligament fossa; Ip, lateral process; mclf, medial collateral ligament fossa; $\mathrm{mt} \mathrm{II,} \mathrm{contact} \mathrm{for} \mathrm{metatarsal} \mathrm{II;} \mathrm{mt} \mathrm{III,} \mathrm{contact} \mathrm{for} \mathrm{metatarsal} \mathrm{III;} \mathrm{mt} \mathrm{V,} \mathrm{contact} \mathrm{for} \mathrm{metatarsal} \mathrm{V;} \mathrm{mt} \mathrm{IV,} \mathrm{metatarsal}$ $\mathrm{IV}$; m.tc, attachment for $\mathrm{m}$. tibialis cranialis; pdp, proximodorsal process; plr, posterolateral ridge; pprt, posterior protuberance.

UALVP 59606: A broken segment of metatarsal IV was sectioned (Figs. 13, 15), which allowed the fragments to be virtually repositioned to their original locations. The cortex is composed predominantly of primary fibrolamellar bone (Fig. 15C, F), although there is a region of concentrated secondary remodeling on the posterolateral side (Fig. 15B), and another smaller region towards the endosteal surface of the anterior side The medullary cavity is entirely lined with endosteal lamellae, which are thicker towards the anterior side (Fig. 15D). In this area, the endosteal layer is penetrated by simple vascular canals that communicate with the secondary osteons just periosteal to the endosteal layer. Throughout the cortex, primary osteons are oriented predominantly reticularly (Fig. 15C), although this varies and some areas have patches of longitudinal or plexiform vasculature. Some of the longitudinally-oriented primary osteons are connected by simple anastomosing vascular canals. Osteocyte lacunae are uniformly dense throughout the cortex. At least six LAGs are preserved in the cortex (Fig. 15C, E). LAGs become more closely spaced towards the periosteal surface; this is most prominent between LAGs 1-2 and 2-3, where the latter growth interval is less than half the size of the previous one. At the periosteal surface, at least three LAGs are densely packed in a zone of avascular parallel-fibered bone (Fig. 15F). These LAGs and the zone of avascular parallel-fibered bone extend around the entire periosteal surface, indicating that they are not simply double or triple-LAGs, and that they represent an external fundamental system (Fig. 15E, F). 

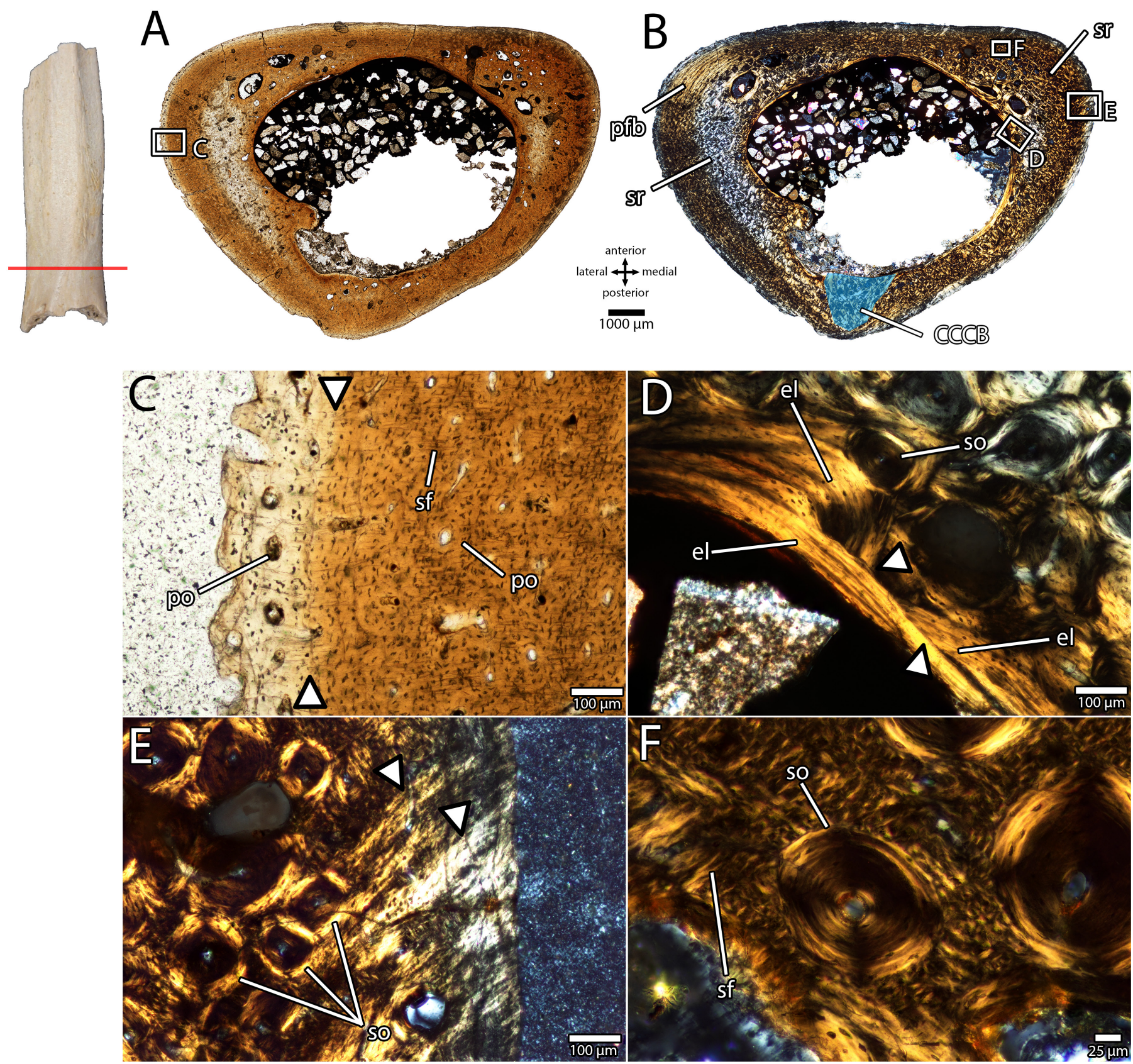

Figure 14. Osteohistology of UALVP 55585, metatarsal III of Citipes elegans. Overview of histological thin section of UALVP 55585 in plane-polarized (A) and cross-polarized (B) light, showing locations of close-up images. Image shows the location of the section on UALVP 55585 in posterior view (not to scale). Detail (C) of transition to woven-fibered primary bone (arrows) towards the periosteal surface of the metatarsal, indicating rapid growth, under plane-polarized light. Close-up (D) of multiple generations of endosteal lamellae (arrows) and cross-cut secondary osteons near the medullary cavity under cross-polarized light. Detail (E) of well developed Sharpey's fibers (arrows) near the periosteal surface under cross-polarized light. Close-up (F) of well developed secondary osteons with multiple internal lamellae under cross-polarized light. Abbreviations: el, endosteal lamellae; so, secondary osteon.

CAENAGNATHIDAE R.M. Sternberg, 1940 Gen. et sp. indet.

Newly referred material: TMP 1980.016.1503, partial sacrum; TMP 1981.019.0252, parietals; TMP 1981.019.0285, partial sacrum; TMP 1984.163.0102, sacrum; TMP 1996.012.0142, partial dentaries; TMP 2001.012.0216, partial right quadrate.

Horizon and locality: Dinosaur Park Formation, Dinosaur Provincial Park, Alberta, Canada.

\section{Description}

Hundreds of vertebrae, phalanges, and partial metatar- 

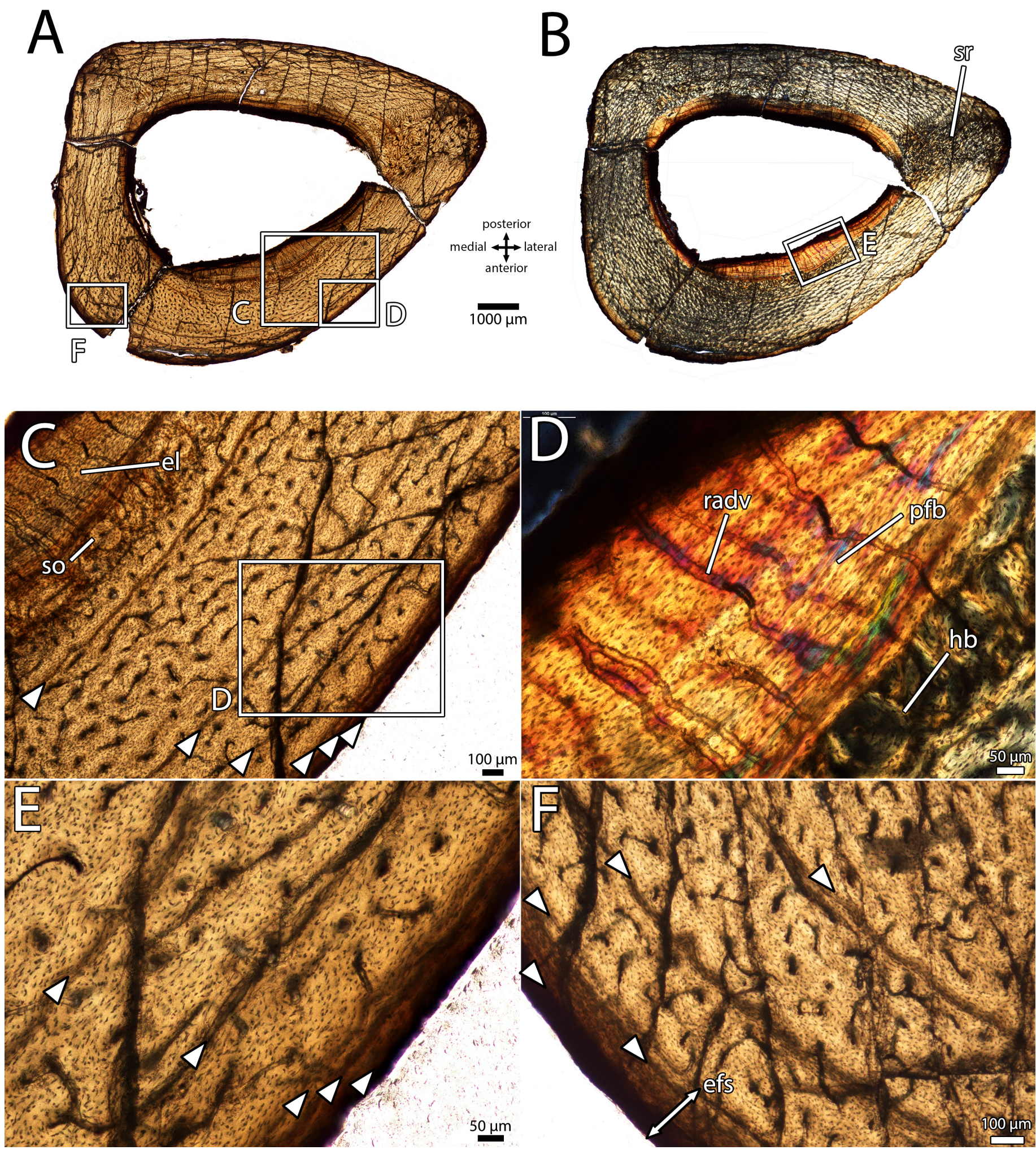

Figure 15. Osteohistology of UALVP 59606, metatarsal IV of Citipes elegans. Overview of histological thin section of UALVP 59606 in plane-polarized (A) and cross-polarized (B) light, showing locations of close-up images. Detail (C) of cortex showing predominantly primary fibrolamellar bone with longitudinal-reticular vascularity, endosteal layer, and cyclical growth marks (arrows), under plane-polarized light. Close-up (D) of well developed endosteal layer on the medullary cavity, showing secondary excavation by simple vascular canals, under cross-polarized light. Close-up (E) of tightly packed cyclical growth marks (arrows) near the periosteal surface of the cortex, under plane-polarized light. Close-up (F) of periosteal surface of cortex, showing avascular parallel-fibered bone indicating an incipient external fundamental system (double ended arrow) with three LAGs (arrows). Abbreviations: efs, incipient external fundamental system; el, endosteal lamellae; hb, Haversian bone; pfb, parallel-fibered bone; radv, radial simple vascular canal; so, secondary osteon. 
sals have been collected from the DPF, but these have few characters that would allow them to be linked to a particular taxon. The eventual discovery of associated skeletons will likely enable much of this material to be identified. However, at the moment they provide little information on the diversity or anatomy of DPF caenagnathids and thus they are not included in this review.

TMP 1981.019.0252: A pair of indistinguishably fused parietals (Fig. 16) shows a number of unusual features compared to other oviraptorosaurs and theropods. The parietals are dorsally arched but lack any development of a sagittal crest along the midline. They are incomplete posteriorly, as indicated by Currie (1992), but comparison to other oviraptorosaurs suggest that they would not have extended much further. As a result, they are nearly as wide transversely as long anteroposteriorly, which is unusual for most theropods, but more similar to the broad parietals of oviraptorosaurs. The anterior edge is rounded in dorsal view (Fig. 16C) and has a prominent W-shaped shelf. Along the midline, there is an anteriorly-tapering triangular process that would have separated the posterior parts of the frontals on the dorsal surface of the skull. A depressed, posteriorly-slotted shelf in the parietal would have accommodated each frontal, and their positions indicate that the frontals were widely separated at their posterior ends. The degree of separation indicated by these facets is both wider transversely and further anteroposteriorly than is typically the case in oviraptorosaurs. Currie (1992) suggested that the parietals had an anteriorly-projecting lateral process that would have contributed to the postorbital bar and formed part of the supratemporal fenestra. Instead, this process closely resembles the anterior process of the laterosphenoid in oviraptorids, and it is more likely that it represents a portion of the laterosphenoid fused to the parietal. This interpretation is supported by a crack with a finished edge separating the parietal from this structure on the left and a change in bone texture in this region on the right, where
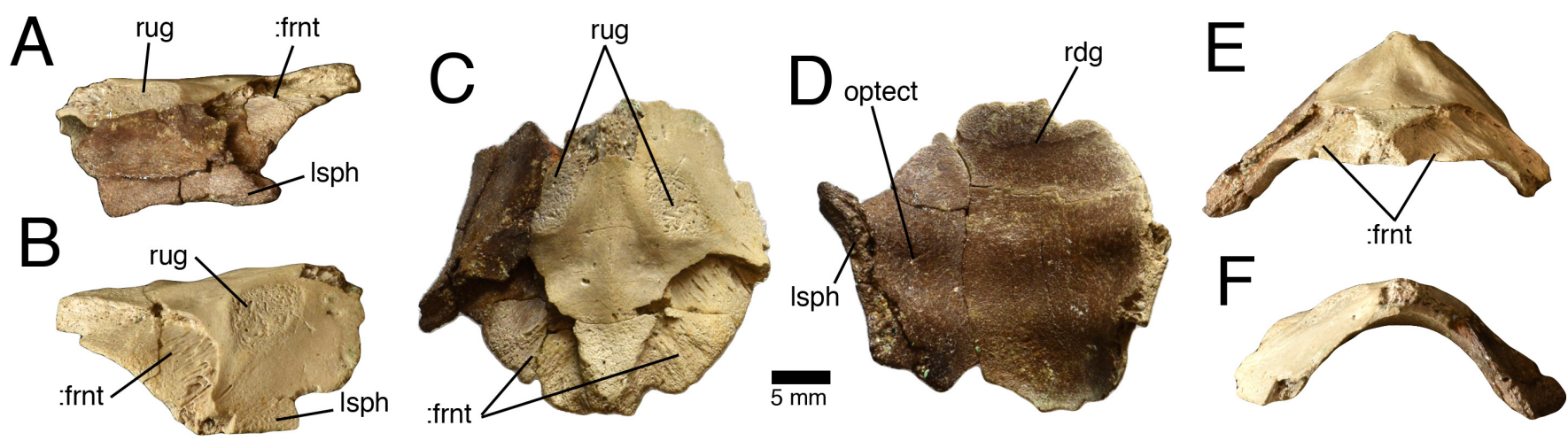

Figure 16. TMP 1981.019.0252, parietals of an indeterminate caenagnathid. Fused parietals of TMP 1981.019.0252 in right lateral (A), left lateral (B), dorsal (C), ventral (D), anterior (E), and posterior (F) views. Abbreviations: frnt, contact surfaces for frontals; Isph, laterosphenoid; optect, fossa for optic tectum; rdg, ridge; rug, rugosity. 

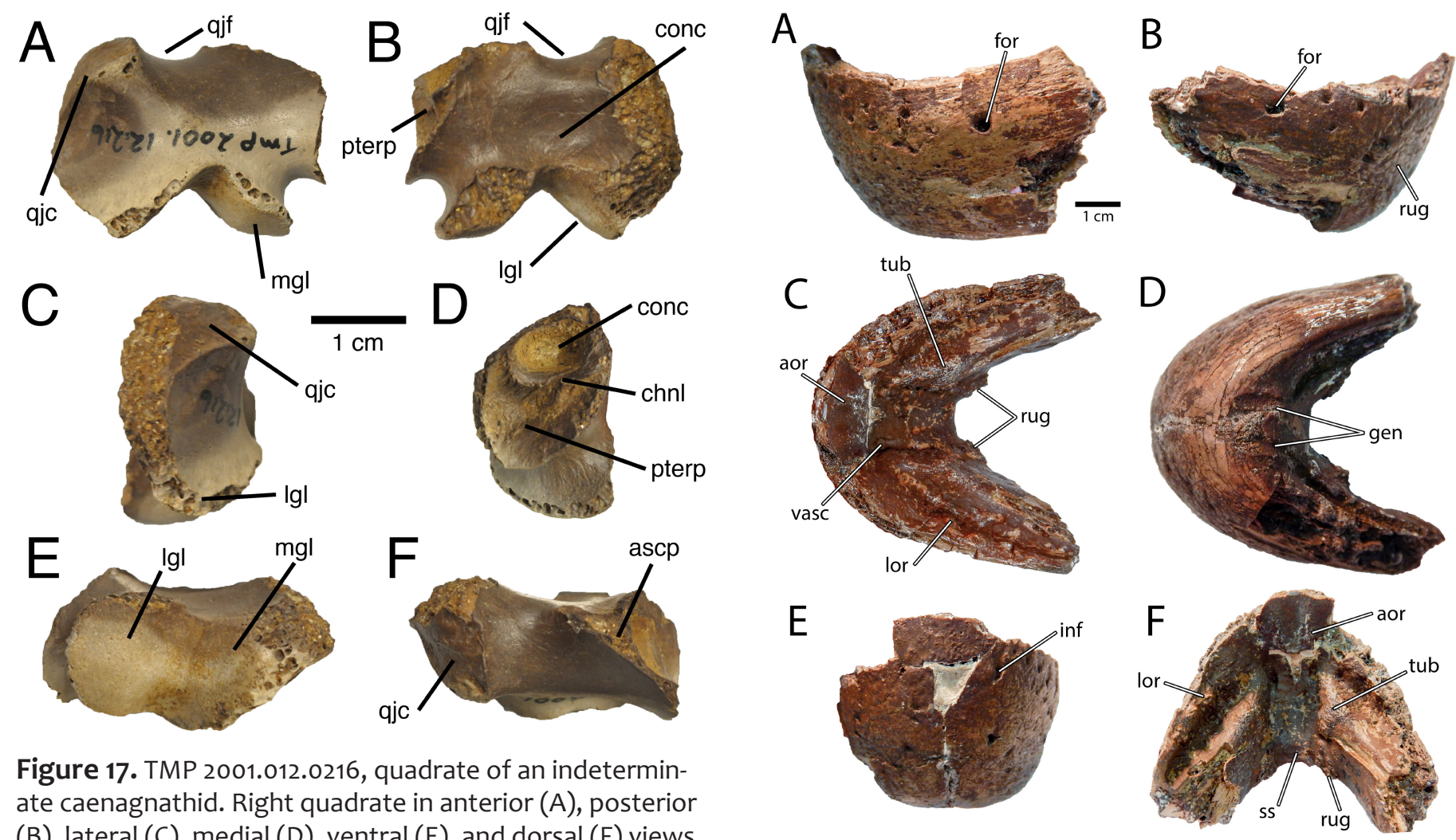

Figure 17. TMP 2001.012.0216, quadrate of an indeterminate caenagnathid. Right quadrate in anterior $(A)$, posterior (B), lateral (C), medial (D), ventral (E), and dorsal (F) views. Abbreviations: ascp, ascending process; chnl, channel; conc, concavity; lgl, lateral glenoid; mgl, medial glenoid; pterp, pterygoid process; qjc, quadratojugal contact.

shared a similar cross-section with oviraptorids. The medial edge of surface of the quadrate has a large process that would have contacted the pterygoid. This process is oval-shaped in medial view and is divided into two concave regions (Fig. 17D). The dorsal concavity is small, deep and elliptical, with its long axis oriented anteroposteriorly. It is separated from the larger, shallower concavity by a rugose semi-circular ridge. A small channel oriented anteroventral-posterodorsal communicates between these two concavities. The anterior surface of the quadrate is somewhat convex, although there is a depression ventral to the quadratojugal facet and a deep groove separating the condyles from the pterygoid process. The posterior surface of the quadrate is concave, but otherwise unremarkable. At the base of the ascending process, on the posterior side, there is a small depression that suggests that the posterior surface of the ascending process was deeply concave, as in oviraptorids.

TMP 1996.012.0142: TMP 1996.012.0142 is a large pair of fused dentaries (Fig. 18), comparable in size to the large specimens referred to Chirostenotes pergracilis (TMP 1992.036.1237; TMP 2001.012.0012). Both dentaries are broken just anterior to where the lateral pneumatopore would presumably have penetrated the lateral surface of the dentary (Fig. 18A, B). The dorsal edges of both dentaries are abraded and broken, but based on the tapering thickness of

Figure 18. TMP 1996.012.0142, fused dentaries of an indeterminate caenagnathid. Partial fused dentaries in left lateral (A), right lateral (B), occlusal (C), ventral (D), anterior (E), and posterodorsal (F) views. Abbreviations: aor, anterior occlusal ridge; for, foramen; gen, attachment of $\mathrm{m}$. genioglossus; inf, foramen for inferior alveolar nerve; lor, lateral occlusal ridge; rug, rugosity; ss, symphyseal sulcus; tub, tubercle of lingual ridge; vasc, vascular groove.

the preserved occlusal margin, the amount of missing bone is minor. In lateral view (Fig. 18A, B), the anterior edge of the fused dentaries is strongly upturned, more so than equivalently-sized specimens (TMP 1992.036.1237 and TMP 2001.012.0012; Chirostenotes pergracilis), but similar to some smaller specimens (TMP 1992.036.0390; TMP 1992.040.0044). However, the point of maximum curvature of the anteroventral margin is rounded, rather than square as in these small specimens. The dentaries are powerful and robustly built, and the occlusal margin extends far above the lingual ridge, contributing to the deep appearance of the dentaries in lateral view. The rugose lateral surface of each dentary is pierced by numerous foramina, which do not appear to be organized into distinct rows (Fig. 18A). A slit-like foramen for the inferior alveolar nerve exits on the anterior surface of the dentary (Fig. 18E). On the lateral side of each dentary, roughly equivalent in position to the posterior edge of the symphyseal shelf, there is a large, round foramen (Fig. 18A, B). This feature has not been observed in other caenagnathid dentaries. The attachment for $m$. genioglossus takes the form of two anteroposteriorly oriented 
ellipses, separated by a rugose region of bone (Fig. 18D). This is similar to the attachment in TMP 1992.036.0390 and TMP 1992.036.1237 (Chirostenotes pergracilis), but dissimilar to that of TMP 2001.012.0012 (Chirostenotes pergracilis). Like all DPF caenagnathids, the occlusal surfaces of the dentaries are complexly ornamented by a series of ridges and grooves (Fig. 18C). The arrangement of these ridges and grooves is consistent with other caenagnathids, consisting of lateral lingual grooves bordered medially by lingual ridges with anterior tubercles, separated along the midline by a deep symphyseal sulcus. A rugose anterior occlusal ridge is present just lateral to the midline, and posterolateral to this, separated by an anterior occlusal groove, there is an extensive raised patch of rugose bone. Posterior to this are at least three lateral occlusal ridges on the left side (Fig. 18C, F). Each of these are rugose, with several nodules of bone on their dorsal apices. The lingual groove is invaded by numerous foramina, and it is deepest and widest anteriorly. The lingual ridge has a low tubercle at its anterior end, which is rugose and gnarled. In addition to protruding dorsally from the lingual ridge, each of these tubercles also extends medially into the symphyseal sulcus (Fig. 18F), overhanging the longitudinal vascular canals on the lateral edges of the symphyseal sulcus.
Each longitudinal vascular canal extends posteriorly from a large foramen at the junction of the symphyseal shelf and the occlusal region of the beak. Where they approach the posterior end of the symphyseal shelf, they bifurcate, with one branch extending ventrally towards the attachment for $m$. genioglossus, and the other extending posteroventrally towards the Meckelian groove. Separating these branches is an unusual, triangular patch of rugose bone that is not present to this extent in other caenagnathid dentaries (Fig. 18C, F), although it is incipiently developed in TMP 1992.036.1237. A small tubercle is present along the midline at the anterior end of the symphyseal sulcus, similar to those described in other caenagnathids (Currie et al. 1993; Funston and Currie 2014). The Meckelian groove extends along the ventral surface of the dentary and anteriorly, each forms a deep pit just below the unusual triangular patches of rugose bone. The attachment sites for the splenial, angular, and surangular cannot be observed in TMP 1996.012.0142.

TMP 1984.163.0102: TMP 1984.163.0102 is a relatively complete sacrum (Fig. 19A-F), missing portions of the neural spines. As in other caenagnathids, six fused vertebrae form the sacrum, which measures $221 \mathrm{~mm}$ in length, slightly larger than TMP 1979.020.0001 (199 mm). Like in TMP

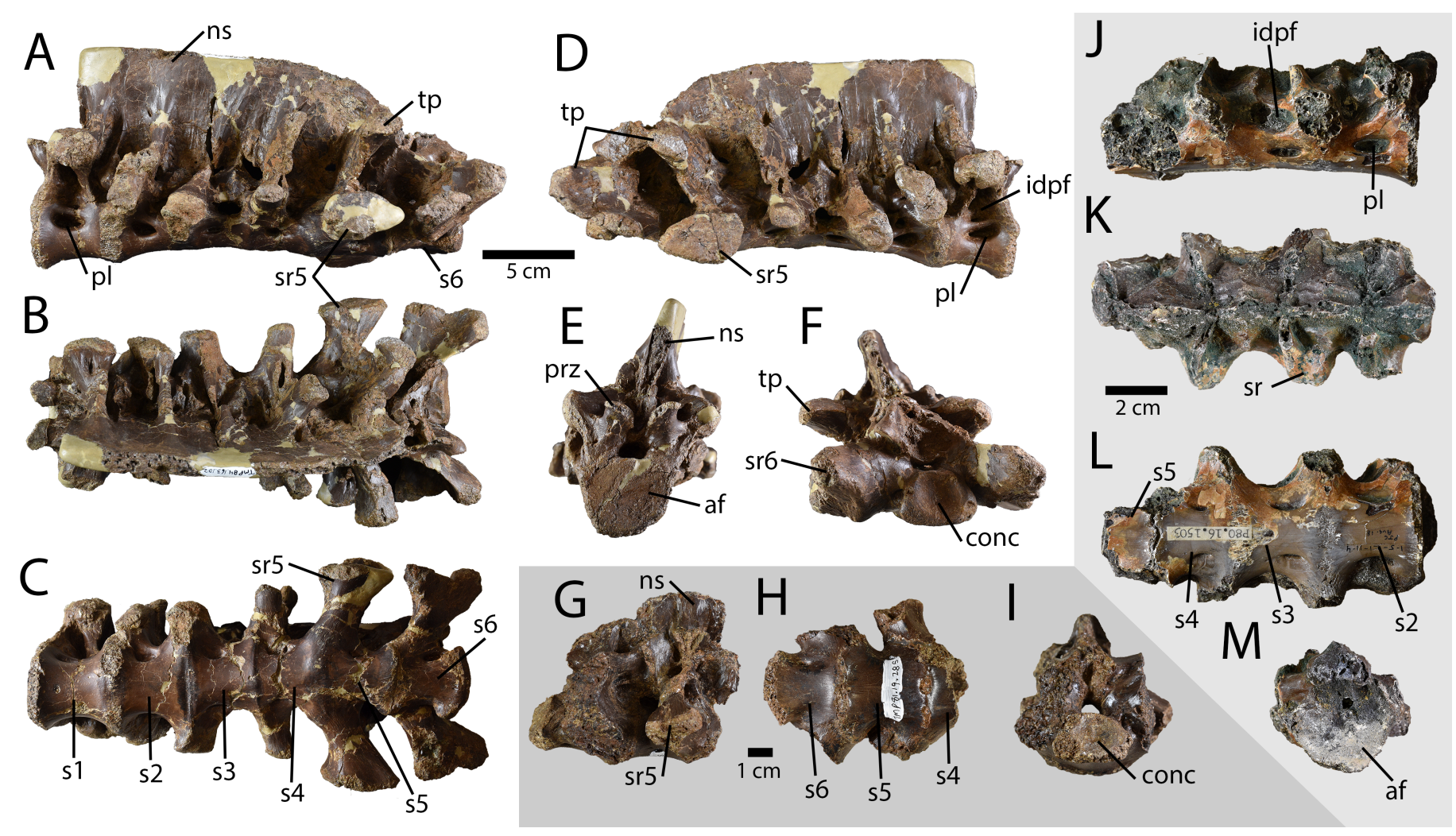

Figure 19. Sacra of indeterminate caenagnathids. Sacrum of TMP 1984.163.0102 (A-F) in left lateral (A), dorsal (B), ventral (C), right lateral (D), anterior (E) and posterior (F) views. Sacrum of TMP 1981.019.0285 (G-I) in right lateral (g), ventral $(\mathrm{H})$, and posterior (I) views. Sacrum of TMO 1980.016.1503 (J-M) in right lateral $(J)$, dorsal $(K)$, ventral $(L)$ and posterior (M) views. $5 \mathrm{~cm}$ scale bar applies to images $(A-F), 1 \mathrm{~cm}$ scale bar to images $(G-I)$, and $2 \mathrm{~cm}$ scale bar to images $(J-M)$. Abbreviations: af, articular face; conc, concavity; idpf, infradiapophyseal fossa; ns, neural spine; pl, pleurocoel; prz, prezygapophysis; s1-s6, sacral vertebrae 1 to 6; sr5, sacral rib 5; tp, transverse process. 
1979.020.0001, the centra are low and wide, and each has a deep lateral pleurocoel. They decrease in transverse width towards the posterior end of the sacrum. The centra are completely fused to each other, but a crack is visible between the last sacral vertebra and the preceding one (Fig. 19C). This crack appears to be natural, extending around the entirety of the centrum. This indicates that although the neural arch of the last sacral is extensively fused to the rest of the sacrum, that the centrum of this vertebra was not. There is no midline groove along the ventral surface of the sacrum, but this is highly variable in oviraptorosaurs. The neural arches are tall and indistinguishably fused, except for a gap between neural spines three and four (Fig. 19A, D). The neural spines decrease in height in each successive vertebra, so that the sacrum is much taller overall at its anterior end than its posterior end. As in TMP 1979.020.0001, the neural arches are invaded by a complex series of pneumatic fossae divided by delicate laminae of bone. On the first sacral vertebra, these include two infradiapophyseal fossae, but these are displaced in the posterior vertebrae by the fused sacral ribs. The sacral ribs are placed lower on the centrum in each successive vertebra, and on the posterior three vertebrae, there is a large transverse process that extends laterally from the neural arch above the sacral rib. The transverse processes of the first three sacral vertebrae are indistinguishably fused with the sacral ribs. The fifth and sixth sacral ribs are largest and each is expanded into a hatchet-like process at its lateral end.

TMP 1980.016.1503: This is a partial sacrum comprising mostly the centra of the second to fifth sacral vertebrae (Fig. 19J-M). Parts of the neural arches are adhered to the dorsal surfaces of the centra, but they are badly damaged and do not include the neural spines. The bases of the sacral ribs are present and fused to the centra, but the rest of the ribs have been broken. Each vertebra has a large lateral pleurocoel, which is low on the centrum, nearly flush to its ventral surface (Fig. 19J). These pleurocoels decrease in size posteriorly along the series. The articular face of the second sacral is undamaged, which indicates it had not yet fused to the first sacral. Its infradiapophyseal fossa is divided into anterior and posterior pits, rather than dorsal and ventral pits as in TMP 1984.163.0102. The anterior three centra are fused and the sutures between them are obliterated. However, the fourth and fifth vertebrae seem to be less well fused than the other vertebrae, and a suture is still visible between them (Fig. 19L). No midline groove is apparent on the ventral surfaces of the centra. The neural arches are badly damaged, but it is clear nonetheless that they hosted numerous complex pneumatic fossae, including infradiapophyseal and infrapostzygapophyseal fossae.

TMP 1981.019.0285: This partial sacrum (Fig. 19G-I) comprises complete sacral vertebrae five and six, and the posterior portion of sacral four. The centra are complete- ly fused with each other and the sacral ribs, including the last sacral. The last sacral measures $31.5 \mathrm{~mm}$, which is slightly smaller than the last sacral vertebrae of TMP 1984.163.0102 (38 mm), despite more complete fusion to sacral five (Fig. 19H). Each centrum has small lateral pleurocoels, and in sacral six, these are nearly flush to the ventral surface of the centrum. The neural arches have deep infraprezygapophyseal fossae that are divided by a lamina, as well as supradiapophyseal fossae that invade the space above the sacral ribs. The neural spines are broken but in sacral five, a broken region probably represents the base of a lateral process for attachment to the ilium, like in TMP 1984.163.0102. Sacral six has an inclined posterior articular face, which faces posterodorsally. As in TMP 1981.023.0039, it is deeply concave and roughly trapezoidal in shape (Fig. 19I).

\section{PHYLOGENETIC RESULTS}

The pruned phylogenetic analysis produced one most parsimonious tree of 642 steps (Fig. 20). Bremer support is strong for the major clades of oviraptorosaurs (Fig. 20), but weaker for the branches within each clade. As in most previous analyses, Incisivosaurus gauthieri is the most basal oviraptorosaur, even after including characters previously scored for Similicaudipteryx yixianensis (Xu 2020). The topology of the oviraptorid portion of the tree is identical to that of Funston et al. (in review), except for the exclusion of Ganzhousaurus nankangensis, and therefore will not be further described. Caenagnathidae is monophyletic and includes Nomingia gobiensis, which is frequently recovered as a basal oviraptorid (Lamanna et al. 2014; Funston and Currie 2016; Lü et al. 2016, 2017). Microvenator celer is recovered as the earliest-diverging caenagnathid, followed by Gigantoraptor erlianensis. Anomalipes zhaoi is recovered as more deeply nested than Gigantoraptor erlianensis, rather than as its sister taxon, contrary to the position recovered by Yu et al. (2018). Chirostenotes pergracilis and Hagryphus giganteus are sister taxa, and they diverge from a clade comprising the paraphyletic 'elmisaurs' and the large-bodied Anzu wyliei and its kin. Nomingia gobiensis is recovered at the base of this clade, rootward of Citipes elegans and Elmisaurus rarus, which are sister taxa. Apatoraptor pennatus is sister to clades of Caenagnathasia martinsoni + Epichirostenotes curriei, and Caenagnathus collinsi + Anzu wyliei, each of which form a sister pair.

\section{Ancestral State Estimations}

Ancestral state estimation for biogeography is generally consistent with previous analyses (Funston and Currie 2016). Oviraptorosaurs are estimated to have had an Asian origin, with a dispersal to North America at the base of Caenagnathidae (Fig. 20). However, the inclu- 


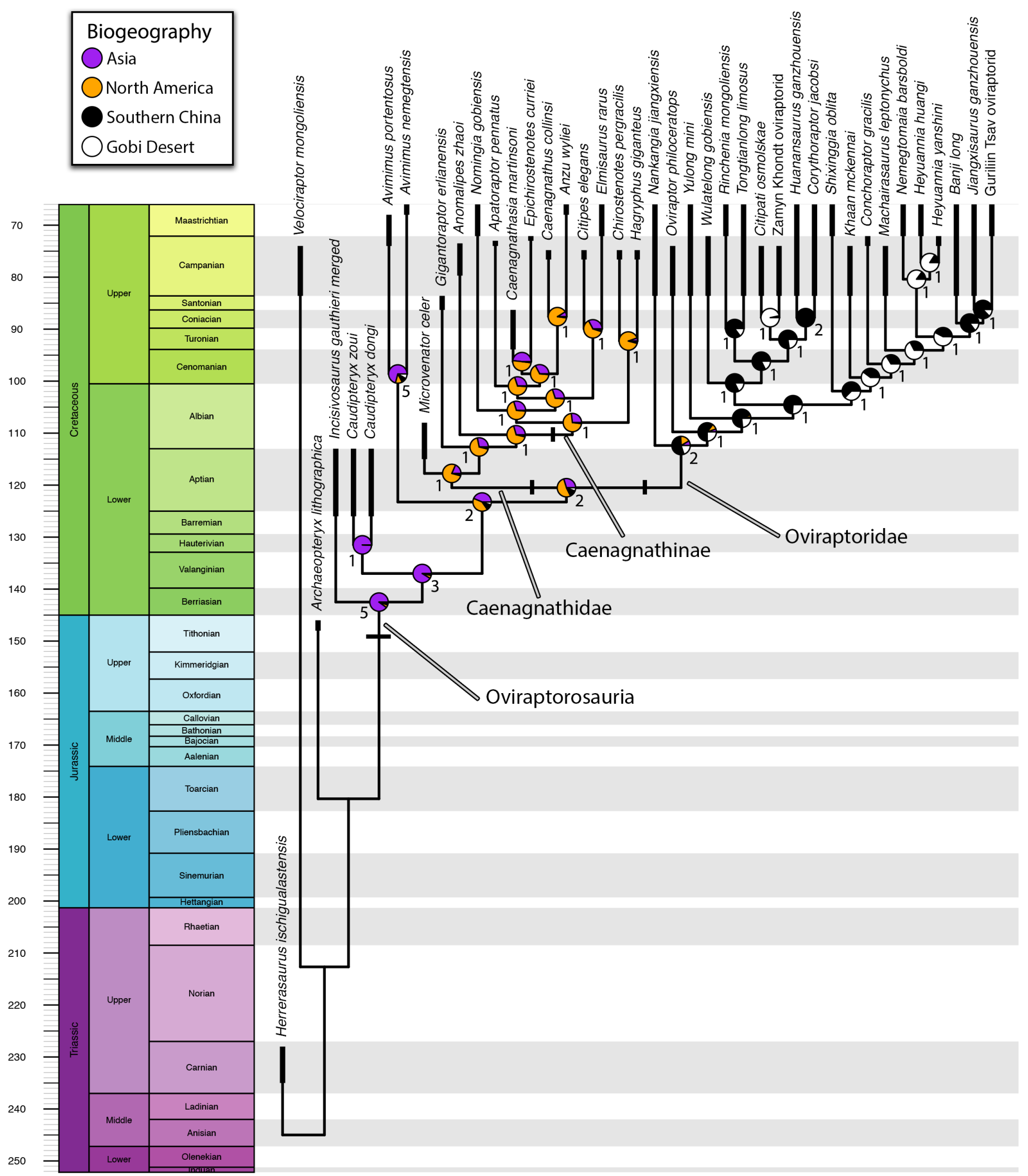

Figure 20. Phylogeny of Oviraptorosauria. Time-calibrated single most parsimonious tree of 642 steps. Stratigraphic ranges of tips indicated by thickened branches. Pie charts at nodes indicate posterior probability of ancestral state estimation of biogeographic range using stochastic simulation. Numbers at nodes indicate Bremer support values (decay indices). 
sion of Anomalipes zhaoi within the analysis increases the likelihood that some later clades of caenagnathids originated in Asia rather than North America. For example,

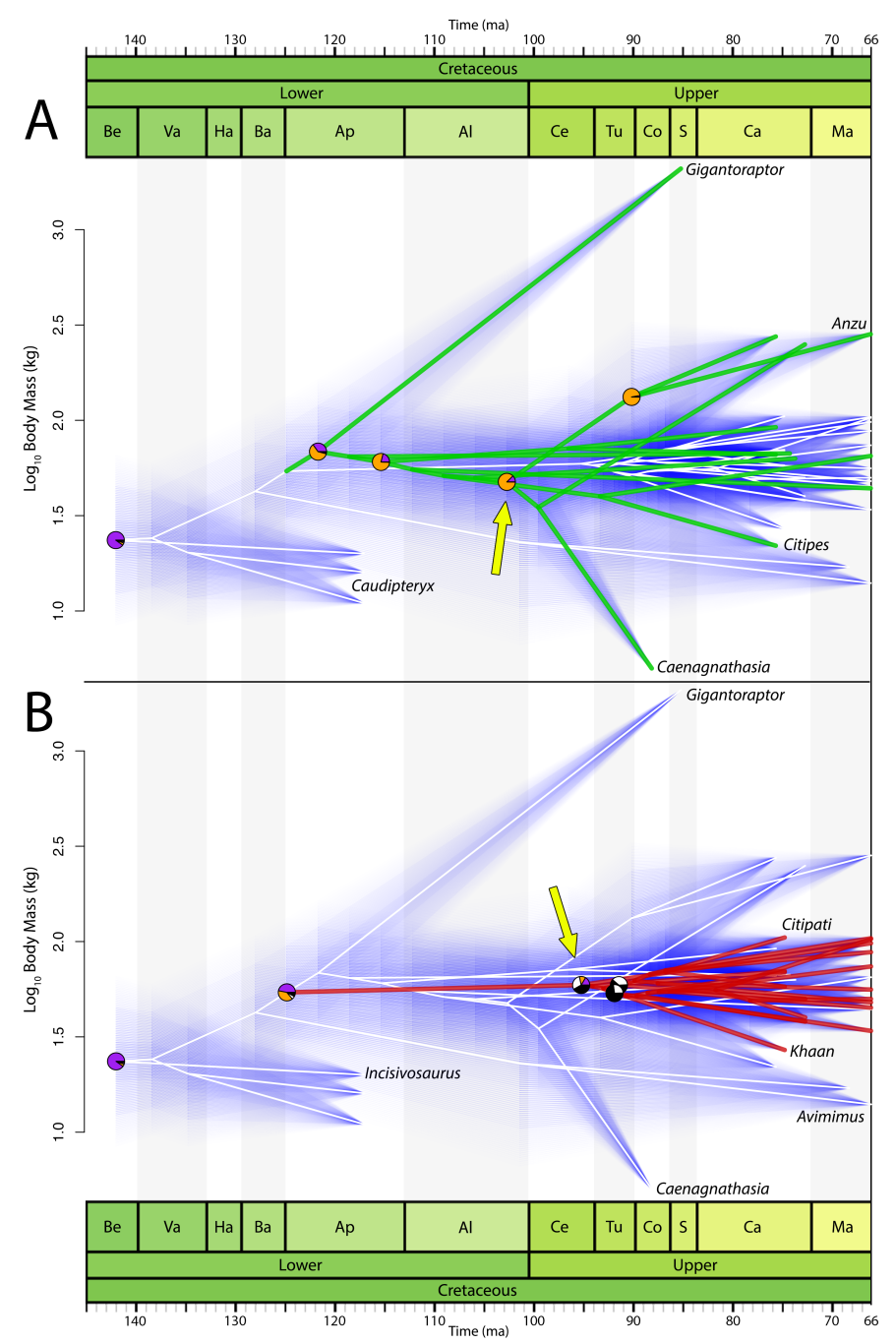

Figure 21. Body mass evolution of Oviraptorosauria. Time calibrated phenograms of Log10 Body Mass (kg) versus time (Ma) for Oviraptorosauria. Blue halos represent 95\% confidence intervals and branches indicate phylogenetic relationships. Each plot displays the same data, but Caenagnathidae is highlighted in green in (A) and Oviraptoridae is highlighted in red in (B) for clarity. Yellow arrows indicate nodes where important changes in body size range occur. Pie charts show ancestral estimations of biogeographic range (as in Fig. 20) for important clades of caenagnathids (A) and oviraptorids (B). Node labels from left to right in (A): Oviraptorosauria; Caenagnathidae; Anomalipes + Caenagnathinae; Caenagnathinae more derived than Apatoraptor pennatus; Anzu + Caenagnathus. Node labels from left to right in (B): Oviraptorosauria; Caenagnathoidea; Oviraptoridae; Heyuanninae (bottom); Citipatinae (top). Colours for node labels as in Fig. 20. Abbreviations: Al, Albian; Ap, Aptian; Ba, Barremian; Be, Berriasian; Ca, Campanian; Ce, Cenomanian; Co, Coniacian; Ha, Hauterivian; Ma, Maastrichtian; S, Santonian; Tu, Turonian; Va, Valanginian. the clade of Caenagnathasia martinsoni + Epichirostenotes curriei is equally likely to have had an Asian or North American ancestral range. However, some clades, like Chirostenotes pergracilis + Hagryphus giganteus and Anzu wyliei + Caenagnathus collinsi, almost certainly have a North American origin. Ancestral state estimation of body mass (Fig. 21) shows an increase from basal oviraptorosaurs to Caenagnathoidea (Caenagnathidae + Oviraptoridae). The ancestral body masses of caenagnathids and oviraptorids were close, although caenagnathids are estimated to have been slightly larger ancestrally, probably because of the giant Gigantoraptor erlianensis. The body masses of each of these lineages remain similar throughout the early Cretaceous (although this interval is very poorly sampled for each group). Roughly $100 \mathrm{Ma}$, in the AlbianCenomanian, a lineage of North American caenagnathines shows a drastic increase in the range of body sizes (Fig. 21A), and this lineage produces both the large Anzu wyliei and the smaller Caenagnathasia martinsoni and Citipes elegans. Oviraptorids appear to radiate in body size later (Fig. 21B), during the Turonian-Coniacian (although the earliest known oviraptorid is from the Campanian), and they occupy a much smaller range of body masses that overlaps with most Asian and North American caenagnathines. The range of body masses in known oviraptorids falls almost entirely within the $95 \%$ confidence limits of estimated body mass at their ancestral node (Fig. 21B), which suggests that body size range changed minimally during oviraptorid evolution. In general, each family of oviraptorosaurs shows expansion in body mass range, rather than any evidence of directional size trends or constriction of body mass range.

\section{DISCUSSION}

\section{Osteohistology and Growth}

Osteohistology of the pubes (UALVP 56638) of Caenagnathus collinsi shows that this individual was at least 12 years old and approaching maximum body size (Figs. 4, 5). It can therefore be considered a skeletally mature individual. As expected in any theropod, growth was initially rapid, but continued at a slower pace later in life. It is likely that sexual maturity preceded or coincided with the abrupt decrease in LAG spacing in the outer cortex (Castanet et al. 2004; Erickson et al. 2007; Lee and Werning 2008; Köhler et al. 2012). Despite the large size of this individual, the anteroposterior thickness of the pubis was still increasing late in life. This may be related to its central role in anchoring locomotor musculature, a conclusion also supported by asymmetry in secondary remodelling (Fig. 5). However, the mediolateral diameter of the pubis was not increasing, and therefore it is unlikely that the animal was increasing body mass significantly. 
Based on the parallel-fibered bone matrix and the densely packed LAGs, bone near the lateral periosteal surface of the pubis (Fig. 4A) can be characterized as an external fundamental system (Woodward et al. 2011), even though the bone on the anterior surface of the pubis appears to be actively growing - albeit at a slow rate, and probably driven by biomechanics. This variation reinforces the usefulness of full transverse sections for osteohistological studies. UALVP 56638 is similar in size and length to the pubes of the type of Anzu wyliei (CM 78000), which suggests Caenagnathus collinsi was a large animal. Cullen et al. (2020) recently described some large elements probably referable to Anzu wyliei (ROM VP 65884), and their osteohistological analyses of the ribs, gastralia, tibia, fibula, and manual phalanx show that this individual was still actively growing, despite its large size. Thus, known specimens of Anzu wyliei may not represent their maximum body size, and it may have been significantly larger at adulthood than Caenagnathus collinsi. However, Cullen et al. (2020) did not histologically sample a pubis, so a direct comparison of the growth of ROM VP 65884 and UALVP 56638 is not possible.

The osteohistology of UALVP 59606 (Fig. 15) also shows that this individual was near maximum body size, although it was from a much smaller individual than that represented by UALVP 56638. The decreased spacing of LAGs throughout the cortex of UALVP 59606 and their dense spacing at the periosteal surface (Fig. 15) are evidence of decreasing growth rate throughout the final years of life (Lee et al. 2013). This is supported by the higher proportion of parallel-fibered bone at the periosteal surface, and the nearly avascular nature of this zone (Francillon-Vieillot et al. 1990; Castanet et al. 2000; de Margerie et al. 2002; de Margerie 2004). The presence of six LAGs indicates this individual was at least six years old, although it is clear that expansion of the medullary cavity has erased at least part of the growth record. Indeed, the innermost LAG is truncated by the medullary cavity, which shows that not only has the earlier growth been resorbed, but also that the shape of the metatarsal changed throughout life. The unusual osteohistology and abundant secondary remodelling in the cortex of UALVP 55585 are probably the result of its proximity to the metaphysis of the element, which makes it less suitable for skeletochronology. As the main load-bearing element of the pes, metatarsal III was probably subject to more stress (Snively and Russell 2002; Snively et al. 2004), which may have induced higher rates of remodelling (Padian and Lamm 2013). The absence of CGMs in the cortex of UALVP 55585 (Fig. 14) precludes determination of the exact age at death of this individual. This absence may be the result of cortical remodeling or drift, as suggested by the region of compact coarse cancellous bone on the posterior side of the cortex. In any case, bone at the periosteal surface around most of the cortex is poorly vascularized and parallel-fibered, indicative of slow growth (Francillon-Vieillot et al. 1990). The exception is the unusual area of porous woven bone at the periosteal surface of the anterolateral corner of the metatarsal, but this may be related to the insertion of $m$. tibialis cranialis in this location. In these traits, the osteohistology of UALVP 55585 is similar to that of UALVP 55639 (Funston et al. 2020), a small pair of fused dentaries in which the cortex is heavily remodeled and the primary bone remaining is poorly vascularized and parallel-fibered. In both specimens, the endosteal layer is composed of several layers and secondary osteons are well developed, showing multiple internal lamellae, each of which is evidence of prolonged secondary remodeling (Bromage et al. 2009).

No ontogenetic series of caenagnathids is yet known, but some insights into their general growth patterns can be made from the new material sampled here and previous descriptions of caenagnathid osteohistology (Funston et al. 2016a, 2020; Cullen et al. 2020; Funston and Currie 2020). Several lines of evidence suggest that growth early in life was relatively rapid, as in other coelurosaurs (Varricchio 1993; Skutschas et al. 2016; Woodward et al. 2020). The two youngest specimens are likely TMP 1985.043.0070 (Funston et al. 2020) and UALVP 57349 (Funston and Currie 2018), a pair of fused dentaries and a tibia, respectively. In each, there is a high proportion of woven-fibered bone, dense vasculature, and dense osteocyte lacunae (although osteocyte lacunar density is unlikely to reflect mass-specific growth rates; see Cullen et al. 2020). UALVP 57349 preserves a possible CGM in the mid-cortex, which, rather than manifesting as a distinct LAG, is represented by an annulus of parallel-fibered bone (Funston and Currie 2018). This suggests that while growth rate decreased, growth did not completely cease, in contrast to the clear LAGs in ontogenetically older caenagnathids. The larger specimens (UALVP 56638, UALVP 59400, UALVP 59606) each show wide growth zones towards the endosteal part of the cortex, followed by a stark transition to more closely spaced LAGs. This suggests that rapid growth was sustained for several years and before growth rate abruptly dropped. It is likely that sexual maturity coincided with or preceded this shift in growth rate, because this phenomenon results in slowed growth in extant tetrapods that take longer than one year to reach reproductive maturity (Castanet et al. 2004; Lee and Werning 2008; Köhler et al. 2012; Botha-Brink et al. 2016). Each of these individuals continued to grow for several years after the reduction in growth rate, and thus sexual maturity preceded skeletal maturity. 


\section{Diversity of DPF Caenagnathids}

Most lines of evidence suggest that three taxa coexisted in the DPF. Where multiple specimens of a single element are known, three morphotypes can usually be delineated, as is the case for mandibles (Funston et al. 2020), ilia (Rhodes et al. 2020), and metatarsals (Funston et al. 2015, 2016a). Only two morphotypes can be distinguished in known manual unguals, but there are few complete examples known from the DPF. Other elements are known from too few specimens or are too poorly preserved to establish morphotypes. Unfortunately, there is little anatomical overlap between associated skeletons and isolated specimens, which prevents confident referral of morphotype to taxon. This is especially problematic for Caenagnathus collinsi and Citipes elegans. For these taxa, only mandibles and tarsometatarsi, respectively, can be referred unequivocally. However, the more complete material of Chirostenotes pergracilis (Funston and Currie 2020) allows for comparison of a broader range of skeletal elements. Where the morphology of these specimens is inconsistent with or lacks the apomorphies of Chirostenotes pergracilis, this taxon can be eliminated as a possible identification. Thus, these elements are likely representatives of Caenagnathus collinsi or Citipes elegans.

To which of these taxa these excluded elements pertain is ambiguous, but a possible solution lies in the relative sizes of the elements. Considerable size variation is present in isolated caenagnathid bones from the DPF, and in many cases it corresponds to morphotype variation, such that elements of similar size tend to be the same morphotype as well. Covariation in size and morphotype could be explained by either allometry, ontogeny, or taxonomy, but osteohistological evidence points towards the latter. In combination with the recently described UALVP 59400 (Funston and Currie 2020), the osteohistology of UALVP 56638 and UALVP 59606 indicate that three taxa of different maximum adult body size are present in the DPF caenagnathid material. The largest of these is represented by UALVP 56638, which was actively growing until it was a much larger body size than either UALVP 59400 or UALVP 59606. UALVP 59606 and UALVP 55639 (Funston et al. 2020) represent the smallest size morph, which ceased growth at a much smaller size than would be expected of a large individual like UALVP 56638, and show evidence of slower growth rates at similar sizes to UALVP 59400 (Funston and Currie 2020). Finally, UALVP 59400 appears to be intermediate between these size morphs (Funston and Currie 2020), as does TMP 1992.036.1237 (Funston et al. 2020). Fusion between distal tarsal IV and the proximal end of metatarsal IV distinguishes the smaller UALVP 59606 from UALVP 59400, despite both specimens being at similar stages of osteohistological maturity. While a larger osteohistological sample of metatarsals would increase confidence in this assertion, this provides evidence that coossification of the distal tarsals and metatarsus is an apomorphic feature of Citipes elegans. Fusion of the hindlimb elements appears to progress with maturity in other oviraptorosaurs (Funston et al. 2016b, 2019, in review), so this feature can likely serve as an external indicator of maturity as well as an apomorphy. Even if future discoveries show that older Chirostenotes pergracilis did possess a fused tarsometatarsus, the smaller size of UALVP 59606 and UALVP 55639 at maturity supports their distinction as a separate taxon. Thus, osteohistological evidence of skeletal maturity in each of these size morphs supports the hypothesis, first formed on the basis of mandibles (Currie et al. 1993; Longrich et al. 2013), that three caenagnathid taxa of distinct maximum adult size existed in the DPF: the larger Caenagnathus collinsi, the intermediate Chirostenotes pergracilis, and the smaller Citipes elegans.

By excluding specimens from Chirostenotes pergracilis using the absence of apomorphies, and subsequently sorting into size classes - under the assumption that Caenagnathus collinsi was significantly larger than Citipes elegans at maturity-most isolated bones from the DPF can be provisionally referred to one of the three taxa (Tab. 1). This assumes that there were only three caenagnathid taxa in the DPF, but there is currently no evidence that suggests this assumption is incorrect. Confirmation of these referrals will rely on systematic osteohistological sampling of material to establish ontogenetic stage, or the future discovery of associated skeletons with overlapping elements. The referral of new specimens to each of these three taxa drastically improves their skeletal representation (Fig. 22), and our understanding of their anatomy and ecology.

\section{Caenagnathus collinsi}

Caenagnathus collinsi was erected on the basis of the relatively complete mandibles (CMN 8776) by Sternberg (1940). Since that time, no unambiguous referrals have been made, and CMN 8776 remains the only example of the 'shallow-beaked' dentary morphotype from the DPF. Caenagnathus collinsi has generally been assumed to be of larger body size at adulthood than other caenagnathids in the DPF, primarily because the holotype mandible (230 mm long) is the largest yet known from the DPF. Funston et al. (2015) suggested that Caenagnathus collinsi was intermediate in body size between Chirostenotes pergracilis and Anzu wyliei, but the large pubes described here (UALVP 56638) are the same size as those of CM 78000 (Anzu wyliei), showing that Caenagnathus collin$s i$ was much larger than currently estimated. However, Cullen et al. (2020) showed that large material probably representing Anzu wyliei was still actively growing, and thus Anzu wyliei may also have been larger than current- 


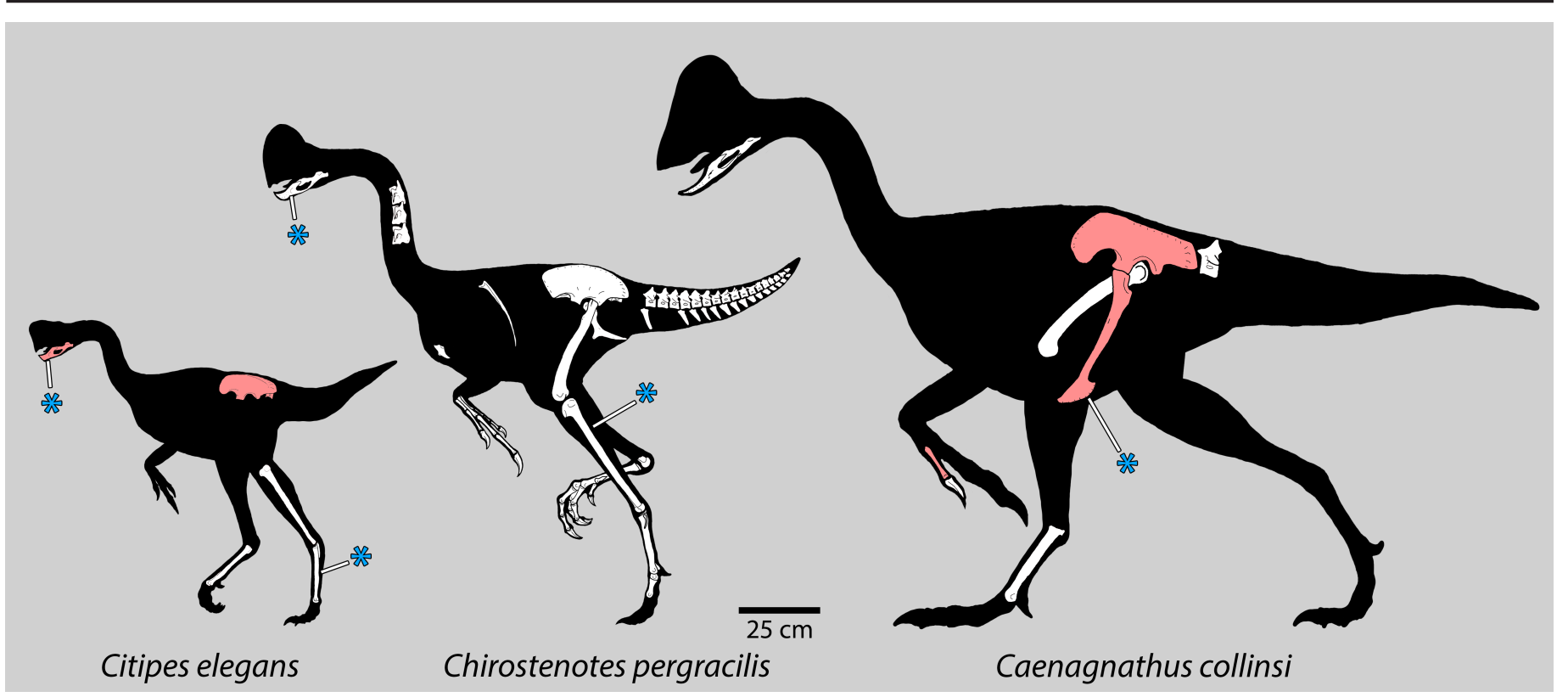

Figure 22. Skeletal reconstructions of Dinosaur Park Formation caenagnathids. Skeletal reconstructions of Citipes elegans (left), Chirostenotes pergracilis (middle), and Caenagnathus collinsi (right), showing variation in skeletal representation and body size. Previously referred material is indicated in white and newly referred material is indicated in red for each taxon. Blue asterisks indicate elements that have been histologically sampled for each taxon. Citipes elegans: dentaries, metatarsal IV; Chirostenotes pergracilis: dentaries, tibia; Caenagnathus collinsi: pubis.

ly recognized. Funston et al. (2015) referred some large isolated elements to Caenagnathus collinsi on the basis of larger size and some morphological differences, but in light of new evidence, some of these referrals are doubtful. For example, osteohistological analyses of Chirostenotes pergracilis dentaries (Funston et al. 2020) and postcrania (Funston and Currie 2020) show that these individuals were not yet at maximum body size, although they had slowed their growth rate. Thus, whether the elements, especially the femur (TMP 1986.036.0323), referred by Funston et al. (2015) are outside of the body size range of Chirostenotes pergracilis is unclear.

Furthermore, the caenagnathid identity of some of the material described by Funston et al. (2015) is suspect. Two astragalocalcanea were identified as caenagnathid based on the presence of a median fossa rather than a transverse groove at the base of the ascending process, a deep excavation for the fibula, and a simple contact between the astragalus and calcaneum (Funston et al. 2015). However, further examination of a range of oviraptorosaurs suggests that these features are more reminiscent of ornithomimids than oviraptorosaurs. Indeed, Funston and Currie (2018) argued, based on an extensive survey of coelurosaur tibiae, that oviraptorosaurs were distinguished by the position of the fibula lateral to the tibia, rather than anterior to it, at the distal end of the crus. Accordingly, all oviraptorosaurs examined, including caenagnathids (CM 78000, Anzu wyliei; MPC-D 100/119, Nomingia gobiensis; RSM P2600.1, Caenagnathidae indet.), lack any excavation of the calcaneum altogether. Thus, a calcaneum that is deeply incised and an ascending process inset from the lateral surface of the astragalocalcaneum both argue for a non-oviraptorosaur identity of TMP 1993.036.0631 and TMP 1995.074.0049. Instead, these elements are identical to those described by McFeeters et al. (2017), and should therefore be regarded as ornithomimids.

Similarly, some of the morphological characteristics that Funston et al. (2015) used to distinguish the second metatarsals they describe from those of Chirostenotes pergracilis and Citipes elegans are similar in some ways to ornithomimids. These include the well-developed posterior process on the proximal end, which is similar to those of Ornithomimus velox (Claessens and Loewen 2016) and Struthiomimus altus (Osborn, 1917). The termination of the articular facet for metatarsal III near the midpoint of the metatarsal is also more similar to ornithomimids than other caenagnathids, which have a less well-developed arctometatarsalian condition than ornithomimids (Snively et al. 2004), and therefore have more anterior exposure of metatarsal III. Whether other caenagnathids show these features, or if they are autapomorphies of Caenagnathus collinsi, are unknown. However, these metatarsals have the characteristic laterally-protruding contact for metatarsal IV at their proximal ends, which indicates that metatarsal III would have separated metatarsals II and IV throughout most of their length. This feature is a synapomorphy of Caenagnathidae, and therefore I retain these specimens as representatives of Caenagnathus collinsi. They can be differentiated from Chirostenotes pergracilis by 
the posterior process on the proximal end and from mature individuals of both Chirostenotes pergracilis and Citipes elegans by larger size. Cullen et al. (2020) described partial metatarsals that may pertain to Anzu wyliei, but these are too fragmentary to evaluate whether they are similar to the metatarsals referred to Caenagnathus collinsi. The third metatarsal of an as-yet-undescribed specimen of Anzu wyliei has a flattened facet for metatarsal II that ends about halfway up the shaft of the element, which would be the expectation from TMP 1993.036.0198.

The larger size of 'Macrophalangia' canadensis (CMN 8538) than TMP 1979.020.0001 raises suspicions that it may represent Caenagnathus collinsi rather than Chirostenotes pergracilis (Longrich et al. 2013). Another tarsometatarsus, TMP 1993.036.0181, is virtually identical to CMN 8538, but is slightly larger. Funston and Currie (2020) followed Currie and Russell (1988) in the synonymy of 'Macrophalangia' canadensis and Chirostenotes pergracilis, and therefore referred both of these specimens to the latter taxon. However, there are some differences between CMN 8538 and TMP 1979.020.0001 that may distinguish them. For example, the shaft of metatarsal I is more triangular in CMN 8538, whereas it is distinctly diamond-shaped in TMP 1979.020.0001. Furthermore, pedal phalanx I-1 is longer than metatarsal I in CMN 8538, whereas these are equal in length in TMP 1979.020.0001. Both of these features in CMN 8538 are also exhibited by Anzu wyliei (CM 78000). Another potential difference may lie in metatarsal V, which is tightly curled in TMP 1979.020.0001, and described as a 'small round splint about $60 \mathrm{~mm}$. in length' by Sternberg (1932). This morphology could not be verified because the metatarsals were on loan when the specimen was examined for this study. Furthermore, the morphology of metatarsal V in TMP 1979.020.0001 is unique among oviraptorosaurs, and it is therefore unclear whether it was aberrant or pathological in this individual. These features may argue against the referral of CMN 8538 to Chirostenotes pergracilis, but osteohistological analysis is necessary to eliminate ontogenetic change as a possible source of this variation. Indeed, osteohistological analysis of Chirostenotes pergracilis material (TMP 1992.036.1237 and UALVP 59400) suggests that these individuals, although nearing maximum size, were not yet fully grown (Funston and Currie 2020; Funston et al. 2020), so CMN 8538 may be within the upper bounds of the Chirostenotes pergracilis body size range. If overlapping material were discovered that showed CMN 8538 and CMN 8776 were the same taxon, then 'Macrophalangia' canadensis would have priority. In this case, the family would have to be renamed 'Chirostenotidae', as Chirostenotes pergracilis is the oldest valid genus in the family.

In any case, the large unguals described by Bell et al. (2015) and Funston et al. (2015) also likely pertain to
Caenagnathus collinsi. They are clearly oviraptorosaur and, in addition to larger size, they differ from Chirostenotes pergracilis in the presence or absence of transverse grooves separating the flexor tubercles from the proximal articular surfaces. Furthermore, the flexor tubercle of ungual II-3 is closer to the proximal articular surface in the large unguals, and the larger unguals I-2 and II- 3 are both more tightly curved than those of Chirostenotes pergracilis (CMN 2367, TMP 1979.020.0001). The ilium referred here (UALVP 59791) is likewise larger than can be expected for Chirostenotes pergracilis, and lacks two autapomorphic features of its ilium: the great height of the iliac blade above the acetabulum and the convexity of the dorsal margin of the ilium. The pubes (UALVP 56638) closely match the ilium in size and together they form a complementary concavo-convex contact that differs from those of other caenagnathids. These features strongly support the notion that they pertain to the same taxon, and distinguish them from Chirostenotes pergracilis, which lacks this autapomorphic feature of Caenagnathus collinsi. A manual phalanx I-1 (UALVP 59921) may also be referable to Caenagnathus collinsi on the basis of its large size and minor morphological differences from CMN 2367 and TMP 1979.020.0001. The shaft of the phalanx is relatively deeper in the flexor-extensor plane than those of CMN 2367 and TMP 1979.020.0001, in which the shaft is not as deep as the distal condyle. Furthermore, UALVP 59921 lacks the ventrally protruding proximal articulation, an autapomorphic feature which is shared by CMN 2367 and TMP 1979.020.0001. However, the range of variation in these features in caenagnathids is poorly known, and future osteohistological analysis may provide more information on the affinities of UALVP 59921.

The rarity of Caenagnathus collinsi in the DPF is perplexing, especially considering that taphonomic biases in the DPF preferentially preserve larger taxa (Brown et al. 2013). Perhaps, as was the case for Apatoraptor pennatus in the Horseshoe Canyon Formation, some previously collected specimens have been misidentified as ornithomimids (Funston and Currie 2016). Alternatively, the scarcity of specimens could reflect small or transient populations of Caenagnathus collinsi in the DPF region. In any case, Caenagnathus collinsi remains one of the most enigmatic caenagnathids and future discoveries will be especially valuable for understanding its anatomy and biology.

\section{Chirostenotes pergracilis}

Chirostenotes pergracilis was first described by Gilmore

(1924a) on the basis of a pair of articulated hands discovered in 1924 (CMN 2367). A second, more complete skeleton collected in 1979 (TMP 1979.020.0001) was described by Currie and Russell (1988), illustrating other aspects of 
the anatomy and solidifying the caenagnathid identity of Chirostenotes pergracilis. The manus of CMN 2367 and TMP 1979.020.0001 are identical in proportions and exhibit few morphological differences, strongly supporting their referral to the same taxon. This specimen also suggested to Currie and Russell (1988) that CMN 8538, previously considered a separate taxon ('Macrophalangia' canadensis), was in fact referable to Chirostenotes pergracilis (but see above). Longrich et al. (2013) tentatively referred some mandibular material to Chirostenotes pergracilis, but this was on the basis of size (without assessing maturity) and relative abundance, and had little support at that time. They also referred some postcrania from Texas to Chirostenotes sp., but they provided no characters to support these referrals. Funston and Currie (2014) followed Longrich et al. (2013) in the referral of a relatively complete mandible (TMP 2001.012.0012) to Chirostenotes pergracilis, but this was because revising the taxonomy was outside of the scope of that study. Thus, no further unambiguous material was known until Funston and Currie (2020) described a skeleton collected in 2016 (UALVP 59400), which they referred on the basis of three lines of evidence. First, the upturned mandible distinguished the specimen from the autapomorphic elongate symphysis of Caenagnathus collinsi. Second, the unfused distal tarsal IV contrasts with those of Citipes elegans, which are autapomorphically fused to distal tarsal III and the proximal metatarsus at maturity. Finally, osteohistological evidence of maturity in UALVP 59400 indicates that neither of these features were the result of differences in ontogenetic stage. The studies of Funston et al. (2020) and Funston and Currie (2020) support most of the referrals of mandibular material to Chirostenotes pergracilis by Longrich et al. (2013), with some important caveats. Critically, Funston et al. (2020) showed that fusion of the dentaries does not indicate skeletal maturity in caenagnathids, and that other features, like the definition of the attachment of $m$. genioglossus, may be better maturity indicators. However, that study also showed that some small dentaries are, in fact, adults of a smaller-bodied taxon, and this complicates maturity estimation for small dentaries based on size in the absence of osteohistological analyses. In any case, the mandible of UALVP 59400 provides both a morphological and size comparison for an adult Chirostenotes pergracilis, and this can be used to refer other mandibles. Based on their large sizes and clear morphological similarity to UALVP 59400, TMP 1990.056.0006, TMP 1992.026.1237 and TMP 2001.012.0012 can be referred to Chirostenotes pergracilis. The affinities of the juvenile dentaries TMP 1984.043.0070 are less clear, and they could be juvenile Chirostenotes pergracilis or Citipes elegans. Based on morphological similarity to TMP 1992.036.1237, Funston et al. (2020) referred them to
Chirostenotes pergracilis, which I follow here, with the acknowledgement that future work may show they are better referred to Citipes elegans.

\section{Citipes elegans}

Citipes elegans has the most complicated taxonomic history of the DPF caenagnathids. Parks (1933) first described ROM 781, a small tarsometatarsus clearly differing from theropods known at the time. Parks (1933) established the species under the genus 'Ornithomimus', but it was soon clear that it pertained to a different kind of animal, possibly similar to Chirostenotes pergracilis (Sternberg 1934). Russell (1972) suggested it was referable instead to the genus 'Macrophalangia', which was subsequently synonymized with Chirostenotes by Currie and Russell (1988). Shortly thereafter, Currie (1989) recognized its similarity to Elmisaurus rarus from Mongolia, and referred it as Elmisaurus elegans. Meanwhile, there was also debate about the taxonomy of mandibular material from the DPF. Cracraft (1971) described a portion of a small ASC complex as 'Caenagnathus' sternbergi, noting similarity to Caenagnathus collinsi. Currie et al. (1993) described more mandibular material from the DPF, and provisionally referred some dentaries to 'Caenagnathus' sternbergi, noting that there was no anatomical overlap, but that it was more conservative than erecting a new taxon. Sues (1997) addressed both of these issues, arguing that ROM 781 was better referred to Chirostenotes, but as a different species: Chirostenotes elegans. He also suggested that the mandibular material of 'Caenagnathus' sternbergi was the same taxon (Sues 1997), but Currie and Padian (1997) preferred to keep the mandibular material separate. Varricchio (2001) preferred to keep all of the taxa separate for clarity, referring an articular to 'Caenagnathus' sternbergi and a partial pes to Elmisaurus elegans. Currie (2005a) delineated four taxa from the DPF: three 'caenagnathines' and one 'elmisaurine', Elmisaurus elegans. He commented that at least one of the 'caenagnathines' was a junior synonym of another, but it was uncertain which, and so he retained three taxa: Caenagnathus collinsi, 'Caenagnathus' sternbergi, and Chirostenotes pergracilis. Longrich et al. (2013) followed the approach of Sues (1997) in associating the mandibles of 'Caenagnathus' sternbergi and the tarsometatarsi of Elmisaurus elegans, but they distinguished this material from Elmisaurus and erected a new genus, Leptorhynchos, to which they referred the species. However, the genus Leptorhynchos is diagnosed on the basis of mandibular material, and so the holotype of the species, a tarsometatarsus, cannot be referred to the genus because it shows none of the diagnostic characters. In a correction to their article, Longrich et al. (2013) attempt to resolve this by designating TMP 1992.036 .0390 as a paratype of the spe- 
cies 'Leptorhynchos' elegans, using 'size and provenance' as characters to support this interpretation. However, Funston et al. (2020) showed that size cannot be used to assess maturity in dentaries without osteohistological analysis and the presence of more than one taxon in the DPF has been recognized since 1971, so provenance does not distinguish 'Ornithomimus' elegans nor 'Caenagnathus' sternbergi. There is therefore no concrete evidence that TMP 1992.036.0390 pertains to the same taxon as ROM 781, and the latter cannot be referred to Leptorhynchos. The only dentaries that can be confidently referred to 'Ornithomimus' elegans are UALVP 56639, and these show no features that unite them with Leptorhynchos gaddisi to the exclusion of other caenagnathines. Thus, as it stands, material of 'Ornithomimus' elegans cannot be referred to an existing genus, and the new genus Citipes is erected for this material.

Osteohistological sections of the mandibles (Funston et al. 2020) and metatarsals of Citipes elegans show that this taxon had a small body size relative to other oviraptorosaurs at maturity. The mandible (UALVP 55639) is heavily remodeled and the remaining primary bone is low in vascularity, indicating slow growth. Although there is no EFS present, the slow-growing bone at the periosteal surface indicates that this individual had more or less ceased growth, and was close to maximum body size. Despite their histological maturity, this mandible is considerably smaller than those of Caenagnathus collinsi and Chirostenotes pergracilis. This suggests that Citipes elegans had a smaller body size at maturity than the former two taxa. The osteohistology of the metatarsals (UALVP 59606 and UALVP 55585) support this assertion. Although it lacks growth marks, UALVP 55585 shows little evidence of active growth and extensive secondary remodeling, more reminiscent of subadult theropods rather than juveniles (Funston et al. 2016a). The absence of CGMs in this specimen may be the result of its distance from the midshaft of the element, and its proximity to the metaphysis. Additionally, the section is located close to the insertion of $m$. tibialis cranialis, so its histology may reflect biomechanical loads rather than the growth of the individual. The abrupt decrease in LAG spacing in the cortex of UALVP 59606 indicates a decreasing growth rate, and the closely packed LAGs in avascular bone at the periosteal surface are consistent with an EFS, suggesting cessation of growth. Accordingly, this individual can be interpreted as a mature adult. However, the unbroken articular surfaces for metatarsals II and III show that the tarsometatarsus of this individual had not yet fused, suggesting that the distal tarsals fused first.

The small dentaries described by Funston et al. (2020) are highly incomplete, which means that their morphological similarity to other dentaries is unknown. Thus, although it is clear that UALVP 55639 is from an old individual of a small taxon, probably Citipes elegans, it provides few morphological characters that would allow other small dentaries to be referred without osteohistological analysis. A single character appears to distinguish it from TMP 1984.043.0070 and TMP 1992.036.1237: a transversely flatter ventral surface in cross section. Whereas this is shared with TMP 1992.036.0390, it is possible that this feature is allometric, and would be expressed in the dentaries of Chirostenotes pergracilis at an equivalent size, examples of which are not yet known with certainty. Indeed, a large pair of fused dentaries (TMP 1996.012.0142) combines a mix of features similar to Chirostenotes pergracilis and the putative Citipes elegans dentaries (TMP 1992.036.0390), showing that these characters are not restricted to animals of small body size. Therefore, other small isolated dentaries like TMP 1979.008.0622, TMP 1991.144.0001, TMP 1992.040.0044, and TMP 1992.036.0390 cannot be confidently referred to Citipes elegans without osteohistological analysis showing that they are adults, or the discovery of new material showing that the more upturned morphotype overlaps with diagnostic postcrania of Citipes elegans and is not ontogenetically variable. Regardless, these specimens remain the most promising candidates for relatively complete mandibular material of Citipes elegans and should be the subject of future work.

Three pelvic elements, including a left and right ilium and an isolated last sacral vertebra, were recovered in 1981 from the same site (Rhodes et al. 2020), although they were not articulated. The ilia are identical to each other in size, morphology, and style of preservation. The isolated last sacral vertebra is the correct size for the associated ilia, and is clearly from a caenagnathid. Accordingly, these specimens are best interpreted as representing the same individual, which appears to have been relatively mature on the basis of the distinct muscle attachment sites. The ilia are remarkably different from those of Caenagnathus collinsi and Chirostenotes pergracilis. The iliac blade is much more robust, with pronounced muscular attachment sites, and its dorsal edge is transversely thickened, whereas those of Caenagnathus collinsi and Chirostenotes pergracilis are thin and delicate. The pubic peduncle also differs from these taxa in the larger size, horizontal ventral edge, and the presence of a large foramen. Although these specimens have not been histologically sampled and their ontogenetic stage is therefore unknown, several lines of evidence support their referral to Citipes elegans. The morphological differences between these ilia and those of TMP 1979.020.0001 and UALVP 59791 are difficult to explain as the result of ontogeny, as they show the opposite pattern than would be expected: the smaller elements are more robust and have more pronounced muscular attachment sites. The flattened dorsal edge and the features of the pubic peduncle are also 
unlikely to change throughout ontogeny, as these features are consistent in ontogenetic series of other oviraptorosaurs (e.g., Funston et al. in review). Furthermore, these ilia lack the autapomorphies of either of these other taxa. They do not have a ridge on the pubic peduncle for the concavo-convex iliopubic contact of Caenagnathus collinsi, and they lack the dorsally expanded and convex iliac blade of Chirostenotes pergracilis. Thus, the only remaining taxon to accommodate them is Citipes elegans, and these specimens fit the expectation of smaller body size in this taxon. The new material shows that the hindlimbs of Citipes elegans differed significantly from those of Caenagnathus collinsi and Chirostenotes pergracilis. The ilium is robust and well-muscled, despite being lower dorsoventrally than Chirostenotes pergracilis. The tibia described by Funston et al. (2016) is relatively similar to those of Chirostenotes pergracilis and Elmisaurus rarus, but is slightly more elongate for its distal width than either of those taxa. However, this may be a result of negative allometry, rather than a taxonomic difference. Osteohistological analysis may provide more data on the ontogenetic stage of this element and whether it remains referable to Citipes elegans. The tarsometatarsus is intermediate in morphology between Chirostenotes pergracilis and Elmisaurus rarus: whereas it is fused proximally, it is not as robust nor as coossified as that of Elmisaurus rarus. Funston et al. (2016) referred TMP 2000.012.0008 to Citipes elegans, but this specimen is more likely a young ornithomimid (B. McFeeters pers. comm. 2017). Cullen et al. (2020) showed that large metatarsals probably referable to Anzu wyliei have cruciate ridges, and so these cannot be used to characterize the small-bodied 'elmisaurs' and were clearly more broadly distributed within Caenagnathidae. Thus, although the small third metatarsals described by Funston et al. (2016) can be distinguished from Chirostenotes pergracilis, it is unclear whether they could represent Caenagnathus collinsi, except where they have been histologically sampled (UALVP 55585). Advanced histological maturity in UALVP 59606 suggests that fusion of the distal tarsals to the metatarsals indicates skeletal maturity, and that it precedes coossification of the metatarsals to each other. In other oviraptorosaurs, coossification of the hindlimb bones also appears to coincide with skeletal maturity (Funston et al. 2019). In this case, fused tarsometatarsi (TMP 1982.016.0006; TMP 1982.039.0004; TMP 1996.012.0141) can be considered to represent mature individuals, further supporting previous arguments of small body size in adult Citipes elegans.

\section{Indeterminate Caenagnathid Material}

Despite the improvement to skeletal representation of each DPF caenagnathid taxon, the identity of numerous important but isolated bones remain ambiguous. In most cases, this is because they are either not distinctive enough, do not overlap with specimens of known affinities, or their relative sizes cannot be established.

The parietals and quadrate (Figs. 16, 17) are the first unambiguous caenagnathid cranial elements from the DPF. Currie (1987) mentioned the parietals, and they were briefly described in a symposium paper (Currie 1992). As mentioned by Currie (1992), although they are likely oviraptorosaur on the basis of their transverse expansion and absence of a sagittal crest, they cannot currently be assigned to any caenagnathid taxon because no overlapping material exists and there is no way to determine their ontogenetic stage. Parietals are not yet known for any caenagnathid, so whether this specimen represents a large or small individual is unclear. The parietals differ from those of avimimids and oviraptorids in the presence of pitted plateaus that likely anchored temporal musculature, but the functional significance of these features is unknown.

The quadrate has the saddle-shaped articulation that is typical of oviraptorosaurs, but is more deeply incised to match the tall articular ridge of the mandible. Because Caenagnathus collinsi has lower articular ridges than Chirostenotes pergracilis, it is more likely that the quadrate pertains to the latter taxon than to the former. However, the articular of Citipes elegans is not yet unambiguously known, and if the tall articular ridge of 'Caenagnathus' sternbergi does represent the condition in Citipes elegans, this would be another possible identification for the quadrate. The quadrate articulates nicely with TMP 2001.012.0012 (Chirostenotes pergracilis), and thus the individual represented by the quadrate was therefore likely to be similar in body size to that individual. Several features distinguish the quadrate from those of oviraptorids, particularly the large quadratojugal foramen and the large, protruding process for the pterygoid. The deeper articular groove-matched with the taller articular ridge of the mandible-suggest that the caenagnathid jaw was more constrained to anteroposterior movement than those of oviraptorids. Indeed, in oviraptorids, the articular groove of the quadrate is often oblique to the midline, suggesting that some transverse movement was possible.

The large dentaries TMP 1996.012.0142 (Fig. 18) are problematic in that they blur the line between the smaller, more upturned morphotype, and the larger, more anteriorly projecting dentaries of Chirostenotes pergracilis. While it is tempting to interpret them as evidence that the upturned morphotype is distinct throughout a range of body sizes and therefore referable to Citipes elegans, TMP 1996.012.0142 is much larger than expected for an adult Citipes elegans, based on the maturity of UALVP 55639. Furthermore, TMP 1996.012.0142 does not share the distinctive flattened ventral margin that appears to 
distinguish UALVP 55639 from Chirostenotes pergracilis. Similarly, some other small details of the occlusal surface are more similar to Chirostenotes pergracilis than to the smaller, upturned dentaries like TMP 1992.036.0390. For example, the unusual patches of rugose bone posterior to the symphyseal sulcus are more pronounced but otherwise similar to those in TMP 1992.036.1237 (Chirostenotes pergracilis). This region is not rugose in TMP 1992.036.0390, nor in UALVP 55639 (Citipes elegans), despite its advanced ontogenetic stage. Likewise, the medial projection of the tubercle of the lingual ridge in TMP 1996.012.0142 is a better developed version of the morphology incipiently shown by TMP 2001.012.0012 and TMP 1992.036.1237. Also, the degree of posterior divergence of the dentaries is intermediate between TMP 2001.012.0012 and TMP 1992.036.0390. A possible explanation is that TMP 1996.012.0142 is an exceptionally old individual of Chirostenotes pergracilis. This is supported by the robustness of the dentaries and the extensive development of rugosity, similar to the relatively old TMP 1992.036.1237 (Funston et al. 2020). In this case, the dentary may continue to deepen throughout ontogeny, as is the case for some other theropods like tyrannosaurs (Carr 1999; Currie 2003). Isolated sacra known from the DPF show little variation, although most of their anatomical overlap is in the centra. Each of these can be identified as caenagnathid by their extensive pneumatization, the elongate pleurocoels nearly continuous with the ventral surfaces of the centra, and the large, hatchet-shaped sacral ribs five and six (Currie and Russell 1988; Sues 1997). The only complete isolated sacrum (TMP 1984.163.0102) incorporates six vertebrae (Fig. 19), as is the case in Anzu wyliei, Chirostenotes pergracilis, Epichirostenotes curriei, and Nomingia gobiensis, suggesting that sacral number varied minimally in caenagnathids. All known caenagnathid sacra known show prominent lateral pleurocoels on the anterior centra and fusion of the neural spines into a broad plate (Currie and Russell 1988; Sues 1997). The last two sacral ribs are much larger than the rest, and expand laterally into wide, hatchet-shaped processes. The last sacral vertebra is frequently less well fused to the rest of the sacrum (as in TMP 1979.020.0001, MPC-D 100/119, TMP 1984.163.0102), and usually has an inclined, concave posterior articular surface. Unfortunately, consistency in the morphology of the known sacra from the DPF means that they cannot be assigned with confidence to a taxon unless associated with other material. Therefore, it is not clear whether all known isolated sacra pertain to Chirostenotes pergracilis, to which they are identical, or if the sacra of Caenagnathus collinsi and Citipes elegans differed minimally from Chirostenotes pergracilis.

Several isolated pelvic elements from the DPF can be identified as caenagnathids by a number of features. These were described by Rhodes et al. (2020), but they did not refer them to any genus. Whereas each ilium can now be referred relatively confidently to one of the three genera, only the large pubes UALVP 56638 can be confidently referred (to Caenagnathus collinsi). The smaller pubes from the DPF are more difficult to interpret, but they are likely from a different taxon than UALVP 56638. Each of these can be identified as caenagnathid on the basis of a posteriorly enclosed medial fossa on the proximal end, a mesopubic condition, and a transversely narrow pubic apron. Despite being half the length of UALVP 56638, TMP 1994.012.0603 is nearly as broad proximally, because the shafts bow laterally at the proximal end. In contrast, the pubic shafts of UALVP 56638 are more or less straight in anterior view. Although slightly larger, TMP 1980.016.2095 is closer in size to TMP 1994.012.0603 and is more consistent in morphology; it shares a proximally bowed morphology with TMP 1994.012.0603, contrasting with the straight shafts of UALVP 56638. Similarly, the proportion of the pubes occupied by the pubic apron differs between these morphotypes. In UALVP 56638, the pubic apron occupies about two-thirds of the proximodistal length of the pubes, whereas in the other specimens this ratio is closer to one half. The pubic fenestra also differs in shape between UALVP 56638, where it is slit-like, and TMP 1994.012.0603, where it is more oval and rounded. Its shape cannot be determined in TMP 1980.016.2095. Thus, the smaller pubes can be distinguished from Caenagnathus collinsi and are probably both representative of either Chirostenotes pergracilis or Citipes elegans, but which of these cannot be determined.

\section{Ecology of DPF Caenagnathids}

The high diversity of caenagnathids in the DPF raises questions about why they were able to be so successful in this ecosystem. The DPF was clearly an exceptionally rich ecosystem: each major vertebrate group is represented by multiple coexisting taxa (Currie 2005b; Currie and Russell 2005; Mallon et al. 2012). Previous work has shown that oviraptorosaurs occupied a small but stable niche in other ecosystems (Funston et al. 2018), and this appears to be true in the DPF as well. Caenagnathids are among the rarest elements of the dinosaurian fauna, especially when compared to other similarly-sized theropods like dromaeosaurs, ornithomimids, and troodontids. Each of these groups is about equal in species richness to caenagnathids, but are known from more abundant and more complete remains. The greater abundance and completeness of ornithomimids could possibly be explained by their larger body sizes (Brown et al. 2013), but equally large caenagnathids like Caenagnathus collinsi are still far less abundant than ornithomimids. Furthermore, if caenagnathids were as common as dromaeosaurs, troodontids, 
and ornithomimids, then they should be equally represented by non-dental elements like frontals, phalanges, and vertebrae in microsite assemblages, but this is not the case. These lines of evidence suggest that caenagnathids were truly less abundant than other small theropods in the DPF, even if they had similar species richness.

However, caenagnathids are found throughout Dinosaur Provincial Park and in almost all stratigraphic horizons of the DPF (Fig. 23). Their distribution within different regions of Dinosaur Provincial Park is clearly non-random (Fig. 23B), but this can probably be explained by taphonomic and collection biases. An abundance of caenagnathid material has been collected from BB 047 in the southwestern part of the 'core' of Dinosaur Provincial Park. This mixed-faunal bonebed was prospected intensely in the 1980s and early 1990s and was exhaustively excavated in 1996 (Currie 2005b), which probably accounts for the increased detection of caenagnathids. Because they lack teeth, caenagnathids are likely underrepresented in hydraulically concentrated microsite assemblages, and so mixed-faunal mesofossil bonebeds like BB 047 may more accurately represent their true abundance. Another concentration of caenagnathids has been recovered in the Steveville area (Fig. 23B), which has historically produced numerous well-preserved specimens of the smaller-bodied animals of the DPF (Gilmore 1924b; Sternberg 1932; Fox 2005; Currie and Evans 2020). Caenagnathid abundance is low elsewhere in Dinosaur Provincial Park, but specimens have been recovered from almost all legal Sections with extensive outcrop (Fig. 23B). Thus, where collection efforts, taphonomy, and outcrop are sufficient for their detection, caenagnathids are consistently found in the DPF.

Whether caenagnathid abundance or diversity varies stratigraphically throughout the DPF interval is currently unclear. Few caenagnathid specimens have associated stratigraphic information, which prohibits in depth analysis
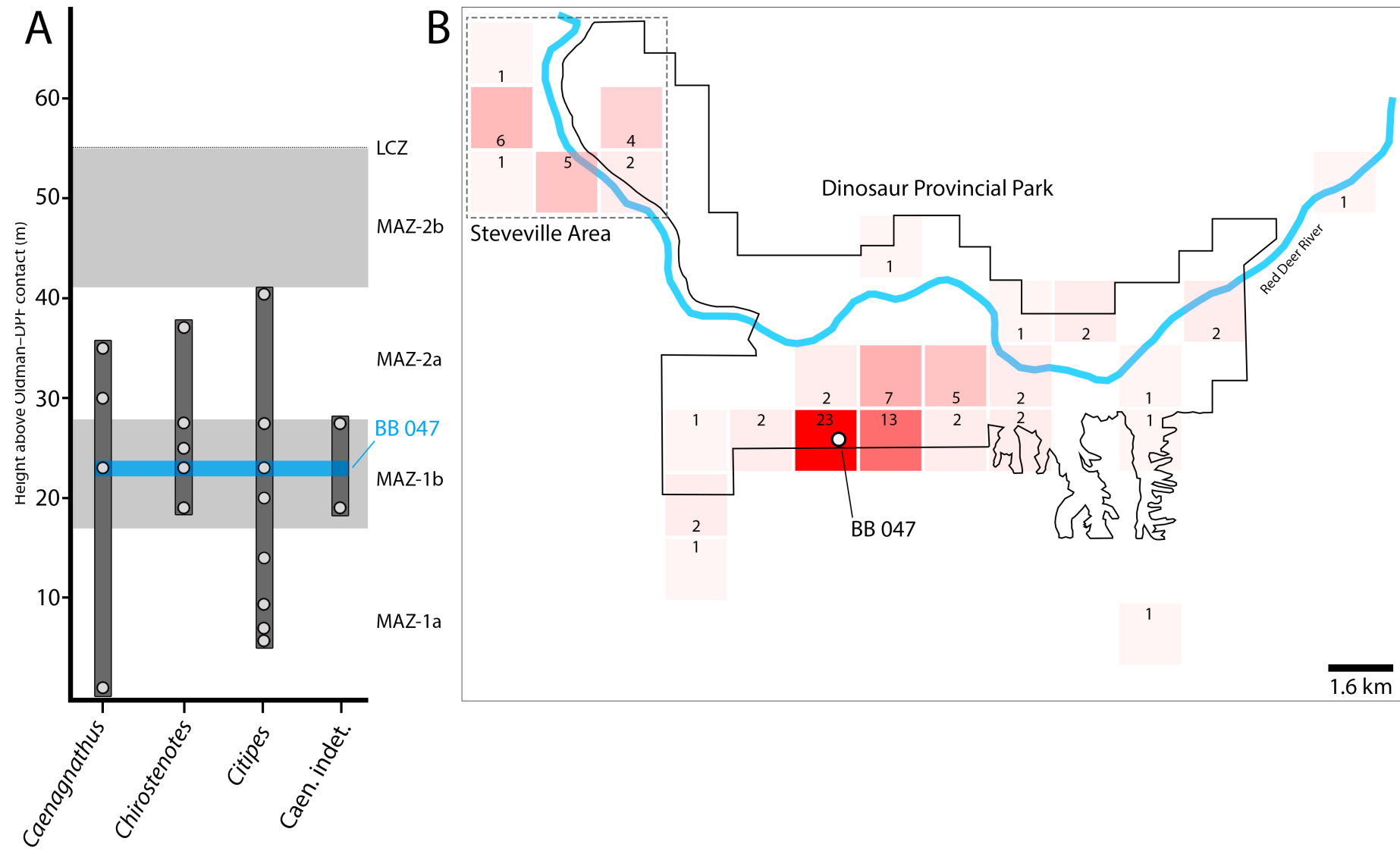

Figure 23. Stratigraphic and geographic distribution of Dinosaur Park Formation caenagnathids. Stratigraphic column (A) of caenagnathid occurrences within the Dinosaur Park Formation, organized by taxon and with Megaherbivore Assemblage Zones (MAZ) of Mallon et al. (2012) indicated. Points indicate specimens for which stratigraphic position can be estimated based on height above the base of the Dinosaur Park Formation (Table 1). Grey columns indicate inferred minimum stratigraphic ranges for each taxon. Blue bar indicates the stratigraphic position of BB 047, which has produced an abundance of caenagnathid material. Map (B) of the environs of Dinosaur Provincial Park, showing raw abundance of specimens in each legal Section (1 sq. mile or $2.6 \mathrm{~km} 2$ ). Intensity of colour reflects abundance of specimens, which is also indicated with numbers for each Section. Notable concentrations of specimens (Steveville Area and BB 047) are indicated. 
of their biostratigraphy. The stratigraphic positions of some specimens can be roughly estimated using the elevation at which they were collected and the closest site where the elevation of the Oldman-Dinosaur Park Formation contact has been measured (Fig. 23A). These rough estimates show that the vast majority of caenagnathid specimens known have been collected from the lower DPF (Fig. 23A). Notably, specimens of each taxon have been recovered from BB 047, approximately $23 \mathrm{~m}$ above the Oldman-Dinosaur Park Formation boundary, within MAZ-1b of Mallon et al. (2012). However, the stratigraphic range of each taxon also extends into the upper DPF and MAZ-2a of Mallon et al. (2012). The paucity of specimens from the upper DPF is likely the result of less outcrop or taphonomic changes, as similar declines in abundance exist for other dinosaur groups (Currie and Russell 2005).

Thus, current evidence suggests that all three caenagnathid taxa coexisted in the DPF, rather than constituting an anagenic lineage or a series of sequential forms replaced in association with faunal turnover. Considering the apparently highly specialized niche that oviraptorosaurs occupied relative to other theropods (Funston et al. 2018; Ma et al. 2020), some evidence of resource partitioning might be expected where species richness is relatively high, as is the case in the DPF. The variation in adult body sizes between each taxon may have facilitated the use of different resources later in life, and may have contributed to feeding height stratification (Mallon et al. 2013), although this is untestable with currently known material and it is unclear what proportion of the caenagnathid diet comprised plant material. Morphological differences in the mandibles (Currie et al. 1993) and hindlimbs (Funston et al. 2016a) suggest that there was also niche segregation between semaphoronts of similar body size. The shallow dentaries of Caenagnathus collinsi were clearly adapted for processing different types of foods than the sharply upturned dentaries of Chirostenotes pergracilis (Funston and Currie 2014). Lamanna et al. (2014) suggested that the mandible of Anzu wylie $i$ was better adapted for a herbivorous diet than those of Chirostenotes pergracilis. Comparison to extant raptorial birds supports the assertion that Chirostenotes pergracilis relied more on carnivory (Funston and Currie 2014), although beak morphology in birds is controlled by a broad range of factors, not just diet (Bright et al. 2016; Olsen 2017; Navalón et al. 2019). Differences in the hindlimb between Chirostenotes pergracilis and Citipes elegans suggest that these taxa exhibited locomotory differences. Fusion of the tarsometatarsus in Citipes elegans may be indicative of a habitus incorporating more cursorial behaviour (Snively et al. 2004), and this is supported by the more robust ilium with well-defined muscular attachment sites (Rhodes et al. 2020). Although it is unclear exactly what dietary roles and niches caenagnathids filled in the DPF ecosystem, these lines of evidence suggest that caenagnathids coexisted by minimizing niche overlap, rather than sharing niche space. This mirrors coexistence patterns in DPF megaherbivores, where ecomorphological differences manifest both between and within dinosaur families (Mallon and Anderson 2013, 2014, 2015; Mallon et al. 2013; Mallon 2019). This appears to have enabled fine-scale resource partitioning, which helped to structure stable, high-diversity herbivore assemblages throughout the Late Cretaceous of North America (Mallon 2019). That all three DPF caenagnathids coexist throughout MAZ-1b and MAZ-2a suggests that this was a stable ecological arrangement, but improved stratigraphic data may further support or refute this idea.

\section{Caenagnathid Phylogeny and Evolution}

The results of the phylogenetic analysis are broadly similar to previous analyses in that Microvenator celer and Gigantoraptor erlianensis are recovered as early diverging caenagnathids, and the remaining 'crown' caenagnathids form a monophyletic group, here called Caenagnathinae (Funston et al. in review). Anomalipes zhao i is recovered as a member of the non-caenagnathine 'stem', which is expected based on its morphology and geological age. Few studies have provided much insight into the relationships within caenagnathines, and those that have differ considerably in the relationships they recover. Like most previous work, this analysis finds no support for a monophyletic 'Elmisauridae', in contrast to Funston and Currie (2016). Instead, Citipes elegans, Elmisaurus rarus, and Apatoraptor pennatus are found as close outgroups to the larger-bodied taxa like Anzu wyliei, Caenagnathus collinsi, and Epichirostenotes curriei. Perplexingly, Caenagnathasia martinsoni is also recovered in this latter group, despite drastic differences in body size and morphology. The basal position of Chirostenotes pergracilis is also novel, as it has been deeply nested in Caenagnathinae in previous studies (Longrich et al. 2013; Funston and Currie 2016; Yu et al. 2018). However, each of these results is poorly supported by decay indices, which suggests that new data could alter the recovered topology.

The basal position of Chirostenotes pergracilis suggests that changes in the mandibular and pedal structure in other DPF caenagnathids are derived characters. The shallow dentaries of Caenagnathus collinsi and the later Anzu wyliei contrast starkly with those of other oviraptorosaurs, which are upturned into a raptorial beak. This innovation in Caenagnathus collinsi probably points to a change in diet, because the caenagnathid dentary was likely engaged in food processing (Cracraft 1971; Currie et al. 1993; Funston and Currie 2014). Although the diets of caenagnathids are unclear, Lamanna et al. (2014) 
suggested that the mandible of Anzu wyliei is well adapted for herbivory, whereas Funston and Currie (2014) interpreted the sharply upturned dentaries of Chirostenotes pergracilis as well-adapted for efficient shearing of prey. Thus, Anzu wyliei and Caenagnathus collinsi were likely more strictly herbivorous than the ancestral caenagnathid stock. Fusion of the tarsometatarsus in Citipes elegans is likewise recovered as a derived feature in this analysis. This is likely indicative of a more cursorial lifestyle, as fusion would have served a shock-absorbing function (Snively et al. 2004). Powerful hindlimb musculature, as revealed by the ilia of Citipes elegans (Rhodes et al. 2020), supports this conclusion. Enhanced cursorial ability in Citipes elegans may have served for predator avoidance, but it could also have improved prey capture ability. If the sharply upturned dentaries from the DPF are referable to Citipes elegans, they may provide an independent line of support for more reliance on carnivory. The more upturned shape would have improved the ability to rip food, but the reduced occlusal area would have hampered grinding and shearing necessary for processing plant material. Thus, although both trends are tentative and require further testing to verify, derived characters in two caenagnathine lineages appear to represent divergences in diet from a generalist ancestral stock. Ancestral estimation of body mass suggests that caenagnathids expanded their body size range earlier and to a much greater degree than oviraptorids (Fig. 21). Although this possibly represents some innate biological difference between caenagnathids and oviraptorids, it more likely reflects the dispersal of caenagnathids to North America and the resulting diversification. Current evidence indicates that the earliest caenagnathids, including giant forms, had dispersed to North America by the Albian-Cenomanian (Makovicky and Sues 1998; Simon et al. 2019). During this interval, terrestrial ecosystems in North America were undergoing drastic reorganizations, including turnovers in both the flora and fauna (Cifelli et al. 1997; Sues and Averianov 2009; Zanno and Makovicky 2011, 2013; Prieto-Marquez et al. 2016; Jud et al. 2018; Nesbitt et al. 2019; Zanno et al. 2019). The presence of caenagnathids in North America during this interval may have enabled them to occupy opening niches and expand in body size range. Unfortunately, the fossil record of early Late Cretaceous oviraptorosaurs is exceptionally poor, and this idea is difficult to test. Furthermore, it is unclear why caenagnathids might have been able to radiate during this interval when oviraptorids could not. It is possible that the diversifications of each group were not synchronous: poor stratigraphic constraint of the numerous recently described Chinese oviraptorids leads to uncertainty in the timing of the origin and diversification of oviraptorids. Improved stratigraphic data may show that oviraptorids diversified later than currently predicted, which is hinted at by their conspicuous absence in the well-sampled Cenomanian-Santonian beds of the Bayanshiree Formation of eastern Mongolia (Ishii et al. 2000, 2004; Tsubamoto 2010; Averianov and Sues 2012). This may help to explain the differences in their global distribution and body size ranges.

\section{Future Directions}

Great strides have been made in the study of caenagnathids and other oviraptorosaurs in the past 20 years, but some critical gaps remain. Any associated material of Caenagnathus collinsi or Citipes elegans would drastically improve our understanding of these animals, and thus targeted prospecting and collection of small theropods may prove fruitful. Until such discoveries are made, systematic osteohistological sampling of existing material can further improve the taxonomy and skeletal representation of DPF caenagnathids. A broad sample of the numerous caenagnathid metatarsals already collected might reveal body size and morphological differences that allow referral of isolated material. Sampling well-preserved, morphologically important dentaries is less desirable, but other approaches like high-resolution $\mu$-CT scanning may be able to non-destructively provide evidence of ontogenetic stage. This could provide further evidence of the mandible of Citipes elegans, or the postcrania of Caenagnathus collinsi. Surveys of vertebrae, unguals, and phalanges may also reveal variation that is useful for taxonomy, especially now that cervical and caudal vertebrae are known for Chirostenotes pergracilis (Funston and Currie 2020). The crania of the DPF caenagnathids remain completely unknown, and future discoveries may lead to identification of the isolated bones described here.

The biology of DPF caenagnathids also holds promise for future work. Little is known of the niche of caenagnathids or other oviraptorosaurs and biomechanical studies may provide clues to their diets and locomotion. This could, in turn, elucidate the mechanisms of coexistence in DPF caenagnathids and diverse oviraptorosaur assemblages elsewhere (Lü et al. 2017; Funston et al. 2018). The life history of caenagnathids is poorly known, and a coincident benefit of systematic osteohistological sampling for taxonomy might be further data on their growth rates, longevity, and the timing of skeletal changes like tarsometatarsal fusion (Funston et al. 2019). Other aspects of caenagnathid biology, like gregariousness (Funston et al. 2016b) or reproductive behaviour (Norell et al. 1995), are presently out of reach, but may eventually be possible to examine as the fossil record improves and new techniques to study it are developed.

The evolution of oviraptorosaurs in the late Early Cretaceous and early Late Cretaceous (Albian-Santonian) is another major gap, paralleled in most dinosaur groups. 
Targeted efforts have improved our understanding of some other groups, like tyrannosaurs (Brusatte et al. 2016; Nesbitt et al. 2019; Zanno et al. 2019), and these kinds of projects may lead to breakthroughs in the study of oviraptorosaurs as well. The gigantic caenagnathids like Gigantoraptor erlianensis are particularly perplexing in that little is known of their origin or extinction, although a recent major advance shows that they inhabited North America as well as Asia (Simon et al. 2019). Any new gigantic caenagnathid material, especially from North America, could provide valuable evidence regarding the origins and early evolution of caenagnathids. The origin of oviraptorids is likewise unclear: a great diversity of oviraptorids appeared suddenly in the Campanian. Improved stratigraphic resolution in the formations producing oviraptorids may support the suspicion that they diversified later and more rapidly than currently estimated. Instability in the recent phylogenies of oviraptorosaurs suggests that continued systematic work is also necessary to produce robust hypotheses of their relationships and evolution.

\section{CONCLUSIONS}

The material described and sampled here greatly improves our knowledge of caenagnathid anatomy, taxonomy, and development. New specimens and osteohistological analyses support the hypothesis that three genera were present in the DPF. Large pelvic elements probably referable to Caenagnathus collinsi show that it was the largest DPF caenagnathid, comparable in size to known specimens of Anzu wyliei. In contrast, evidence of slowed growth in smaller material shows that Citipes elegans was smaller at maturity than either Caenagnathus collinsi or Chirostenotes pergracilis. The ecology of DPF caenagnathids remains poorly understood because of insufficient data on diet, locomotion, and growth. However, it is clear that they were minor but persistent members of the DPF fauna, and all three genera appear to have coexisted in the lower part of the DPF. Variation in mandibular and tarsometatarsal morphology suggest they minimized dietary and locomotory niche overlap, respectively, but what niches they occupied is unclear. Increased skeletal representation of DPF caenagnathids improves phylogenetic resolution, and the new analysis differs from previous studies in the basal position of Chirostenotes pergracilis and the paraphyly of 'elmisaurs'. Caenagnathids occupied a much broader range of body sizes than oviraptorids, possibly as a result of dispersal to North America during an interval of extensive ecosystem restructuring. These advances provide an important foundation for future work on caenagnathids, which have historically been among the most enigmatic theropods from the Late Cretaceous.

\section{ACKNOWLEDGEMENTS}

I am indebted to my PhD supervisor, P. Currie (University of Alberta), and the rest of my examining committee, whose comments greatly improved this manuscript when it formed a portion of my doctoral thesis: D. Evans (ROM), R. Holmes (University of Alberta), A. Murray (University of Alberta), H. Proctor (University of Alberta), and J. Anderson (University of Calgary). Collections access and assistance was provided by K. Shepherd (CMN), B. Strilisky, R. Russell, T. Courtenay, G. Housego, F. Therrien, and D. Brinkman (All RTMP), as well as C. Coy, $\mathrm{H}$. Gibbins, and R. Sissons (All UALVP). Numerous colleagues contributed valuable discussion, and I thank $\mathrm{M}$. Burns, G. Bradley, V. Arbour, W.S. Persons IV, M. Rhodes, M. Powers, A. McIntosh, S. Hamilton, Y.-Y. Wong, O. Vernygora, A. Dyer, and A. LeBlanc for their insights. I thank D. Evans, T. Cullen, and D.J. Simon for discussions about caenagnathid taxonomy, and P. Currie for clarifying the provenance and collection of many specimens, as well as discussions of anatomy, taxonomy, phylogeny, and ecology. The Willi Hennig Society made TNT v1.5 freely available online. This work was funded by grants from Alberta Innovates, the Alberta Historical Resources Foundation, the Alberta Lottery Fund, the Dinosaur Research Institute, Natural Sciences and Engineering Research Council of Canada (NSERC), the University of Alberta, Vanier Canada, and the Royal Society (Grant NIFIR1\191527). The funders had no role in study design, data collection and analysis, decision to publish, or preparation of the manuscript. Many thanks to C. Heck, editor R. Holmes, and an anonymous reviewer for their detailed, constructive reviews of the manuscript.

\section{LITERATURE CITED}

An, W., H.-W. Kuang, Y.-Q. Liu, N. Peng, K.-M. Xu, H. $\mathrm{Xu}$, P. Zhang, K.-B. Wang, S.-Q. Chen, and Y.-X. Zhang. 2016. Detrital zircon dating and tracing the provenance of dinosaur bone beds from the Late Cretaceous Wangshi Group in Zhucheng, Shandong, East China. Journal of Palaeogeography 5:72-99.

Averianov, A.O., and H.-D. Sues. 2012. Correlation of Late Cretaceous continental vertebrate assemblages in Middle and Central Asia. Journal of Stratigraphy 36:462-485.

Balanoff, A.M., M.A. Norell, A.V.C. Hogan, and G.S. Bever. 2018. The endocranial cavity of oviraptorosaur dinosaurs and the increasingly complex, deep history of the avian brain. Brain, Behavior and Evolution 91:125-135.

Barsbold, R., H. Osmólska, M. Watabe, P.J. Currie, and K. Tsogtbaatar. 2000. A new oviraptorosaur [Dinosauria, Theropoda] from Mongolia: the first dinosaur with a pygostyle. Acta Palaeontologica Polonica 45:97-106. 
Bell, P.R., P.J. Currie, and D.A. Russell. 2015. Large caenagnathids (Dinosauria, Oviraptorosauria) from the uppermost Cretaceous of western Canada. Cretaceous Research 52:101-107.

Botha-Brink, J., D. Codron, A.K. Huttenlocker, K.D. Angielczyk, and M. Ruta. 2016. Breeding young as a survival strategy during Earth's greatest mass extinction. Scientific Reports 6.

Bright, J.A., J. Marugán-Lobón, S.N. Cobb, and E.J. Rayfield. 2016. The shapes of bird beaks are highly controlled by nondietary factors. Proceedings of the National Academy of Sciences 113:5352-5357.

Bromage, T.G., R.S. Lacruz, R. Hogg, H.M. Goldman, S.C. McFarlin, J. Warshaw, W. Dirks, A. Perez-Ochoa, I. Smolyar, D.H. Enlow, and A. Boyde. 2009. Lamellar bone is an incremental tissue reconciling enamel rhythms, body size, and organismal life history. Calcified Tissue International 84:388-404.

Brown, C.M., D.C. Evans, N.E. Campione, L.J. O'Brien, and D.A. Eberth. 2013. Evidence for taphonomic size bias in the Dinosaur Park Formation (Campanian, Alberta), a model Mesozoic terrestrial alluvial-paralic system. Palaeogeography, Palaeoclimatology, Palaeoecology 372:108-122.

Brusatte, S.L., M.J. Benton, M. Ruta, and G.T. Lloyd. 2008. Superiority, competition, and opportunism in the evolutionary radiation of dinosaurs. Science 321:1485-1488.

Brusatte, S.L., A. Averianov, H.-D. Sues, A. Muir, and I.B. Butler. 2016. New tyrannosaur from the mid-Cretaceous of Uzbekistan clarifies evolution of giant body sizes and advanced senses in tyrant dinosaurs. Proceedings of the National Academy of Sciences 113:3447-3452.

Campione, N.E., D.C. Evans, C.M. Brown, and M.T. Carrano. 2014. Body mass estimation in non-avian bipeds using a theoretical conversion to quadruped stylopodial proportions. Methods in Ecology and Evolution 5:913-923.

Carr, T.D. 1999. Craniofacial ontogeny in Tyrannosauridae (Dinosauria, Coelurosauria). Journal of Vertebrate Paleontology 19:497-520.

Castanet, J., K.C. Rogers, J. Cubo, and J. Jacques-Boisard. 2000. Periosteal bone growth rates in extant ratites (ostriche [sic] and emu). Implications for assessing growth in dinosaurs. Comptes Rendus de l'Académie Des Sciences-Series III-Sciences de La Vie 323:543-550.

Castanet, J., S. Croci, F. Aujard, M. Perret, J. Cubo, and E. de Margerie. 2004. Lines of arrested growth in bone and age estimation in a small primate: Microcebus murinus. Journal of Zoology 263:31-39.

Cifelli, R.L., J.I. Kirkland, A. Weil, A.L. Deino, and B.J. Kowallis. 1997. High-precision 40Ar/39Ar geochronology and the advent of North America's Late Cretaceous terrestrial fauna. Proceedings of the National Academy of Sciences 94:11163-11167.

Claessens, L.P. A.M., and M.A. Loewen. 2016. A redescription of Ornithomimus velox Marsh, 1890 (Dinosauria, Theropoda). Journal of Vertebrate Paleontology 36:e1034593.

Cracraft, J. 1971. Caenagnathiformes: Cretaceous birds convergent in jaw mechanism to dicynodont reptiles. Journal of Paleontology 45:805-809.
Cullen, T.M., D.J. Simon, E.K. C. Benner, and D.C. Evans. 2020. Morphology and osteohistology of a large-bodied caenagnathid (Theropoda, Oviraptorosauria) from the Hell Creek Formation (Montana): implications for size-based classifications and growth reconstruction in theropods. Papers in Palaeontology, manuscript PALA-07-19-4558-OA

Currie, P.J. 1989. The first records of Elmisaurus (Saurischia, Theropoda) from North America. Canadian Journal of Earth Sciences 26:1319-1324.

Currie, P.J. 1992. Saurischian dinosaurs of the Late Cretaceous of Asia and North America; pp. 237-249 in N.J. Mateer and P.-j. Chen (eds.), Aspects of Nonmarine Cretaceous Geology: International Symposium on Nonmarine Cretaceous Correlations. China Ocean Press, Beijing.

Currie, P.J. 1997. Elmisauridae; pp. 209-210 in P.J. Currie and K. Padian (eds.), Encyclopedia of Dinosaurs. Academic Press, San Diego.

Currie, P.J. 2003. Cranial anatomy of tyrannosaurid dinosaurs from the Late Cretaceous of Alberta, Canada. Acta Palaeontologica Polonica 48:191-226.

Currie, P.J. 2005a. Theropods, including birds; pp. 367-397 in P.J. Currie and E.B. Koppelhus (eds.), Dinosaur Provincial Park: A Spectacular Ancient Ecosystem Revealed. Indiana University Press, Bloomington.

Currie, P.J. 2005b. History of research; pp. 3-33 in P.J. Currie and E.B. Koppelhus (eds.), Dinosaur Provincial Park: A Spectacular Ancient Ecosystem Revealed. Indiana University Press, Bloomington.

Currie, P.J. and E.B. Koppelhus (eds.). 2005. Dinosaur Provincial Park: A Spectacular Ancient Ecosystem Revealed. Indiana University Press, Bloomington, 648 pp.

Currie, P.J., and D.A. Russell. 1988. Osteology and relationships of Chirostenotes pergracilis (Saurischia, Theropoda) from the Judith River (Oldman) Formation of Alberta, Canada. Canadian Journal of Earth Sciences 25:972-986.

Currie, P.J., and D.A. Russell. 2005. The geographic and stratigraphic distribution of articulated and associated dinosaur remains; pp. 537-569 in P.J. Currie and E.B. Koppelhus (eds.), Dinosaur Provincial Park: A Spectacular Ancient Ecosystem Revealed. Indiana University Press, Bloomington.

Currie, P.J., and D.C. Evans. 2020. Cranial anatomy of new specimens of Saurornitholestes langstoni (Dinosauria, Theropoda, Dromaeosauridae) from the Dinosaur Park Formation (Campanian) of Alberta. The Anatomical Record 303:691-715.

Currie, P.J., S.J. Godfrey, and L. Nessov. 1993. New caenagnathid (Dinosauria: Theropoda) specimens from the Upper Cretaceous of North America and Asia. Canadian Journal of Earth Sciences 30:2255-2272.

Currie, P.J., G.F. Funston, and H. Osmolska. 2016a. New specimens of the crested theropod dinosaur Elmisaurus rarus from Mongolia. Acta Palaeontologica Polonica 61:143-157.

Currie, P.J., R.B. Holmes, M.J. Ryan, and C. Coy. 2016b. A juvenile chasmosaurine ceratopsid (Dinosauria, Ornithischia) 
from the Dinosaur Park Formation, Alberta, Canada. Journal of Vertebrate Paleontology 36:e1048348.

Erickson, G. 2000. Growth curve of Psittacosaurus mongoliensis Osborn (Ceratopsia: Psittacosauridae) inferred from long bone histology. Zoological Journal of the Linnean Society 130:551-566.

Erickson, G.M., K. Curry Rogers, D.J. Varricchio, M.A. Norell, and X. Xu. 2007. Growth patterns in brooding dinosaurs reveals the timing of sexual maturity in non-avian dinosaurs and genesis of the avian condition. Biology Letters 3:558-561.

Fox, R.C. 2005. Late Cretaceous mammals; pp. 417-435 in P.J. Currie and E.B. Koppelhus (eds.), Dinosaur Provincial Park: A Spectacular Ancient Ecosystem Revealed. Indiana University Press, Bloomington.

Francillon-Vieillot, H., V. de Buffrenil, J. Castanet, J. Gkraudie, F.J. Meunier, J.Y. Sire, L. Zylberberg, and A.J. de Ricqlès. 1990. Microstructure and mineralization of vertebrate skeletal tissues; pp. 471-530 in J.G. Carter (ed.), Skeletal Biomineralization: Patterns, Processes, and Evolutionary Trneds. Van Nostrand Reinhold, New York.

Funston, G.F. 2019. Anatomy, Systematics, and Evolution of Oviraptorosauria (Dinosauria, Theropoda). PhD Dissertation, University of Alberta, Edmonton, Alberta, 795 pp.

Funston, G.F., and P.J. Currie. 2014. A previously undescribed caenagnathid mandible from the late Campanian of Alberta, and insights into the diet of Chirostenotes pergracilis (Dinosauria: Oviraptorosauria). Canadian Journal of Earth Sciences 51:156-165.

Funston, G.F., and P.J. Currie. 2016. A new caenagnathid (Dinosauria: Oviraptorosauria) from the Horseshoe Canyon Formation of Alberta, Canada, and a reevaluation of the relationships of Caenagnathidae. Journal of Vertebrate Paleontology 36:e1160910.

Funston, G.F., and P.J. Currie. 2018. A small caenagnathid tibia from the Horseshoe Canyon Formation (Maastrichtian): Implications for growth and lifestyle in oviraptorosaurs. Cretaceous Research 92:220-230.

Funston, G.F., and P.J. Currie. 2020. New material of Chirostenotes pergracilis (Theropoda, Oviraptorosauria) from the Campanian Dinosaur Park Formation of Alberta, Canada. Historical Biology DOI: 10.1080/08912963.2020.1726908:1-15.

Funston, G.F., P.J. Currie, and M. Burns. 2016a. New elmisaurine specimens from North America and their relationship to the Mongolian Elmisaurus rarus. Acta Palaeontologica Polonica 61:159-173.

Funston, G.F., W.S. Persons, G.J. Bradley, and P.J. Currie. 2015. New material of the large-bodied caenagnathid Caenagnathus collinsi from the Dinosaur Park Formation of Alberta, Canada. Cretaceous Research 54:179-187.

Funston, G.F., S.E. Mendonca, P.J. Currie, and R. Barsbold. 2018. Oviraptorosaur anatomy, diversity and ecology in the Nemegt Basin. Palaeogeography, Palaeoclimatology, Palaeoecology.

Funston, G.F., P.J. Currie, M.J. Ryan, and Z.-M. Dong. 2019. Birdlike growth and mixed-age flocks in avimimids (Theropoda, Oviraptorosauria). Scientific Reports 9:18816.
Funston, G.F., C. Tsogtbaatar, T. Khishigjav, Y. Kobayashi, C. Sullivan, and P.J. Currie. In review. A new, two-fingered dinosaur sheds light on the radiation of Oviraptorosauria. Royal Society Open Science, Manuscript Number RSOS-201184.

Funston, G.F., R.D. Wilkinson, D.J. Simon, A.H. Leblanc, M. Wosik, and P.J. Currie. 2020. Histology of caenagnathid (Theropoda, Oviraptorosauria) dentaries and implications for development, ontogenetic edentulism, and taxonomy. The Anatomical Record 303:918-934.

Funston, G.F., P.J. Currie, D.A. Eberth, M.J. Ryan, T. Chinzorig, D. Badamgarav, and N.R. Longrich. 2016b. The first oviraptorosaur (Dinosauria: Theropoda) bonebed: evidence of gregarious behaviour in a maniraptoran theropod. Scientific Reports 6:35782.

Gilmore, C.W. 1924a. A new coelurid dinosaur from the Belly River Cretaceous of Alberta. Canada Geological Survey Bulletin 38:1-12.

Gilmore, C.W. 1924b. On Troodon validus: An orthopodous dinosaur from the Belly River Cretaceous of Alberta, Canada. University of Alberta Bulletin 1:1-43.

Ishii, K. M. Watabe, S. Suzuki, S. Ishigaki, R. Barsbold, and K. Tsogtbaatar (eds.). 2000. Hayashibara Museum of Natural Sciences Research Bulletin Vol. 1. Hayashibara Museum of Natural Sciences, Okayama, Japan, 137 pp.

Ishii, K., M. Watabe, S. Suzuki, S. Ishigaki, R. Barsbold, and K. Tsogtbaatar (eds.). 2004. Hayashibara Museum of Natural Sciences Research Bulletin Vol. 2 Hayashibara Museum of Natural Sciences, Okayama, Japan, 134 pp.

Jud, N.A., M.D. D’Emic, S.A. Williams, J.C. Mathews, K.M. Tremaine, and J. Bhattacharya. 2018. A new fossil assemblage shows that large angiosperm trees grew in North America by the Turonian (Late Cretaceous). Science Advances 4:eaar8568.

Klein, N., and M. Sander. 2008. Ontogenetic stages in the long bone histology of sauropod dinosaurs. Paleobiology 34:247-263.

Köhler, M., N. Marín-Moratalla, X. Jordana, and R. Aanes. 2012. Seasonal bone growth and physiology in endotherms shed light on dinosaur physiology. Nature 487:358-361.

Lamanna, M.C., H.-D. Sues, E.R. Schachner, and T.R. Lyson. 2014. A new large-bodied oviraptorosaurian theropod dinosaur from the latest Cretaceous of Western North America. PLoS ONE 9:e92022.

Lee, A.H., and S. Werning. 2008. Sexual maturity in growing dinosaurs does not fit reptilian growth models. Proceedings of the National Academy of Sciences 105:582-587.

Lee, A.H., and P.M. O'Connor. 2013. Bone histology confirms determinate growth and small body size in the noasaurid theropod Masiakasaurus knopfleri. Journal of Vertebrate Paleontology 33:865-876.

Lee, A.H., A.K. Huttenlocker, K. Padian, and H.N. Woodward. 2013. Analysis of growth rates; pp. 217-252 in K. Padian and E.-T. Lamm (eds.), Bone Histology of Fossil Tetrapods. University of California Press, Berkeley, California.

Longrich, N.R., K. Barnes, S. Clark, and L. Millar. 2013. Caenagnathidae from the Upper Campanian Aguja Formation 
of West Texas, and a revision of the Caenagnathinae. Bulletin of the Peabody Museum of Natural History 54:23-49.

Lü, J., R. Chen, S.L. Brusatte, Y. Zhu, and C. Shen. 2016. A Late Cretaceous diversification of Asian oviraptorid dinosaurs: evidence from a new species preserved in an unusual posture. Scientific Reports 6:35780.

Lü, J., P.J. Currie, L. Xu, X. Zhang, H. Pu, and S. Jia. 2013. Chicken-sized oviraptorid dinosaurs from central China and their ontogenetic implications. Naturwissenschaften 100:165-175.

Lü, J., G. Li, M. Kundrát, Y.-N. Lee, Z. Sun, Y. Kobayashi, C. Shen, F. Teng, and H. Liu. 2017. High diversity of the Ganzhou oviraptorid fauna increased by a new "cassowary-like" crested species. Scientific Reports 7.

Ma, W., S.L. Brusatte, J. Lü, and M. Sakamoto. 2020. The skull evolution of oviraptorosaurian dinosaurs: the role of niche-partitioning in diversification. Journal of Evolutionary Biology 33:178-188.

Ma, W., J. Wang, M. Pittman, Q. Tan, L. Tan, B. Guo, and X. Xu. 2017. Functional anatomy of a giant toothless mandible from a bird-like dinosaur: Gigantoraptor and the evolution of the oviraptorosaurian jaw. Scientific Reports 7:10.1038/s41598017-15709-7.

Makovicky, P.J., and H.-D. Sues. 1998. Anatomy and phylogenetic relationships of the theropod dinosaur Microvenator celer from the Lower Cretaceous of Montana. American Museum Novitates 3240:1-27.

Mallon, J.C. 2019. Competition structured a Late Cretaceous megaherbivorous dinosaur assemblage. Scientific Reports 9:15447.

Mallon, J.C., and J.S. Anderson. 2013. Skull ecomorphology of megaherbivorous dinosaurs from the Dinosaur Park Formation (Upper Campanian) of Alberta, Canada. PLoS ONE 8:e67182.

Mallon, J.C., and J.S. Anderson. 2014. The functional and palaeoecological implications of tooth morphology and wear for the megaherbivorous dinosaurs from the Dinosaur Park Formation (Upper Campanian) of Alberta, Canada. PLoS ONE 9:e98605.

Mallon, J.C., and J.S. Anderson. 2015. Jaw mechanics and evolutionary paleoecology of the megaherbivorous dinosaurs from the Dinosaur Park Formation (upper Campanian) of Alberta, Canada. Journal of Vertebrate Paleontology 35:e904323.

Mallon, J.C., D.C. Evans, M.J. Ryan, and J.S. Anderson. 2012. Megaherbivorous dinosaur turnover in the Dinosaur Park Formation (upper Campanian) of Alberta, Canada. Palaeogeography, Palaeoclimatology, Palaeoecology 350352:124-138.

Mallon, J.C., D.C. Evans, M.J. Ryan, and J.S. Anderson. 2013. Feeding height stratification among the herbivorous dinosaurs from the Dinosaur Park Formation (upper Campanian) of Alberta, Canada. BMC Ecology 13:1-15.

de Margerie, E. 2004. Assessing a relationship between bone microstructure and growth rate: a fluorescent labelling study in the king penguin chick (Aptenodytes patagonicus). Journal of Experimental Biology 207:869-879. de Margerie, E., J. Cubo, and J. Castanet. 2002. Bone typology and growth rate: testing and quantifying 'Amprino's rule' in the mallard (Anas platyrhynchos). Comptes Rendus Biologies 325:221-230.

McFeeters, B., M.J. Ryan, C. Schröder-Adams, and P.J. Currie. 2017. First North American occurrences of Qiupalong (Theropoda: Ornithomimidae) and the palaeobiogeography of derived ornithomimids. FACETS 2:355-373.

Navalón, G., J.A. Bright, J. Marugán-Lobón, and E.J. Rayfield. 2019. The evolutionary relationship among beak shape, mechanical advantage, and feeding ecology in modern birds. Evolution 73:422-435.

Nesbitt, S.J., and M.R. Stocker. 2008. The vertebrate assemblage of the Late Triassic Canjilon Quarry (Northern New Mexico, USA), and the importance of apomorphy-based assemblage comparisons. Journal of Vertebrate Paleontology 28:1063-1072.

Nesbitt, S.J., R.K. Denton, M.A. Loewen, S.L. Brusatte, N.D. Smith, A.H. Turner, J.I. Kirkland, A.T. McDonald, and D.G. Wolfe. 2019. A mid-Cretaceous tyrannosauroid and the origin of North American end-Cretaceous dinosaur assemblages. Nature Ecology \& Evolution 3:892-899.

Norell, M.A., J.M. Clark, L.M. Chiappe, and D. Dashzeveg. 1995. A nesting dinosaur. Nature 378:774-776.

Olsen, A.M. 2017. Feeding ecology is the primary driver of beak shape diversification in waterfowl. Functional Ecology 31:1985-1995.

Osborn, H.F. 1917. Article XLIII Skeletal adaptations of Ornitholestes, Struthiomimus, Tyrannosaurus. Bulletin of the American Museum of Natural History 35:733-771.

Osmólska, H. 1981. Coossified tarsometatarsi in theropod dinosaurs and their bearing on the problem of bird origins. Palaeontologia Polonica 42:79-95.

Osmólska, H. 2004. Evidence on relation of brain to endocranial cavity in oviraptorid dinosaurs. Acta Palaeontologica Polonica 49:321-324.

Padian, K., and E.-T. Lamm. 2013. Bone Histology of Fossil Tetrapods: Advancing Methods, Analysis, and Interpretation. University of California Press, Berkeley, 285 pp.

Parks, W.A. 1933. New species of dinosaurs and turtles from the Upper Cretaceous Formations of Alberta. University of Toronto Studies Geological Series 34:1-24.

Porfiri, J.D., F.E. Novas, J.O. Calvo, F.L. Agnolín, M.D. Ezcurra, and I.A. Cerda. 2014. Juvenile specimen of Megaraptor (Dinosauria, Theropoda) sheds light about tyrannosauroid radiation. Cretaceous Research 51:35-55.

Prieto-Marquez, A., G.M. Erickson, and J.A. Ebersole. 2016. A primitive hadrosaurid from southeastern North America and the origin and early evolution of 'duck-billed' dinosaurs. Journal of Vertebrate Paleontology 36:e1054495.

$\mathrm{Pu}$, H., D.K. Zelenitsky, J. Lü, P.J. Currie, K. Carpenter, L. Xu, E.B. Koppelhus, S. Jia, L. Xiao, H. Chuang, T. Li, M. Kundrát, and C. Shen. 2017. Perinate and eggs of a giant caenagnathid 
dinosaur from the Late Cretaceous of central China. Nature Communications 8:14952.

Qiu, R., X. Wang, Q. Wang, N. Li, J. Zhang, and Y. Ma. 2019. A new caudipterid from the Lower Cretaceous of China with information on the evolution of the manus of Oviraptorosauria. Scientific Reports 9:6431.

Redelstorff, R., and P.M. Sander. 2009. Long and girdle bone histology of Stegosaurus: implications for growth and life history. Journal of Vertebrate Paleontology 29:1087-1099.

Revell, L.J. 2012. phytools: an R package for phylogenetic comparative biology (and other things): phytools: R package. Methods in Ecology and Evolution 3:217-223.

Rhodes, M.M., G.F. Funston, and P.J. Currie. 2020. New material reveals the pelvic morphology of Caenagnathidae (Theropoda, Oviraptorosauria). Cretaceous Research 114:104521.

Russell, D.A. 1972. Ostrich dinosaurs from the Late Cretaceous of western Canada. Canadian Journal of Earth Sciences 9:375-402.

Simon, D.J., D.J. Varricchio, X. Jin, and S.F. Robison. 2019. Microstructural overlap of Macroelongatoolithus eggs from Asia and North America expands the occurrence of colossal oviraptorosaurs. Journal of Vertebrate Paleontology e1553046.

Skutschas, P.P., E. A. Boitsova, A.O. Averianov, and H.-D. Sues. 2016. Ontogenetic changes in long-bone histology of an ornithomimid theropod dinosaur from the Upper Cretaceous Bissekty Formation of Uzbekistan. Historical Biology 29:715-729.

Snively, E., and A. Russell. 2002. The tyrannosaurid metatarsus: bone strain and inferred ligament function. Palaeobiodiversity and Palaeoenvironments 82:35-42.

Snively, E., A.P. Russell, and G.L. Powell. 2004. Evolutionary morphology of the coelurosaurian arctometatarsus: descriptive, morphometric and phylogenetic approaches. Zoological Journal of the Linnean Society 142:525-553.

Sternberg, C.M. 1932. Two new theropod dinosaurs from the Belly River Formation of Alberta. The Canadian FieldNaturalist 46:99-105.

Sternberg, C.M. 1934. Notes on certain recently described dinosaurs. The Canadian Field-Naturalist 48:7-8.

Sternberg, R.M. 1940. A toothless bird from the Cretaceous of Alberta. Journal of Paleontology 14:81-85.

Sues, H.-D. 1997. On Chirostenotes, a Late Cretaceous oviraptorosaur (Dinosauria: Theropoda) from western North America. Journal of Vertebrate Paleontology 17:698-716.

Sues, H.-D., and A. Averianov. 2009. A new basal hadrosauroid dinosaur from the Late Cretaceous of Uzbekistan and the early radiation of duck-billed dinosaurs. Proceedings of the Royal Society B: Biological Sciences 276:2549-2555.

Sues, H.-D., and A. Averianov. 2015. New material of Caenagnathasia martinsoni (Dinosauria: Theropoda: Oviraptorosauria) from the Bissekty Formation (Upper Cretaceous: Turonian) of Uzbekistan. Cretaceous Research 54:50-59.
Sullivan, R.M., S.E. Jasinski, and M.P.A. Van Tomme. 2011. A new caenagnathid Ojoraptorsaurus boerei, n. gen., n. sp (Dinosauria, Oviraptorosauria), from the Upper Ojo Alamo Formation (Naashoibito Member), San Juan Basin, New Mexico. New Mexico Museum of Natural History and Science Bulletin 53:418-428.

Tsubamoto, T. (ed.). 2010. Hayashibara Museum of Natural Sciences Research Bulletin Vol. 3. Hayashibara Museum of Natural Sciences, Okayama, Japan, 193 pp.

Varricchio, D.J. 1993. Bone microstructure of the Upper Cretaceous theropod dinosaur Troodon formosus. Journal of Vertebrate Paleontology 13:99-104.

Varricchio, D.J. 2001. Late Cretaceous oviraptorosaur (Theropoda) dinosaurs from Montana; pp. 42-57 in D.H. Tanke and K. Carpenter (eds.), Mesozoic Vertebrate Life. Indiana University Press, Bloomington.

Woodward, H.N., J.R. Horner, and J.O. Farlow. 2011. Osteohistological evidence for determinate growth in the American alligator. Journal of Herpetology 45:339-342.

Woodward, H.N., K. Tremaine, S.A. Williams, L.E. Zanno, J.R. Horner, and N. Myhrvold. 2020. Growing up Tyrannosaurus rex: Osteohistology refutes the pygmy "Nanotyrannus" and supports ontogenetic niche partitioning in juvenile Tyrannosaurus. Science Advances 6:eaax6250.

$\mathrm{Xu}, \mathrm{X} .2020$. Filamentous integuments in nonavialan theropods and their kin: advances and future perspectives for understanding the evolution of feathers; pp. 67-78 in C. Foth and O.W. Rauhut (eds.), The Evolution of Feathers: From Their Origin to the Present. Springer Nature Switzerland, Switzerlan.

Yao, X., X.-L. Wang, C. Sullivan, S. Wang, T. Stidham, and X. Xu. 2015. Caenagnathasia sp. (Theropoda: Oviraptorosauria) from the Iren Dabasu Formation (Upper Cretaceous: Campanian) of Erenhot, Nei Mongol, China. Vertebrata PalAsiatica 53:291-298.

Yu, Y., K. Wang, S. Chen, C. Sullivan, S. Wang, P. Wang, and X. Xu. 2018. A new caenagnathid dinosaur from the Upper Cretaceous Wangshi Group of Shandong, China, with comments on size variation among oviraptorosaurs. Scientific Reports 8:10.1038/s41598-018-23252-2.

Zanno, L.E., and S.D. Sampson. 2005. A new oviraptorosaur (Theropoda, Maniraptora) from the Late Cretaceous (Campanian) of Utah. Journal of Vertebrate Paleontology 25:897-904.

Zanno, L.E., and P.J. Makovicky. 2011. On the earliest record of Cretaceous tyrannosauroids in western North America: implications for an Early Cretaceous Laurasian interchange event. Historical Biology 23:317-325.

Zanno, L.E., and P.J. Makovicky. 2013. Neovenatorid theropods are apex predators in the Late Cretaceous of North America. Nature Communications 4:2827.

Zanno, L.E., R.T. Tucker, A. Canoville, H.M. Avrahami, T.A. Gates, and P.J. Makovicky. 2019. Diminutive fleet-footed tyrannosauroid narrows the 70-million-year gap in the North American fossil record. Communications Biology 2:64. 